\title{
BrO vertical distributions from SCIAMACHY limb measurements: comparison of algorithms and retrieval results
}

\author{
A. Rozanov ${ }^{1}$, S. Kühl' ${ }^{2}$, A. Doicu ${ }^{4}$, C. McLinden ${ }^{8}$, J. Puksīte ${ }^{2}$, H. Bovensmann ${ }^{1}$, J. P. Burrows ${ }^{1}$, T. Deutschmann ${ }^{3}$, \\ M. Dorf ${ }^{3}$, F. Goutail ${ }^{5}$, K. Grunow ${ }^{9, *}$, F. Hendrick ${ }^{6}$, M. von Hobe ${ }^{7}$, S. Hrechanyy ${ }^{4,7}$, G. Lichtenberg ${ }^{4}$, K. Pfeilsticker ${ }^{3}$, \\ J. P. Pommereau ${ }^{5}$, M. Van Roozendael ${ }^{6}$, F. Stroh ${ }^{7}$, and T. Wagner ${ }^{2,3}$ \\ ${ }^{1}$ Institute of Environmental Physics (IUP), University of Bremen, Bremen, Germany \\ ${ }^{2}$ Max Planck Institute for Chemistry, Mainz, Germany \\ ${ }^{3}$ Institute of Environmental Physics, University of Heidelberg, Heidelberg, Germany \\ ${ }^{4}$ German Aerospace Center (DLR) Oberpfaffenhofen, Oberpfaffenhofen, Germany \\ ${ }^{5}$ LATMOS, CNRS, UVSQ, Guyancourt, France \\ ${ }^{6}$ Belgian Institute for Space Aeronomy (IASB-BIRA), Brussels, Belgium \\ ${ }^{7}$ Jülich Research Center, Jülich, Germany \\ ${ }^{8}$ Environment Canada, Toronto, Canada \\ ${ }^{9}$ Meteorological Institute, Free University of Berlin, Berlin, Germany \\ * now at: Senatsverwaltung für Gesundheit, Umwelt und Verbraucherschutz, Berlin, Germany
}

Received: 28 October 2010 - Published in Atmos. Meas. Tech. Discuss.: 18 November 2010

Revised: 31 May 2011 - Accepted: 13 June 2011 - Published: 4 July 2011

\begin{abstract}
This study presents two scientific and one operational retrieval algorithms used to obtain vertical distributions of bromine monoxide (BrO) from observations of the scattered solar light performed by the SCIAMACHY instrument in limb viewing geometry. The study begins with a discussion of the theoretical basis of all algorithms followed by an investigation of the retrieval sensitivity. Simulations with three different radiative transfer models allow us to analyze influence of the forward model implementation upon the retrieval results. By means of synthetic retrievals we analyze major sources of uncertainties in the resulting $\mathrm{BrO}$ profiles such as different $\mathrm{BrO}$ cross sections, their temperature dependence, and stratospheric aerosols. Finally, the reliability of SCIAMACHY BrO profile retrievals is demonstrated comparing results from different algorithms to each other and to balloon-borne observations.
\end{abstract}

\section{Introduction}

The important roles of bromine compounds in the destruction of stratospheric ozone and the related need for accurate knowledge of the stratospheric bromine budget have

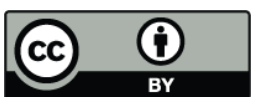

Correspondence to: A. Rozanov (alexei.rozanov@iup.physik.uni-bremen.de) been discussed by different authors in recent years (Sinnhuber et al., 2005; Salawitch et al., 2005; Sioris et al., 2006; Kovalenko et al., 2007). In spite of this, there are few relevant observations. The total inorganic bromine $\left(\mathrm{Br}_{\mathrm{y}}\right)$ in the stratosphere is estimated from the measurements of bromine monoxide $(\mathrm{BrO})$ coupled with a photochemical model. High quality information on vertical distribution of $\mathrm{BrO}$ from the troposphere to the middle stratosphere is obtained from balloon-borne instruments (see e.g. Harder et al., 1998; Pfeilsticker et al., 2000; Pundt et al., 2002; Dorf et al., 2008). The expense and logistics of balloon campaigns mean that only a limited number of launches at selected locations were achieved in the last two decades. An additional important contribution to long-term $\mathrm{BrO}$ observations is provided by multi-year series of low resolution vertical profiles from ground-based zenith sky observations (Hendrick et al., 2009). These measurements, however, are carried out only at a few locations. Space-borne instruments are now available making measurements yielding both long-term observations of stratospheric $\mathrm{BrO}$ distributions and short-term global coverage. In the upper stratosphere $(\sim 30-45 \mathrm{~km})$ global vertical distributions of $\mathrm{BrO}$ are retrieved from the measurements from the Microwave Limb Sounder (MLS) instrument on board the Aura satellite launched in July 2004 (Kovalenko et al., 2007) whereas in the middle and lower stratosphere these are provided from the measurements by the Scanning Imaging Absorption Spectrometer for Atmospheric

Published by Copernicus Publications on behalf of the European Geosciences Union. 
CHartographY (SCIAMACHY) on board the European Environment Satellite (ENVISAT) launched in March 2002 (Rozanov et al., 2005a; Sinnhuber et al., 2005; Sioris et al., 2006). Recently, zonal-mean vertical profiles of $\mathrm{BrO}$ in the middle and lower stratosphere were also obtained from observations from the Optical Spectrograph and InfraRed Imager System (OSIRIS) on board the Odin satellite launched in February 2001 (McLinden et al., 2010). Furthermore, the Superconducting Submillimeter-Wave Limb-Emission Sounder (SMILES) instrument put into operation on board the International Space Station (ISS) in October 2009 is providing vertical distributions of $\mathrm{BrO}$ in the middle and upper stratosphere on the global scale (Kasai et al., 2000).

In this study we investigate the retrieval algorithms aimed to gain vertical distributions of stratospheric $\mathrm{BrO}$ from SCIAMACHY limb measurements, namely, the algorithms developed at (i) Max Planck Institute for Chemistry in Mainz, Germany (MPI Mainz), (ii) Institute of Environmental Physics, University of Bremen, Germany (IUP Bremen), and (iii) German Aerospace Center Oberpfaffenhofen, Germany (DLR). It should be noted here that both MPI Mainz and IUP Bremen retrievals are precision optimized for scientific applications whereas DLR approach represents one for a speed optimized operational processor. The latter is a part of the operational ESA processor employed to generate version 5.01 of Level 2 dataset. The retrieval algorithm of IUP Bremen described here is used to generate version 3.2 of scientific $\mathrm{BrO}$ dataset which is publicly available via the web page of the Institute of Environmental Physics (IUP), University of Bremen.

This manuscript is structured as follows. In Sect. 2 we provide essential details on the SCIAMACHY instrument and limb observation geometry. In Sect. 3 we discuss the theoretical basis of the retrieval algorithms and technical implementation details. The discussion starts with a general formulation of the inverse problem in Sect. 3.1. Thereafter, we show in Sect. 3.2 how the inverse problem is transformed for use in the framework of different retrieval techniques. Section 3.3 describes auxiliary fit functions (so-called pseudo-absorbers or spectral corrections) needed for a successful fitting of minor atmospheric species. In Sect. 3.4 we provide details on the technical implementation of the retrieval and parameter settings for each particular algorithm. Section 4 lists general parameter settings for all three retrievals. In Sect. 5 we discuss the retrieval characteristics and diagnostics such as averaging kernels, precision, measurements response, and vertical resolution, as well as the influence of the a priori information upon the retrieval results. Possible differences in the retrieval results resulting from the usage of different radiative transfer models are analyzed in Sect. 6 by means of comparisons of synthetic retrievals. Section 7 analyses retrieval uncertainties resulting from differences in $\mathrm{BrO}$ absorption cross sections, temperature dependence of $\mathrm{BrO}$ cross sections, and stratospheric aerosol loading. The retrieval results for one SCIAMACHY orbit obtained with all three retrievals are compared in Sect. 8. In Sect. 9 the SCIAMACHY retrievals are compared to collocated balloon-borne observations from different instruments (DOAS, SAOZ, TRIPLE). Finally, Sect. 10 presents a summary and a set of conclusions.

\section{SCIAMACHY limb observations}

SCIAMACHY is a passive imaging spectrometer comprising 8 spectral channels covering a wide spectral range from 214 to $2380 \mathrm{~nm}$. Each channel is equipped with a grating spectrometer with a 1024 element diode array as a detector. The vertical distributions of $\mathrm{BrO}$ considered in this study are retrieved exploiting only the spectral information obtained from channel $2(300-412 \mathrm{~nm})$ of SCIAMACHY. The spectral resolution in this chanel is about $0.26 \mathrm{~nm}$ and the spectral sampling is about $0.11 \mathrm{~nm}$. More details about the instrument design and mission objectives are presented by Burrows et al. (1995) and Bovensmann et al. (1999).

In the limb viewing geometry, the SCIAMACHY instrument observes the atmosphere tangentially to the Earth's surface starting at about $3 \mathrm{~km}$ below the horizon, i.e., when the Earth's surface is still within the field of view (FOV) of the instrument, and then scanning vertically up to the top of the atmosphere (about $100 \mathrm{~km}$ tangent height). At each tangent height a horizontal scan lasting $1.5 \mathrm{~s}$ is performed followed by an elevation step of about $3.3 \mathrm{~km}$. During this step no measurements are made. Thus, the limb observation sequence is performed with a vertical sampling of $3.3 \mathrm{~km}$. In the altitude range relevant for this study, most typical tangent heights of the limb measurements are located around $9.9 \mathrm{~km}, 13.1 \mathrm{~km}, 16.4 \mathrm{~km}, 19.7 \mathrm{~km}, 23.0 \mathrm{~km}, 26.2 \mathrm{~km}$, $29.6 \mathrm{~km}, 32.8 \mathrm{~km}$, and $36.0 \mathrm{~km}$. The vertical instantaneous field of view of the SCIAMACHY instrument is about $2.5 \mathrm{~km}$ at the tangent point. Although the horizontal instantaneous field of view of the instrument is approximately $110 \mathrm{~km}$ at the tangent point, the cross-track horizontal resolution is mainly determined by the detector integration time during the azimuthal (i.e., horizontal cross-track) scan reaching typically about $240 \mathrm{~km}$. This averaging corresponds to one detector readout. In this study, however, an additional azimuthal averaging is performed to increase the signal to noise ratio of input spectra. This results in a cross-track resolution of about $960 \mathrm{~km}$. The horizontal along-track resolution is estimated to be about $400 \mathrm{~km}$. A typical limb observation sequence as performed by the SCIAMACHY instrument is illustrated in Fig. 1 (the plot has been created by S. Noël, IUP, University of Bremen).

In the spectral range considered in this study, the expected values of the signal to noise ratio in horizontally integrated limb measurements range from 4000 to 6000 at tangent heights between 15 and $25 \mathrm{~km}$ decreasing to $1500-2500$ at about $35 \mathrm{~km}$ tangent height. These values have been obtained by modeling with the SCIAMACHY Instrument Simulation 


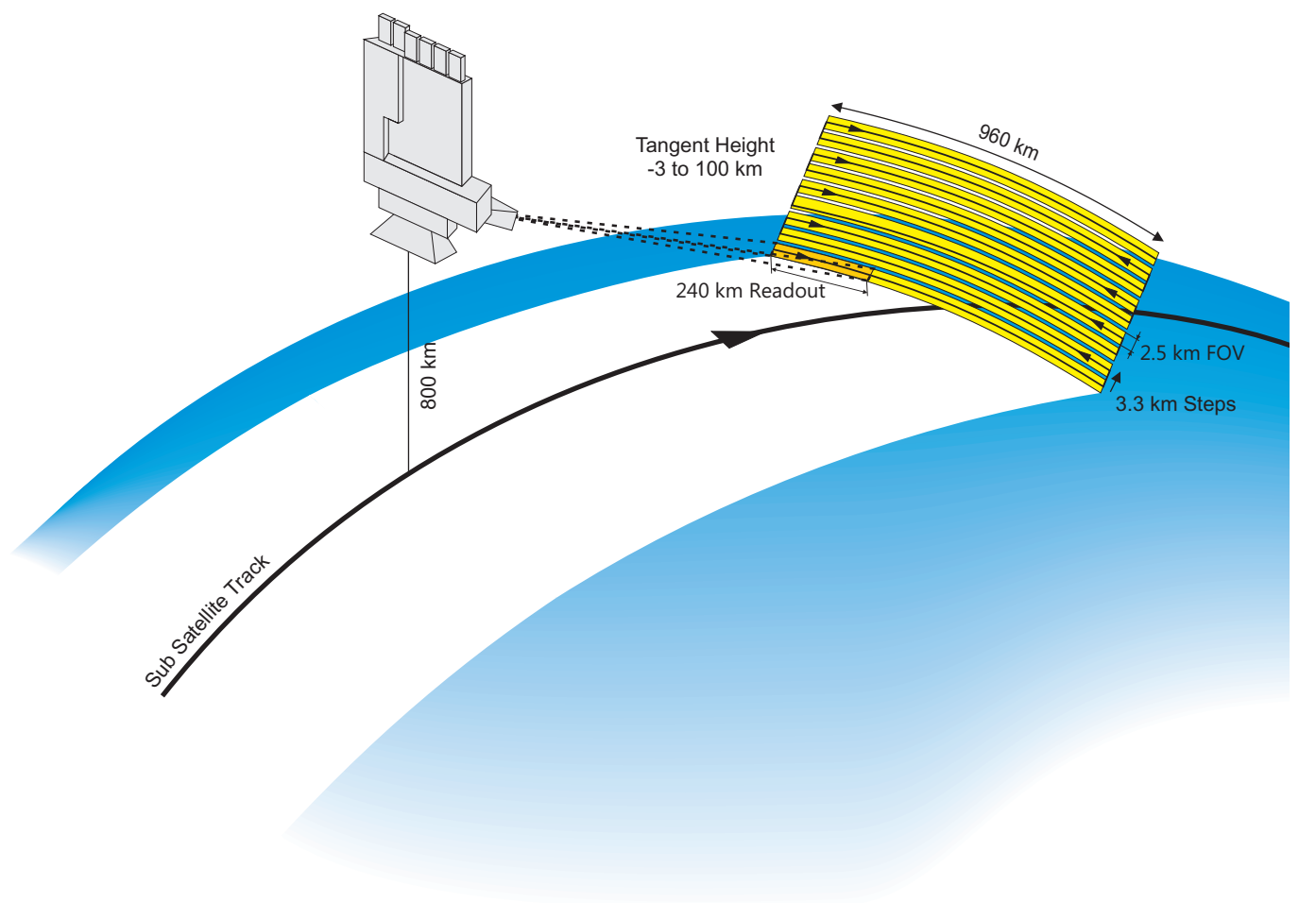

Fig. 1. Typical limb observation sequence as performed by the SCIAMACHY instrument.

Software. The method to calculate the signal to noise ratios and further details on signal to noise characteristics of the SCIAMACHY instrument are presented by Noël et al. (1998).

Throughout this study, version 6.03 of SCIAMACHY Level 1 data is used with the calibration steps from 0 to 5 applied, i.e., the wavelength calibration is performed and the corrections for memory effect, leakage current, pixel-to-pixel gain, etalon, and internal straylight are accounted for. The polarization correction as well as the absolute radiometric calibration are not used.

\section{Retrieval approach}

\subsection{Formulation of the linearized inverse problem}

Most of the retrieval methods aimed to obtain vertical distributions of atmospheric species from measurements of scattered solar light require knowledge of the relationship between the atmospheric parameters and the intensity of radiation as measured by the instrument. This relationship is usually provided by a radiative transfer model, i.e., by the solution of the radiative transfer equation, and can be written in a discrete representation as

$\boldsymbol{y}=\boldsymbol{F}\left(\boldsymbol{x}, \boldsymbol{x}^{*}\right)+\epsilon_{\mathrm{rtm}}+\epsilon_{\mathrm{m}}$.

Here, $\boldsymbol{y}$ is the data vector (also referred to as the measurement vector) containing measured radiances and the mapping
$\boldsymbol{F}$ represents the radiative transfer operator (also referred to as the forward model operator). The latter simulates radiances as they would be measured by the instrument for a known atmospheric state. It should be noted that in the discrete representation the radiative transfer operator applied to any known atmospheric state results in a vector that is further referred to as the model data vector. The state vector $\boldsymbol{x}$ comprises atmospheric parameters (e.g., molecular density profiles, aerosol characteristics, etc.) to be retrieved, $\boldsymbol{x}^{*}$ contains the parameters, which affect the measured spectral signal but cannot be retrieved as a result of a lack of information, $\epsilon_{\mathrm{rtm}}$ is the modeling error accounting for approximations in the radiative transfer modeling as well as instrumental effects not included in the model simulations, and $\varepsilon_{\mathrm{m}}$ is the measurement error. To meet the applicability requirements of commonly used statistical inversion methods, e.g., the optimal estimation technique (Rodgers, 2000), the measurement error is assumed to be stochastic and normally distributed around a zero mean.

As standard inversion methods are developed for linear problems, which is usually not the case for Eq. (1), a linear relation between the atmospheric parameters and the measured radiation needs to be obtained first. This is achieved by expanding the radiative transfer operator, $\boldsymbol{F}\left(\boldsymbol{x}, \boldsymbol{x}^{*}\right)$, in the Taylor series around an initial guess atmospheric state and neglecting higher order terms:

$$
\boldsymbol{y}=\boldsymbol{F}\left(\boldsymbol{x}_{\mathrm{a}}, \boldsymbol{x}_{\mathrm{a}}^{*}\right)+\mathbf{K}\left(\boldsymbol{x}-\boldsymbol{x}_{\mathrm{a}}\right)+\epsilon_{\mathrm{all}} .
$$


Here, the initial guess, also referred to as the a priori, state vector, $\boldsymbol{x}_{\mathrm{a}}$, is the best beforehand estimator of the true solution,

$\mathbf{K}=\left.\frac{\partial \boldsymbol{F}\left(\boldsymbol{x}, \boldsymbol{x}^{*}\right)}{\partial \boldsymbol{x}}\right|_{\boldsymbol{x}=\boldsymbol{x}_{\mathrm{a}}}$

is the partial derivative matrix (also referred to as the weighting function matrix), and

$\epsilon_{\mathrm{all}}=\epsilon_{\mathrm{rtm}}+\epsilon_{\mathrm{m}}+\epsilon_{\mathrm{lin}}+\left.\frac{\partial \boldsymbol{F}\left(\boldsymbol{x}, \boldsymbol{x}^{*}\right)}{\partial \boldsymbol{x}^{*}}\right|_{\boldsymbol{x}^{*}=x_{\mathrm{a}}^{*}}\left(\boldsymbol{x}^{*}-\boldsymbol{x}_{\mathrm{a}}^{*}\right)$

contains the modeling, measurement, and linearization errors as well as the error resulting from unknown atmospheric parameters, which cannot be retrieved from the measurement. Equation (2) represents the most general formulation of the inverse problem specific to the retrieval of atmospheric parameters from spectroscopic measurements.

\subsection{Solution methods}

Most widely, the inverse problem formulated in Sect. 3.1 (vertical profile retrieval from measurements of the scattered solar light) is solved employing the so-called DOAS (Differential Optical Absorption Spectroscopy) technique, which is described in detail by Platt and Stutz (2008). Applying this technique to space-borne observations in the limb viewing geometry, the retrieval is done in two steps: first performing spectral fits at each tangent height independently to obtain auxiliary quantities called slant columns (integrated amounts of absorber along the effective light path) and then solving the inverse problem for slant columns to obtain vertical profiles of atmospheric species of interest (Haley et al., 2004; Krecl et al., 2006; Sioris et al., 2006; Kühl et al., 2008). In the first step of DOAS retrievals, often referred to as the spectroscopic retrieval, a model simulation at the a priori state is not needed (the first term in Eq. 2 cancels out, see below) and the weighting function matrix, $\mathbf{K}$, is replaced by the appropriate cross sections, which makes this approach very efficient computationally.

Alternatively, vertical distributions of atmospheric species can be retrieved employing the so-called global fit approach, where the inverse problem is formulated directly for all available spectral measurements (Milz et al., 2005; Rozanov et al., 2005a; Doicu et al., 2007). Using this method both simulated spectra and weighting functions need to be calculated at each spectral point for the a priori atmospheric state, making the approach much slower as compared to the DOAS technique. On the other hand, it allows the absorption features of atmospheric species to be considered more accurately. As described by Rozanov et al. (2005a), the global fit approach may also include an auxiliary spectral fitting procedure performed at each tangent height independently, which is somewhat similar to the spectroscopic retrieval in the DOAS technique. This spectral fit does not introduce any intermediate quantities (as slant columns in DOAS) and aims only to increase the quality of the input spectra, which are passed to the main inversion. A detailed description of both techniques and their implementation in different retrieval algorithms is given below.

There are also retrieval algorithms, which cannot be directly associated with one of the above discussed techniques. They might employ, for example, an Onion Peeling type approach (Russell and Drayson, 1972; Tukiainen et al., 2008; Noël et al., 2010) or some specific combinations of measured data (Flittner et al., 2000; Bourassa et al., 2007). These methods are, however, outside the scope of our study.

\subsubsection{Transformation of the measurement vector}

All retrieval algorithms discussed in this study solve the inverse problem in the logarithmic representation, i.e., the inverse problem is formulated for the logarithms of the limb radiances rather than for the radiances themselves. As shown in previous studies (Klenk et al., 1982; Hoogen et al., 1999; Rozanov and Kokhanovsky, 2008), this approach improves the linearity of the inverse problem resulting in smaller linearization errors. Furthermore, as spectral contributions of the retrieved atmospheric species and most of contaminating parameters are multiplicative, it is more appropriate to perform spectral fits in the logarithmic representation.

Taking the logarithms of both sides of Eq. (2), neglecting the error term, and, then, expanding the righthand side into the Taylor series around $\boldsymbol{F}\left(\boldsymbol{x}_{\mathrm{a}}\right)$ assuming $\boldsymbol{F}\left(\boldsymbol{x}_{\mathrm{a}}\right) \gg \mathbf{K}\left(\boldsymbol{x}-\boldsymbol{x}_{\mathrm{a}}\right)$, the inverse problem at each particular tangent height, $h_{j}$, can be rewritten as follows:

$\ln \boldsymbol{y}_{j}=\ln \boldsymbol{F}_{j}\left(\boldsymbol{x}_{\mathrm{a}}\right)+\hat{\mathbf{F}}_{j}^{-1} \mathbf{K}_{j}\left(\boldsymbol{x}-\boldsymbol{x}_{\mathrm{a}}\right)$.

Here, the data vector $\boldsymbol{y}_{j}$ contains the limb radiance measured at the considered tangent height in all spectral points within the selected fitting window, the model data vector $\boldsymbol{F}_{j}\left(\boldsymbol{x}_{\mathrm{a}}\right)$ contains corresponding simulated radiances calculated for the a priori state of the atmosphere, $\boldsymbol{x}_{\mathrm{a}}$, and $\hat{\mathbf{F}}_{j}$ is a diagonal matrix containing elements of vector $\boldsymbol{F}_{j}\left(\boldsymbol{x}_{\mathrm{a}}\right)$ at the diagonal. For simplicity reason, the argument $\boldsymbol{x}_{\mathrm{a}}^{*}$ in the parameter list of the model data vector, $\boldsymbol{F}$, is omitted.

To minimize the influence of the solar Fraunhofer structure and avoid the need of the absolute radiometric calibration of the instrument, all algorithms considered in this study use a limb observation at an upper tangent height (often referred to as the reference tangent height, $h_{\text {ref }}$ ) to normalize the measured spectra (details are given below). This results in the following transformation of the data vector:

$\hat{\boldsymbol{y}}_{j}=\left[\ln \frac{I_{j}\left(\lambda_{1}\right)}{I_{\mathrm{ref}}\left(\lambda_{1}\right)}, \ldots, \ln \frac{I_{j}\left(\lambda_{1}\right)}{I_{\mathrm{ref}}\left(\lambda_{1}\right)}, \ldots, \ln \frac{I_{j}\left(\lambda_{1}\right)}{I_{\mathrm{ref}}\left(\lambda_{1}\right)}\right]$,

where $I_{j}\left(\lambda_{1}\right)$ and $I_{\text {ref }}\left(\lambda_{1}\right)$ represent the limb radiance at a wavelength $\lambda_{1}$ measured at the tangent height $h_{j}$ and at the reference tangent height, respectively, and $L$ is the total number of the spectral points in the selected spectral window. The 
appropriate transformation for the weighting function matrix is

$\hat{\mathbf{K}}_{j}=\hat{\mathbf{F}}_{j}^{-1} \mathbf{K}_{\mathbf{j}}-\hat{\mathbf{F}}_{\text {ref }}^{-1} \mathbf{K}_{\text {ref }}$.

Components of the transformed model data vector, $\hat{\boldsymbol{F}}_{j}$, are obtained in exactly the same way as for the measurement vector, $\hat{\boldsymbol{y}}_{j}$. However, as mentioned above, the model data term cancels out if the retrieval is performed employing the DOAS technique.

The full inverse problem as defined by Eq. (2) is rewritten then as

$\hat{\boldsymbol{y}}=\hat{\boldsymbol{F}}\left(\boldsymbol{x}_{\mathrm{a}}\right)+\hat{\mathbf{K}}\left(\boldsymbol{x}-\boldsymbol{x}_{\mathrm{a}}\right)$,

where the full vectors and matrices are obtained, stacking the corresponding quantities for all tangent heights on top of each other.

\subsubsection{Accounting for spectral corrections}

Most commonly, relevant atmospheric parameters are considered in the forward model and either can be retrieved from the measurements or their influence upon the retrieval is neglected ( $\boldsymbol{x}$ and $\boldsymbol{x}^{*}$ state vectors discussed in Sect. 3.1). However, there are also parameters, which have known spectral signatures but for different reasons cannot be included in radiative transfer calculations. These parameters, referred to as the spectral corrections or pseudo-absorbers, describe usually insufficiently quantified instrumental effects, or complex natural phenomena, which are difficult to model. A common way to account for pseudo-absorbers is to include their spectral signatures in the retrieval procedure by fitting the corresponding scaling factors. Formally this leads to the following transformation of the inverse problem formulated in Sect. 3.2.1:

$\hat{\boldsymbol{y}}_{j}=\hat{\boldsymbol{F}}_{j}\left(\boldsymbol{x}_{\mathrm{a}}\right)+\hat{\mathbf{K}}_{j}\left(\boldsymbol{x}-\boldsymbol{x}_{\mathrm{a}}\right)+\mathbf{W}_{j}^{\mathrm{sc}} \boldsymbol{s}$,

where $\mathbf{W}_{j}^{\text {sc }}$ is a matrix containing the spectral corrections and vector $s$ contains the corresponding scaling factors. A detailed discussion of the spectral corrections used in this study is presented in Sect. 3.3.

\subsubsection{Transformation of the inverse problem in the framework of the DOAS technique}

As pointed out above, the standard DOAS technique employs a two step approach separating the spectral fit and the vertical inversion procedure. The inverse problem that needs to be solved at the first inversion step (usually referred to as the spectroscopic retrieval) for each tangent height is defined by

$\ln \frac{I(\lambda)}{I_{\mathrm{ref}}(\lambda)}=\sum_{k=1}^{N_{k}} c_{k} \sigma_{k}(\lambda)+\sum_{m=1}^{M} s_{\mathrm{m}} W_{\mathrm{m}}^{\mathrm{sc}}(\lambda)+P_{\lambda}$.

As discussed in detail in Appendix A this equation, which is a spectral representation of Eq. (A9), can be derived from
Eq. (9) under assumptions specific to the standard DOAS technique (see last paragraph of Appendix A for details). Here, $N_{k}$ is the total number of atmospheric species included in the fit, $\sigma_{k}(\lambda)$ and $c_{k}$ are their absorption cross sections and slant columns, respectively, $W_{\mathrm{m}}^{\mathrm{sc}}(\lambda)$ and $s_{\mathrm{m}}$ represent the spectral corrections and their scaling factors, respectively, $M$ is the total number of spectral corrections included in the fit procedure, and $P_{\lambda}$ is a low order polynomial in wavelength. For the sake of simplicity, the explicit notation of the tangent height dependence (index $j$ ) is omitted.

Equation (10) is solved in the least squares sense to obtain $c_{k}$ and $s_{\mathrm{m}}$ parameters for each tangent height. However, only the slant columns of the atmospheric species of interest are used further in the retrieval process whereas the slant columns of all other atmospheric species included in the fit procedure as well as the scaling factors for the spectral corrections, $s_{\mathrm{m}}$, are auxiliary parameters, used only to improve the fit quality.

The inverse problem to be solved at the second step (vertical inversion) of the standard DOAS technique can be obtained from the logarithmic representation of the general inverse problem given by Eq. (8). This is done by rewriting all of the terms in accordance with the discussion in Appendix A as described below.

In this study, only BrO slant columns obtained at the spectroscopic retrieval stage are considered in the vertical inversion procedure whereas contributions of other parameters are separated from the measured signal based on their unique (not correlated) spectral signatures. Taking into account Eq. (A7) this corresponds formally to the following transformation of the measurement vector elements:

$\left\{\hat{\boldsymbol{y}}_{j}\right\}_{l}=\{\boldsymbol{c}\}_{j} \sigma\left(\lambda_{1}\right)-P_{\lambda}$.

Here, curly brackets are used to denote elements of vectors, i.e., $\left\{\hat{\boldsymbol{y}}_{j}\right\}_{l}$ is the element of the measurement vector corresponding to the tangent height $j$ and wavelength $l$, vector $c$ contains BrO slant columns obtained from the spectroscopic retrieval at different tangent heights, and $P_{\lambda}$ represents a subtraction of a low order polynomial in the wavelength domain. For the sake of simplicity, the subscript " $k$ " indicating the number of retrieved species is omitted for both slant column and the cross section. The transformation of the model data vector components is done in exactly the same way as for the measurement vector:

$\left\{\hat{\boldsymbol{F}}_{j}\right\}_{l}=\left\{\boldsymbol{c}_{\mathrm{a}}\right\}_{j} \sigma\left(\lambda_{1}\right)-P_{\lambda}$,

where $\boldsymbol{c}_{\mathrm{a}}$ contains $\mathrm{BrO}$ slant columns corresponding to the a priori atmospheric state.

The elements of the logarithmic weighting function matrix, $\hat{\mathbf{K}}$, as defined by Eq. (7), can be expressed via the socalled box air mass factors that describe the effective light path enhancement in the corresponding altitude layers, see Eq. (A2). Although in a general case the box air mass factors depend on the wavelength, the assumption about a wavelength independent slant column in the framework of the 
standard DOAS technique requires the corresponding box air mass factor to be wavelength independent as well. The latter is usually achieved calculating the box air mass factor at a representative wavelength or combining values for various wavelengths. Consequently, the elements of the matrix, $\hat{\mathbf{K}}$ can be represented as

$\left\{\hat{\mathbf{K}}_{\mathbf{j}}\right\}_{l, i}=\left\{\hat{\mathbf{A}}_{j}\right\}_{i} H_{i} \sigma\left(\lambda_{1}\right)$.

Here, index $i$ runs through all altitude levels in the forward model, $H_{i}$ is the geometrical thickness of the $i$-th layer, and $\left\{\hat{\mathbf{A}}_{j}\right\}_{i}=\left\{\mathbf{A}_{j}\right\}_{i}-\left\{\mathbf{A}_{\mathrm{ref}}\right\}_{i}$ with $\left\{\mathbf{A}_{j}\right\}_{i}$ and $\left\{\mathbf{A}_{\text {ref }}\right\}_{i}$ being the box air mass factors at the altitude $i$ for the tangent height $j$ and the reference tangent height, respectively.

The terms on the right-hand sides of Eqs. (11)-(13) contain the $\mathrm{BrO}$ absorption cross section, which depends only on wavelength, multiplied by a wavelength independent term. This allows the inverse problem defined by Eq. (8) to be modified as follows:

$\boldsymbol{c}=\boldsymbol{c}_{\mathrm{a}}+\tilde{\mathbf{A}}\left(\boldsymbol{x}-\boldsymbol{x}_{\mathrm{a}}\right)$

where $\tilde{\mathbf{A}} \equiv \hat{\mathbf{A}} \boldsymbol{H}$ and, similar to the slant column vector $\boldsymbol{c}$, the state vector $\boldsymbol{x}$ contains $\mathrm{BrO}$ related components only. Looking at Eq. (A6) it is clear that $\boldsymbol{c}_{\mathrm{a}}=\tilde{\mathbf{A}} \boldsymbol{x}_{\mathrm{a}}$. Thus, the final equation for the linearized inverse problem to be solved at the second step (vertical inversion) of the standard DOAS technique is obtained as

$\boldsymbol{c}=\tilde{\mathbf{A}} \boldsymbol{x}$.

It follows that, in the framework of the DOAS technique, the inverse problem is modified considering the slant columns, obtained at the spectroscopic retrieval stage for each tangent height, as the measurement vector. As all terms in Eq. (15) are independent of the wavelength, no spectral fit needs to be performed during the vertical inversion step.

\subsection{Spectral corrections}

As mentioned above, the spectral corrections also referred to as the pseudo-absorbers are auxiliary functions containing known spectral features which are not included in the forward model. Usually, they describe spectral features due to different kinds of the instrumental effects or complex natural phenomena. In this section we provide a short overview of the spectral corrections commonly used in the framework of the standard DOAS technique (see, e.g., Sioris et al., 2003; Haley et al., 2004) and discuss how these corrections can be extended to the global fit method. In addition, eta and zeta corrections accounting for polarization features of the SCIAMACHY instrument are considered. The idea of using the polarization features as pseudo-absorbers has been previously discussed by McLinden et al. (2002b); Haley et al. (2004) for OSIRIS and by Kühl et al. (2008) for SCIAMACHY limb retrievals.

It is worth noting here that some of the spectral corrections described below (e.g., tilt, Ring effect, and offset corrections) show very similar spectral structures. Thus, if a certain subset of spectral corrections is used, it might also approximate spectral structures attributed to the effects which formally are not included in the fit procedure. This means that one do not necessary need to use all spectral corrections described here and similar fit results can be obtained using different subsets of corrections.

\subsubsection{Tilt}

Because of a moderate spectral resolution and a relatively low sampling ratio (about 2 spectral pixels per FWHM of the slit function) of the SCIAMACHY instrument, the so-called tilt effect is observed in the measured limb spectra. This effect appears as a spectral shift of solar Fraunhofer lines which depends on the spectral slope (tilt) of the background limb radiance, i.e., it varies with the tangent height.

The physical reason of the tilt effect is that the incoming solar radiance is modified by the atmospheric extinction leading to different spectral slopes for different tangent heights. When such signal is imaged and convolved by an optical spectrometer with a wavelength discretizing detector, which tends to undersample the spectra, the shapes of sharp spectral structures are distorted differently for different background spectral slopes. As a result, spectral images of the signal dominating solar Fraunhofer lines are effectively shifted. Thus, ratioing of limb spectra at different tangent heights leads to non-negligible spectral residuals.

From the mathematical point of view, the residual spectral structure results because the forward modeling (if appropriate) and the spectral fitting are performed with a relatively coarse sampling (according to the spectral sampling of the instrument). If modeled properly, i.e., performing the radiative transfer calculations with high spectral resolution and sampling and convolving afterwards, the effect is expected to disappear. Thus, for the $i$-th tangent height this residual spectral structure (so-called tilt spectrum) can be simulated as follows:

$t_{i}(\lambda)=\ln \frac{\mathbf{L}\left\{I^{\mathrm{hr}}\left(\lambda, h_{i}\right)\right\}}{\mathbf{L}\left\{I^{\mathrm{hr}}\left(\lambda, h_{\mathrm{ref}}\right)\right\}}-\ln \frac{I^{\mathrm{lr}}\left(\lambda, h_{i}\right)}{I^{\operatorname{lr}}\left(\lambda, h_{\mathrm{ref}}\right)}$,

where $I^{\mathrm{hr}}\left(\lambda, h_{i}\right)$ and $I^{\mathrm{hr}}\left(\lambda, h_{\text {ref }}\right)$ are the highly resolved and sampled limb radiances simulated for tangent height $i$ and for the reference tangent height, respectively, whereas $I^{\mathrm{lr}}\left(\lambda, h_{i}\right)$ and $I^{\mathrm{lr}}\left(\lambda, h_{\mathrm{ref}}\right)$ are the corresponding radiances calculated with the spectral resolution and sampling of the instrument. The operator $\mathbf{L}$ represents spectral convolution and binning as it occurs in the instrument when detecting the limb signals. Commonly, the tilt spectrum is considered to be caused by scattering processes only, i.e., the radiances are simulated assuming a non-absorbing atmosphere. A similar effect caused by local slope differences occurring as a result of atmospheric absorption is referred to as the $I_{0}$ effect and treated independently as described below. Simulated for 
some standard conditions, the shape of the tilt spectrum is considered to be independent of the tangent height and of the atmospheric scenario and only the scaling factor is fitted, i.e., $t_{i}(\lambda)=k_{i} t(\lambda)$.

\subsection{2 $\quad I_{0}$ effect}

As pointed out in the previous section, the spectral slope of the observed limb radiance can be caused not only by the scattering processes but also by the absorption by atmospheric species. This is because the wavelength dependence of the absorption cross sections of atmospheric species also causes local slopes (within absorption bands) in the spectral dependence of the observed limb radiance which vary with the tangent height. This effect is commonly referred to as the $I_{0}$ effect and the corresponding correction is denoted the $I_{0}$-correction (Aliwell et al., 2002).

As discussed in Appendix B, in the framework of the standard DOAS technique this correction is accounted for replacing in the spectral fit procedure the pre-convolved absorption cross section by the so-called $I_{0}$-corrected cross section:

$\hat{\sigma}(\lambda)=\frac{\mathbf{L}\left\{I_{\mathrm{e}}^{\mathrm{hr}}(\lambda) \sigma^{\mathrm{hr}}(\lambda)\right\}}{\mathbf{L}\left\{I_{\mathrm{e}}^{\mathrm{hr}}(\lambda)\right\}}$.

Here, $\sigma^{\mathrm{hr}}(\lambda)$ and $I_{\mathrm{e}}^{\mathrm{hr}}$ are the absorption cross section and the extraterrestrial solar radiance at a high spectral resolution, respectively. The spectral fit is done then in a usual way.

In the framework of the global fit method the $I_{0}$-correction is commonly calculated as a difference of the total correction and the tilt spectrum:

$\mathcal{I}_{0}(\lambda)=R_{i}(\lambda)-t_{i}(\lambda)$.

Here, the tilt spectrum, $t_{i}(\lambda)$, is calculated as discussed in Sect. 3.3.1 and the total correction, $R_{i}(\lambda)$, is obtained similarly to Eq. (16) but considering both scattering and absorption processes when calculating the radiance (see Appendix $\mathrm{B}$ for details). The $I_{0}$-correction obtained according to Eq. (18) is then fitted with a scaling factor as a pseudoabsorber.

Clearly, only the atmospheric species whose absorption features contribute significantly into the slope of the observed limb radiance need to be accounted for when considering the $I_{0}$ effect. In this study only ozone absorption is sufficiently strong enough to be considered.

\subsubsection{Ring effect}

The fact that solar Fraunhofer lines appear narrower and deeper in direct solar light as compared to the scattered light (so-called Filling in of Fraunhofer lines) has been discovered by Shefov (1959) and independently by Grainger and Ring (1962). This effect, referred to as the Ring effect, is attributed to inelastic scattering processes taking place in the Earth's atmosphere. Later investigations have shown that, for spaceborne and ground-based measurements of the scattered solar light in the UV-Visible spectral range, the rotational Raman scattering provides dominant contribution to the Ring effect (see, e.g., Kattawar et al., 1981; Clarke and Basurah, 1989; Joiner et al., 1995). As the magnitude of the Ring effect depends on the scattering properties of the atmosphere, the solar Fraunhofer structure is not completely canceled when calculating the ratio of limb spectra observed at different tangent heights. As a full radiative transfer modeling of the Ring effect is currently too time consuming it is not properly simulated for each measured atmospheric spectrum. Instead, the Ring spectrum is either simulated for a selected atmospheric state (Vountas et al., 1998) or obtained using an approximation (Chance and Spurr, 1997) or derived from measurements (Solomon et al., 1987). The obtained spectrum is used then as a pseudo-absorber in the fit procedure.

\subsubsection{Wavelength shift}

Wavelength shift is caused by changes in the instrument wavelength calibration with respect to the pre-flight measurements which are used to calibrate the observed spectra. For the SCIAMACHY instrument two types of wavelength calibration distortion are possible. Slight in-flight changes of the optical system adjustment and a temperature instability cause a permanent distortion of the wavelength calibration which does not change significantly during each single measurement. This causes a mismatch of wavelength grids of the measured spectra and absorption cross sections used in the forward modeling or in the spectral fit (depending on the retrieval technique). Moreover, in limb viewing geometry the entrance slit of the instrument is illuminated inhomogeneously with more radiance coming from the lower atmosphere. Thus, the shape of the instrument slit function may slightly vary with the tangent height because of changes in the entrance slit illumination leading to a dynamic, i.e., changing during each limb scan, distortion of the wavelength calibration. This results in a wavelength grid mismatch between limb spectra observed at different tangent heights producing thus a residual structure when ratioing. Both distortions can be accounted for by introducing corresponding spectral corrections, which can be obtained employing a Taylor series expansion of the logarithm of the radiance with respect to the wavelength shift:

$\ln I(\lambda+\Delta \lambda) \approx \ln I(\lambda)+\frac{\mathrm{d} \ln I(\lambda)}{\mathrm{d} \lambda} \Delta \lambda$.

Here, we restrict our considerations to the linear term only and assume $\Delta \lambda$ to be the same for each wavelength, i.e., higher order distortions of the wavelength calibration as stretch/squeeze are not considered. Thus, the spectral corrections are obtained as

$W_{1}^{\text {shift }}=\frac{\mathrm{d} \ln I^{\mathrm{mes}}\left(\lambda, h_{\text {ref }}\right)}{\mathrm{d} \lambda}$ 
for the wavelength grid mismatch of the limb spectrum at the reference tangent height and

$W_{2}^{\text {shift }}=\frac{\mathrm{d} \ln I^{\operatorname{sim}}(\lambda, h)}{\mathrm{d} \lambda}-\frac{\mathrm{d} \ln I^{\operatorname{sim}}\left(\lambda, h_{\text {ref }}\right)}{\mathrm{d} \lambda}$

for the wavelength grid mismatch of the simulated radiances with respect to the measured limb spectrum as used in the global fit approach or

$W_{2}^{\text {shift }}=\frac{\mathrm{d} \sigma(\lambda)}{\mathrm{d} \lambda}$

for the wavelength grid mismatch of the absorption cross sections with respect to the measured limb spectrum as used in the standard DOAS technique. All derivatives with respect to the wavelength shift are calculated numerically.

\subsubsection{Offset}

An offset in the observed limb radiances may occur if the instrument stray light is not completely removed when performing the data calibration. Most commonly used approximations for the remaining stray light contribution are either constant, i.e., wavelength independent, or linearly dependent on the wavelength offsets. Similar to the previous section, the corresponding spectral corrections are obtained employing the Taylor series expansion for the logarithm of the radiance:

$\ln \left(I(\lambda)+k_{1}+k_{2} \lambda\right) \approx \ln I(\lambda)+\frac{1}{I(\lambda)} k_{1}+\frac{\lambda}{I(\lambda)} k_{2}$.

Thus, the corresponding spectral corrections are given by

$W_{1}^{\text {offset }}=\frac{1}{I(\lambda)}$ and $W_{2}^{\text {offset }}=\frac{\lambda}{I(\lambda)}$.

As offset corrections for limb spectra at lower tangent heights may contain significant contributions due to the absorption structure of the retrieved atmospheric species, a strong correlation may occur. To avoid this, the offset correction is commonly applied to the reference spectrum only.

\subsubsection{Eta and zeta functions}

Both eta, $\eta(\lambda)$, and zeta, $\zeta(\lambda)$, functions describe purely instrumental effects related to the sensitivity of the detector to the polarization of the incident light. The polarization sensitivity of the instrument is accounted for when converting the detector response into the intensity of the incoming radiance using so-called polarization correction factor (multiplicative correction) given by

$c_{\mathrm{pol}}(\lambda)=\left[1+\frac{1-\eta(\lambda)}{1+\eta(\lambda)} q(\lambda)+\frac{1-\zeta(\lambda)}{1+\zeta(\lambda)} u(\lambda)\right]^{-1}$,

where $q$ and $u$ are the polarization fractions of the incoming light along the $\mathrm{x}$ - or $\mathrm{y}$-axis and $\pm 45^{\circ}$ direction, respectively, i.e.,

$q(\lambda)=\frac{I_{\mathrm{x}}(\lambda)-I_{\mathrm{y}}(\lambda)}{I(\lambda)}$

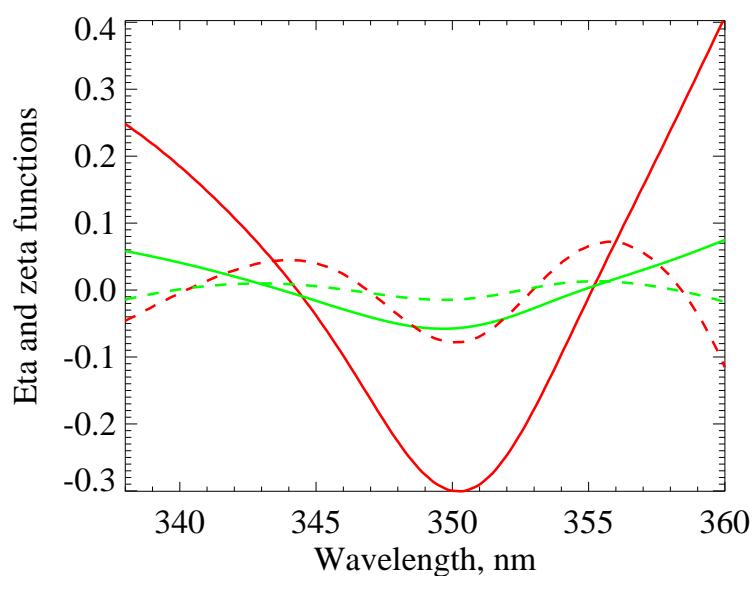

Fig. 2. Logarithms of eta (red) and zeta (green) functions with linear polynomial subtracted shown by solid lines and with cubic polynomials subtracted shown by dashed lines.

and

$u(\lambda)=\frac{I_{+45}(\lambda)-I_{-45}(\lambda)}{I(\lambda)}$,

see Lichtenberg et al. (2006) for details.

It follows from Eq. (25) that the polarization correction depends on the polarization of the incoming light. The latter is estimated using a theoretical model from the measurements done by on-board polarization measurement devices (PMDs). These measurements, however, are done at very low spectral resolution (only one spectral point in $\mathrm{BrO}$ fit window). Due to this inaccuracy, the polarization contribution cannot be removed completely when calibrating the limb spectra and a residual structure remains which, in the linear approximation, can be described by eta and zeta functions themselves. Thus, when solving the inverse problem in the logarithmic representation, as defined by Eq. (8), the logarithms of these functions are included into the fit procedure as spectral corrections (pseudo-absorbers) to account for the spectral residual due to the polarization effects. In Fig. 2 the logarithms of eta and zeta functions are shown with red and green lines, respectively. The solid lines represent the remaining differential structure when subtracting a linear polynomial whereas the dashed lines show the logarithms of eta and zeta functions with a cubic polynomial subtracted.

An additional residual structure remaining when ratioing two limb spectra at different tangent heights is caused by the dependence of eta and zeta functions on the position of the elevation scan mirror, which changes during the vertical scan (i.e., with the tangent height). Although the main effect is described by a scaling factor and, thus, removed including the logarithms of eta and zeta functions in the spectral fit procedure, a secondary effect of changing the spectral structure still remains significant. The solid red line in Fig. 3 shows the residual spectral structure obtained when fitting to each 


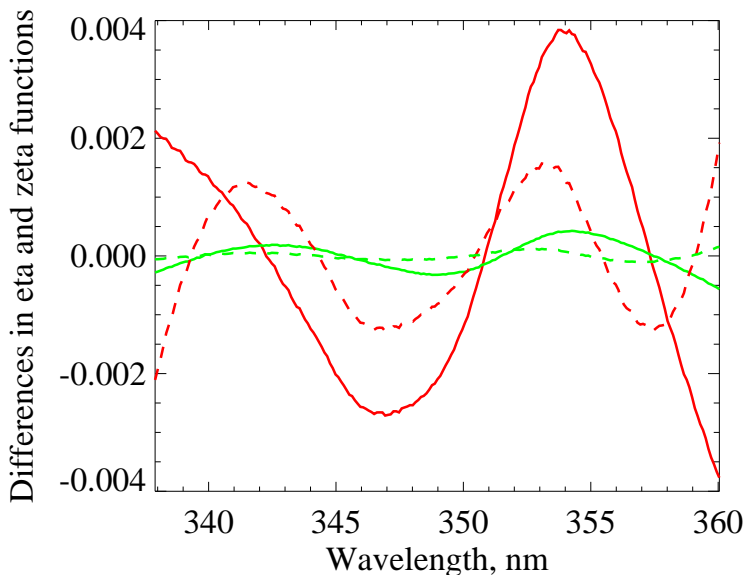

Fig. 3. Differential logarithmic eta (red) and zeta (green) functions. The functions are obtained as the spectral residuals remaining when fitting to each other the logarithms of the eta or zeta functions for different positions of the elevation scan mirror. The fit procedure includes the scaling factor and a linear (solid lines) or a cubic (dashed lined) polynomial.

other the logarithms of eta functions for two different positions of the elevation scan mirror. Here, a scaling factor and a linear polynomial are included in the fit. This residual spectral structure is further referred to as the differential logarithmic eta function. The red dashed line shows the residual structure obtained by fitting a cubic polynomial instead of a linear one. Similar results for differential logarithmic zeta functions are shown with green lines. Our investigations show that the residual spectral structure remains similar for different combinations of tangent heights. Thus, it can be accounted for using the differential logarithmic eta and zeta functions as pseudo-absorbers in the spectral fit procedure.

\subsection{Implementation details}

\subsubsection{MPI Mainz retrieval}

The MPI Mainz retrieval algorithm employs the standard DOAS technique as discussed in Sect. 3.2.3. At the spectroscopic retrieval step the spectral inverse problem as defined by Eq. (10) is solved for each tangent height independently resulting in a set of $\mathrm{BrO}$ slant columns obtained for different tangent heights. Besides $\mathrm{BrO}$, the absorption cross sections of $\mathrm{O}_{3}$ and $\mathrm{NO}_{2}$ are included in the spectral fit. The resulting slant columns of these species, however, are not used in the further retrieval. Although the fitting equation employed in the spectroscopic retrieval by the MPI Mainz algorithm, Eq. (10), is derived neglecting the temperature dependence of all cross sections, this dependence can, nevertheless, be accounted for exploiting the fact that absorption cross sections of most atmospheric species exhibit somewhat different spectral signatures at different temperatures. As it is the temperature dependence of the ozone absorption cross section, which has the major influence on the fit quality, the MPI Mainz algorithm fits three ozone cross sections at temperatures 203,223 and $243 \mathrm{~K}$. In addition, the wavelength dependence of the ozone slant column is accounted for by a Taylor series approach including two first order terms, $c_{\lambda} \sigma_{\mathrm{O}_{3}} \lambda$ and $c_{\sigma} \sigma_{\mathrm{O}_{3}}^{2}$, in the fit procedure (see Puksite et al., 2010 for details). Here, $c_{\lambda}$ and $c_{\sigma}$ are the fit coefficients and the ozone cross section at $223 \mathrm{~K}$ is used. For the sake of simplicity, the wavelength dependence of the cross section is not indicated explicitely. The temperature dependence of other cross sections is not accounted for $\left(\mathrm{NO}_{2}\right.$ and $\mathrm{BrO}$ cross sections at $223 \mathrm{~K}$ are used). Besides the absorption cross sections of the atmospheric species the following spectral corrections (see Sect. 3.3 for details) are considered in the spectroscopic retrieval to increase further the fit quality: Ring, $I_{0}$-correction for ozone cross sections, eta and zeta functions, as well as linear offset corrections $\left(\frac{1}{I_{0}(\lambda)}\right.$ and $\frac{\lambda}{I_{0}(\lambda)}$ terms). In addition, a fourth order polynomial is included in the spectral fit.

At the second retrieval step (vertical inversion), the MPI Mainz approach solves the linearized inverse problem formulated in the framework of the standard DOAS technique, as given by Eq. (15). The measurement vector contains $\mathrm{BrO}$ slant columns obtained at the spectroscopic retrieval stage. The linear relationship between the measurement vector and the state vector containing the retrieved $\mathrm{BrO}$ number densities is established by the box air mass factor matrix. The inverse problem is solved in the least squares sense employing the maximum a posteriori information method as described by Rodgers (2000) which is also referred to as the optimal estimation method. In the framework of this method, the solution is obtained minimizing the following quadratic form:

$\mathcal{F}(\boldsymbol{x})=\|\boldsymbol{c}-\tilde{\mathbf{A}} \boldsymbol{x}\|_{\mathbf{S}_{\varepsilon}^{-1}}^{2}+\left\|\boldsymbol{x}-\boldsymbol{x}_{\mathrm{a}}\right\|_{\mathbf{S}_{\mathrm{a}}^{-1}}^{2}$.

The linearization errors are neglected, i.e., no iterative process is applied, and the final solution is written as:

$\boldsymbol{x}=\left(\tilde{\mathbf{A}}^{T} \mathbf{S}_{\varepsilon}^{-1} \tilde{\mathbf{A}}+\mathbf{S}_{\mathrm{a}}^{-1}\right)^{-1}\left(\tilde{\mathbf{A}}^{T} \mathbf{S}_{\varepsilon}^{-1} \boldsymbol{c}+\mathbf{S}_{\mathrm{a}}^{-1} \boldsymbol{x}_{\mathrm{a}}\right)$.

The box air mass factor matrix, $\tilde{\mathbf{A}}$ is calculated at $344.2 \mathrm{~nm}$ wavelength using the fully spherical Monte Carlo radiative transfer model McArtim (Deutschmann et al., 2011). This wavelength has been selected because of the best agreement between the true and retrieved profiles found for synthetic retrievals (Puķite et al., 2010). The noise covariance matrix, $\mathbf{S}_{\varepsilon}$, is supposed to be diagonal (i.e. a spectrally uncorrelated noise is assumed). Its diagonal elements are set in accordance to the noise level estimated from the fit residuals at the spectroscopic retrieval step. The diagonal elements of the a priori covariance matrix, $\mathbf{S}_{\mathrm{a}}$, are equal and their value is a square of the maximum a priori $\mathrm{BrO}$ concentration. The off-diagonal elements are set to zero assuming no correlation between the layers.

Further details on the MPI Mainz retrieval approach can be found in Kühl et al. (2008) and Puksīte et al. (2006, 2008, 
2010). It is worth noting here that there is also a modified version of the MPI Mainz retrieval working without constraining the inversion by a priori information. This version, however, is not discussed in the current study.

\subsubsection{IUP Bremen retrieval}

The retrieval algorithm of IUP Bremen exploits a two step technique performing first auxiliary spectral fits for each tangent height independently (pre-processing) and then employing the global fit approach during the main inversion procedure. The pre-processing aims to increase the quality of input spectra by removing all spectral features associated to the spectral corrections. The input spectra corrected in this manner are passed then to the main inversion. No other information obtained at the pre-processing step is further used.

As discussed in Appendix $\mathrm{C}$, the fitting equation used in the IUP Bremen retrieval algorithm at the pre-processing stage is obtained from the logarithmic formulation of the inverse problem, as defined by Eq. (9), assuming relative variations of absorber number densities to be the same at all altitude layers and approximating broad-band spectral features by a low order polynomial. Omitting for the sake of simplicity the explicit notation of the tangent height dependence, the fitting equation is written as

$$
\begin{aligned}
\ln \frac{I(\lambda)}{I_{\mathrm{ref}}(\lambda)} & =\ln \frac{I^{\mathrm{s}}(\lambda)}{I_{\mathrm{ref}}^{\mathrm{s}}(\lambda)}+\sum_{k=1}^{N_{k}} W_{k}^{\mathrm{par}}(\lambda) p_{k} \\
& +\sum_{m=1}^{M} W_{\mathrm{m}}^{\mathrm{sc}}(\lambda) s_{\mathrm{m}}+P_{\lambda}
\end{aligned}
$$

which is the same equation as Eq. (C5) but written in a more common spectral form. Here, $p_{k}$ and $s_{\mathrm{m}}$ are fit parameters, $N_{k}$ is the total number of atmospheric species and $M$ is the total number of the spectral corrections included in the fit, $W_{k}^{\mathrm{par}}(\lambda)$ are the vertically integrated logarithmic weighting functions corresponding to relative variations of atmospheric parameters (see Appendix $C$ for details), and $W_{m}^{\mathrm{sc}}(\lambda)$ are the spectral corrections. The IUP Bremen retrieval includes the following spectral corrections (see Sect. 3.3 for details) in the fitting procedure: Ring, tilt, $I_{0}$-correction for ozone absorption, eta function, and scan angle dependence of the eta function (i.e., differential logarithmic eta function). The zeta function is not considered, because it is found to cause instability of the retrieval. Differential spectra are obtained subtracting a linear polynomial. The synthetic radiances, $I^{\mathrm{s}}(\lambda)$ and $I_{\text {ref }}^{\mathrm{s}}(\lambda)$, as well as the weighting functions of atmospheric species are calculated employing the SCIATRAN (Rozanov et al., 2005b) radiative transfer model. Unlike the MPI Mainz retrieval, the temperature dependence of all cross sections is naturally accounted for within the radiative transfer model and does not need to be considered separately (temperature profiles are from ECMWF data base, see Sect. 4).
Equation (30) is solved in the least squares sense to obtain $p_{k}$ and $s_{\mathrm{m}}$ parameters for each tangent height. Although a polynomial is included in the fit equation meaning that its coefficients also need to be fitted, a more common approach, which is also used in the IUP Bremen retrieval, is to subtract the polynomials from each term in Eq. (30) beforehand reducing in this way the number of fit parameters in the main equation. The scaling factors for spectral corrections obtained for each tangent height at the preprocessing stage are used to correct the measured spectra which are passed then to the main inversion procedure. This is done in the following manner:

$\tilde{\boldsymbol{y}}_{j}=\ln \frac{I(\lambda)}{I_{\mathrm{ref}}(\lambda)}-\sum_{m=1}^{M} W_{\mathrm{m}}^{\mathrm{sc}}(\lambda) s_{\mathrm{m}}-P_{\lambda}$.

The scaling factors for trace gas vertical profiles, $p_{k}$, are auxiliary parameters which are not used further in the course of the retrieval process.

After all corrections obtained at the pre-processing stage have been applied the entire spectral information in the selected spectral range at all considered tangent heights is passed to the main inversion procedure and used then to form the measurement vector. The vertical distributions of atmospheric species are obtained then performing the spectral fit for the entire limb measurement sequence simultaneously. This fitting technique is commonly referred to as the global fit approach.

The main inverse problem is formulated according to Eq. (8):

$\tilde{\boldsymbol{y}}=\hat{\boldsymbol{F}}\left(\boldsymbol{x}_{\mathrm{a}}\right)+\hat{\mathbf{K}}\left(\boldsymbol{x}-\boldsymbol{x}_{\mathrm{a}}\right)$.

Here, the measurement vector $\tilde{\boldsymbol{y}}$ contains logarithms of the normalized observed limb radiance at all considered tangent heights corrected according to Eq. (31), i.e., at each tangent height the corrections obtained at the preprocessing step are applied and a polynomial is subtracted. The a priori term in the right-hand side of Eq. (32), $\hat{\boldsymbol{F}}\left(\boldsymbol{x}_{\mathrm{a}}\right)$, contains logarithms of the simulated limb radiance at all considered tangent heights normalized to the reference tangent height in the same manner as for the measurement vector, see Eq. (6). Similarly to the measurement vector, a polynomial is subtracted at each tangent height. The second term in the right-hand side of Eq. (32) contains the logarithmic weighting functions, as defined by Eq. (7), for all atmospheric species of interest at all considered tangent heights. Similarly to other terms, the weighting functions are also used in the differential form, i.e., a polynomial is subtracted from each weighting function at each tangent height. The resulting linear inverse ill-posed problem, as represented by Eq. (32), is solved in the least squares sense by means of Tikhonov regularization with a statistical and a smoothness constraint. This approach is similar to the optimal estimation method described by Rodgers 
(2000). Essentially, an approximate solution is computed minimizing the following quadratic form:

$$
\left\|\hat{\boldsymbol{F}}\left(\boldsymbol{x}_{\mathrm{a}}\right)+\hat{\mathbf{K}}\left(\boldsymbol{x}-\boldsymbol{x}_{\mathrm{a}}\right)-\tilde{\boldsymbol{y}}\right\|_{\mathbf{S}_{\varepsilon}^{-1}}^{2}+\left\|\left(\boldsymbol{x}-\boldsymbol{x}_{\mathrm{a}}\right)\right\|_{\mathbf{R}}^{2},
$$

where $\mathbf{S}_{\varepsilon}$ is the noise covariance matrix and $\mathbf{R}$ is the regularization matrix containing a priori covariances and smoothing constraints. This leads to the following representation for the solution:

$$
\begin{aligned}
\boldsymbol{x}= & \boldsymbol{x}_{\mathrm{a}}+\left(\hat{\mathbf{K}}^{T} \mathbf{S}_{\varepsilon}^{-1} \hat{\mathbf{K}}+\mathbf{R}\right)^{-1} \\
& \times \hat{\mathbf{K}}^{T} \mathbf{S}_{\varepsilon}^{-1}\left(\tilde{\boldsymbol{y}}-\hat{\boldsymbol{F}}\left(\boldsymbol{x}_{\mathrm{a}}\right)\right) .
\end{aligned}
$$

The simulated limb radiances and the weighting functions are calculated using the SCIATRAN radiative transfer model (Rozanov et al., 2005b). Whereas the radiance is simulated accounting for the multiple scattering effects, the weighting functions are obtained in the single scattering approximation. The non-linearity of the inverse problem is accounted for employing the Gauss-Newton iterative approach resulting in the following solution at $(i+1)$-th iterative step:

$$
\begin{aligned}
\boldsymbol{x}_{i+1} & =\boldsymbol{x}_{\mathrm{a}}+\left(\hat{\mathbf{K}}_{i}^{T} \mathbf{S}_{\varepsilon}^{-1} \hat{\mathbf{K}}_{i}+\mathbf{R}\right)^{-1} \\
& \times \hat{\mathbf{K}}_{i}^{T} \mathbf{S}_{\varepsilon}^{-1}\left(\tilde{\boldsymbol{y}}-\hat{\boldsymbol{F}}\left(\boldsymbol{x}_{i}\right)+\hat{\mathbf{K}}_{i}\left(\boldsymbol{x}_{i}-\boldsymbol{x}_{\mathrm{a}}\right)\right) .
\end{aligned}
$$

Here, the state vector, $\boldsymbol{x}$, contains number densities of all atmospheric species considered in the main inversion procedure at all altitude layers. In the current study the retrieval is performed for vertical profiles of $\mathrm{BrO}, \mathrm{O}_{3}$, and $\mathrm{NO}_{2}$. The latter two, however, are auxiliary parameters used to improve the retrieval quality. The iterative process is stopped if the maximum difference between $\mathrm{BrO}$ vertical distributions obtained at two subsequent iterative steps does not exceed $1 \%$. Typically 2-3 iterations are required to achieve the convergence.

Similar to the MPI Mainz retrieval the diagonal elements of the noise covariance matrix, $\mathbf{S}_{\varepsilon}$, are set in accordance to the noise level estimated from the fit residuals at the preprocessing step. The off-diagonal elements are set to zero assuming a spectrally uncorrelated noise. The regularization matrix, $\mathbf{R}$, consist of two terms:

$\mathbf{R}=\mathbf{S}_{\mathrm{a}}^{-1}+\mathbf{T}$,

where $\mathbf{S}_{\mathrm{a}}$ is the a priori covariance matrix as used in the maximum a posteriori information method described by Rodgers (2000) and matrix T, discussed in more details below, contains smoothness constraints. As not only the vertical distribution of $\mathrm{BrO}$ but also those of $\mathrm{O}_{3}$ and $\mathrm{NO}_{2}$ are retrieved during the main inversion procedure, the a priori covariances need to be set for all species. For each particular species the elements of the a priori covariance matrix are set in accordance with the following rule:

$\left\{S_{\mathrm{a}}\right\}_{i, j}=\sigma_{i} \sigma_{j} \exp \left(-\frac{\left|z_{i}-z_{j}\right|}{l_{\mathrm{c}}}\right)$,

where $\sigma_{i}$ and $\sigma_{j}$ are a priori uncertainties at altitudes $z_{i}$ and $z_{j}$, respectively, and $l_{\mathrm{c}}$ is the correlation length (set to $1.5 \mathrm{~km}$ in this study). The full a priori covariance matrix is formed then from the covariance matrices of all species included in the inversion procedure assuming the species to be uncorrelated:

$\mathbf{S}_{\mathrm{a}}=\left[\begin{array}{ccc}\mathbf{S}_{\mathrm{a}}^{\mathrm{O}_{3}} & \mathbf{0} & \mathbf{0} \\ \mathbf{0} & \mathbf{S}_{\mathrm{a}}^{\mathrm{NO}_{2}} & \mathbf{0} \\ \mathbf{0} & \mathbf{0} & \mathbf{S}_{\mathrm{a}}^{\mathrm{BrO}}\end{array}\right]$,

where 0 represents a zero submatrix. A priori uncertainties for $\mathrm{BrO}$ are set according to the volume mixing ratio uncertainty of $25 \mathrm{pptV}$ if it does not exceed $4 \times 10^{7}$ molec $\mathrm{cm}^{-3}$ and set to $4 \times 10^{7}$ molec $\mathrm{cm}^{-3}$ otherwise. For the vertical profiles of $\mathrm{O}_{3}$ and $\mathrm{NO}_{2}$ a priori uncertainties are set to $1000 \%$ and $100 \%$, respectively. The large standard deviation used for $\mathrm{O}_{3}$ means that the statistical regularization is practically turned off and only the smoothness constraint is applied. The smoothness constraint matrix, T, used additionally to the a priori covariance matrix, $\mathbf{S}_{\mathrm{a}}$, in the IUP Bremen retrieval brings an advantage of suppressing oscillations of the solution without overconstraining it when retrieving at a fine altitude grid. The non-zero elements of the smoothness constraint matrix for atmospheric species $k$ are given then by

$\left\{T_{k}\right\}_{i, i-1}=\frac{t_{k, i}}{\sigma_{k, i}\left(z_{i-1}-z_{i}\right)}$

and

$\left\{T_{k}\right\}_{i, i}=-\left\{T_{k}\right\}_{i, i-1}$,

where $i$ runs through all altitude levels starting from the second one, $\sigma_{k, i}$ is the standard deviation of the atmospheric species $k$ at altitude level $i$, and $t_{k, i}$ is the corresponding smoothness coefficient. Finally, the regularization matrix, $\mathbf{R}$ as given by Eq. (36) is obtained as

$\mathbf{R}=\mathbf{S}_{\mathrm{a}}^{-1}+\left[\begin{array}{ccc}\mathbf{T}_{\mathrm{O}_{3}} & \mathbf{0} & \mathbf{0} \\ \mathbf{0} & \mathbf{T}_{\mathrm{NO}_{2}} & \mathbf{0} \\ \mathbf{0} & \mathbf{0} & \mathbf{T}_{\mathrm{BrO}}\end{array}\right]^{T} \times\left[\begin{array}{ccc}\mathbf{T}_{\mathrm{O}_{3}} & \mathbf{0} & \mathbf{0} \\ \mathbf{0} & \mathbf{T}_{\mathrm{NO}_{2}} & \mathbf{0} \\ \mathbf{0} & \mathbf{0} & \mathbf{T}_{\mathrm{BrO}}\end{array}\right]$.

The smoothness coefficients are chosen empirically to increase linearly with the altitude from 10 at the surface layer to 200 at $50 \mathrm{~km}$ for $\mathrm{O}_{3}$, and from 0.7 at the surface layer to 7 at $50 \mathrm{~km}$ for $\mathrm{NO}_{2}$. For $\mathrm{BrO}$, the smoothness coefficient is set to zero below $10 \mathrm{~km}$ and then increases linearly from 1.1 at $11 \mathrm{~km}$ to 6.6 at $30 \mathrm{~km}$. This dynamical setting of the smoothing coefficients relaxes constraints in the lower atmosphere, where stronger gradients of $\mathrm{BrO}$ vertical distribution may occur and introduces a stronger regularization at upper layers, where the sensitivity of measurements decreases (see Sect. 5 for details). 


\subsubsection{DLR retrieval}

Similar to the IUP Bremen retrieval, the DLR algorithm solves the inverse problem employing the global fit approach. However, instead of performing the pre-processing step for each tangent height independently (as in the IUP Bremen retrieval) the DLR algorithm accounts for the spectral corrections directly in the scope of the main inversion procedure.

The inverse problem solved by the DLR retrieval algorithm is formulated according to Eq. (9). Introducing new notations this equation can be rewritten as

$\hat{\boldsymbol{y}}=\hat{\boldsymbol{F}}\left(\boldsymbol{x}_{\mathrm{a}}\right)+\tilde{\mathbf{K}}\left(\tilde{\boldsymbol{x}}-\tilde{\boldsymbol{x}}_{\mathrm{a}}\right)$.

Here,

$\tilde{\mathbf{K}}=\left[\begin{array}{ccccccc}\hat{K}_{1,1} & \ldots & \hat{K}_{1, N_{\mathrm{p}}} & \ldots & W_{1,1}^{\mathrm{sc}} & \ldots & W_{1, M}^{\mathrm{sc}} \\ & \vdots & \vdots & & \vdots & \\ \hat{K}_{N_{\mathrm{m}, 1}} & \ldots & \hat{K}_{N_{\mathrm{m}}, N_{\mathrm{p}}} & \ldots & W_{N_{m, 1}}^{\mathrm{sc}} & \ldots & W_{N_{\mathrm{m}, M}}^{\mathrm{sc}}\end{array}\right]$,

where $\hat{K}_{\mathrm{m}, n}$ and $W_{\mathrm{m}, n}^{\mathrm{sc}}$ are elements of matrices $\hat{\mathbf{K}}$ and $\mathbf{W}^{\mathrm{sc}}$, respectively, $N_{\mathrm{m}}$ is the total number of measurement points (the number of wavelengths multiplied by the number of tangent heights), $N_{\mathrm{p}}$ is the total number of the retrieved parameters (the number of retrieved species multiplied by the number of altitude layers), and $M$ is the total number of spectral corrections included in the fit procedure. Consequently, the state vector $\tilde{\boldsymbol{x}}$ contains now both the trace gas number densities and the scaling factors for the spectral corrections:

$\tilde{\boldsymbol{x}}=\left[\boldsymbol{x}^{T}, s_{1}, \ldots, s_{\mathrm{m}},\right]^{T}$

and

$\tilde{\boldsymbol{x}}_{\mathrm{a}}=\left[\boldsymbol{x}_{\mathrm{a}}^{T}, 0, \ldots, 0\right]^{T}$.

The measurement vector $\hat{\boldsymbol{y}}$ in Eq. (42) contains logarithms of the limb radiances at all considered tangent heights normalized to the reference tangent height. At each tangent height a low order polynomial is subtracted. The state vector $\boldsymbol{x}$ and the weighting function matrix $\hat{\mathbf{K}}$ have exactly the same contents as for the IUP Bremen retrieval, see description of Eq. (32). The current version of the DLR retrieval algorithm employs a cubic polynomial and the wavelength shift correction.

The radiative transfer model incorporated into the DLR retrieval package employs the discrete-ordinate method with matrix exponential as described by Doicu and Trautmann (2009). The solution technique is very similar to that of CDI approach (Rozanov et al., 2001) used in the SCIATRAN (Rozanov et al., 2005b) model. Essentially, the single scattering is treated fully spherically and the source function integration technique (Thomas and Stamnes, 1999) is used to account for the multiple scattering contribution. Similar to the IUP Bremen retrieval, only the radiance is corrected for the multiple scattering whereas the weighting functions are calculated in the single scattering approximation.

Although the inverse problem solved by the DLR algorithm, Eq. (42), is very similar to that given by Eq. (32), the retrieval approach is based on the solution of the modified minimization problem rather than that given by Eq. (33). First, assuming the initial noise covariance matrix, $\mathbf{S}_{\varepsilon}$, to be symmetric and positive definite, the prewhitening technique (Rodgers, 2000) is applied to obtain the "normalized" data with identity noise covariance matrix, $\mathbf{S}_{\varepsilon}=\mathbf{I}$. Further, assuming the a priori covariance matrix to be of the form $\mathbf{S}_{\mathrm{a}}=\sigma_{\mathrm{a}}^{2} \hat{\mathbf{S}}_{\mathrm{a}}$, where $\sigma_{\mathrm{a}}$ is the a priori standard deviation of the retrieved parameter, the stochastic regularization matrix $\mathbf{L}$ can be introduced by the Choleski factorization $\hat{\mathbf{S}}_{\mathrm{a}}^{-1}=\mathbf{L}^{T} \mathbf{L}$. As a result, the minimization problem can be written as

$\left\|\hat{\boldsymbol{F}}\left(\boldsymbol{x}_{\mathrm{a}}\right)+\tilde{\mathbf{K}}\left(\tilde{\boldsymbol{x}}-\tilde{\boldsymbol{x}}_{\mathrm{a}}\right)-\hat{\boldsymbol{y}}\right\|^{2}+\lambda_{\mathrm{a}}^{2}\left\|\mathbf{L}\left(\tilde{\boldsymbol{x}}-\tilde{\boldsymbol{x}}_{\mathrm{a}}\right)\right\|^{2}$,

where $\lambda_{\mathrm{a}}=1 / \sigma_{\mathrm{a}}$ is the stochastic regularization parameter.

The optimal value of the regularization parameter, $\lambda_{\mathrm{a}}$, is found applying the L-curve method (see Rozanov et al., 2007 for details). The basic idea of the method is that the inverse problem defined by Eq. (46) is solved for a sequence of regularization parameters. The pairs of the constrained solution norm, $\left\|\mathbf{L}\left(\tilde{\boldsymbol{x}}-\tilde{\boldsymbol{x}}_{\mathrm{a}}\right)\right\|^{2}$, and the residual norm, $\left\|\hat{\boldsymbol{F}}\left(\boldsymbol{x}_{\mathrm{a}}\right)+\tilde{\mathbf{K}}\left(\tilde{\boldsymbol{x}}-\tilde{\boldsymbol{x}}_{\mathrm{a}}\right)-\boldsymbol{y}\right\|^{2}$, obtained for different values of the regularization parameter form the so-called L-curve. The value of $\lambda_{\mathrm{a}}$ corresponding to the maximum curvature of the L-curve is considered to be the optimal regularization parameter.

Having obtained the optimal value for the regularization parameter, $\lambda_{\text {opt }}$, the solution of the linearized inverse problem is written as:

$\tilde{\boldsymbol{x}}=\tilde{\boldsymbol{x}}_{\mathrm{a}}+\left(\tilde{\mathbf{K}}^{T} \tilde{\mathbf{K}}+\lambda_{\text {opt }}^{2} \mathbf{L}^{T} \mathbf{L}\right)^{-1} \times \tilde{\mathbf{K}}^{T}\left(\hat{\boldsymbol{y}}-\hat{\boldsymbol{F}}\left(\boldsymbol{x}_{\mathrm{a}}\right)\right)$.

The non-linearity of the inverse problem is accounted for employing the Gauss-Newton iterative approach with a decreasing sequence of regularization parameters. In the framework of this approach, the optimal value of the regularization parameter estimated at each iterative step is not directly used to constrain the inverse problem. Instead, in a combination with the regularization parameter from the previous iterative step, it is used to obtain a new regularization parameter according to the following rule, e.g., at the $(i+1)$-th iterative step:

$\lambda_{i+1}=\left\{\begin{array}{cc}\xi \lambda_{\mathrm{opt}, i+1}+(1-\xi) \lambda_{i}, & \lambda_{\mathrm{opt}, i+1}<\lambda_{i} \\ \vartheta \lambda_{i}, & \lambda_{\mathrm{opt}, i+1} \geq \lambda_{i}\end{array}\right.$.

Here, $\xi$ and $\vartheta$ are the input parameters $(\xi, \vartheta<1)$ defining how much the new regularization parameter deviates from its value at the previous iterative step, $\lambda_{i}$, whereas $\lambda_{\text {opt }, i+1}$ is the optimal regularization parameter chosen accordingly to the L-curve method at the current iterative step. Thus, the solution of the non-linear retrieval problem at the $(i+1)$-th iterative step is given by 

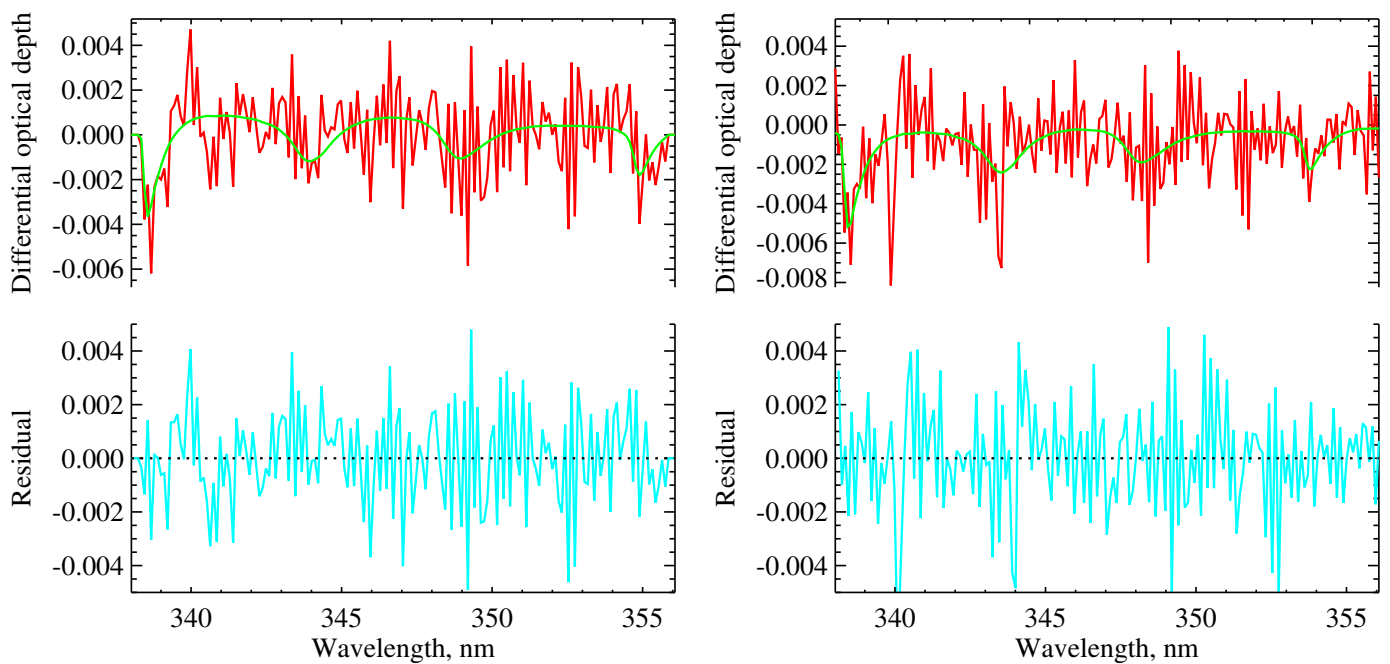

Fig. 4. Example spectral fits at a tangent height of $21 \mathrm{~km}$ for IUP Bremen (left panels) and MPI Mainz (right panels) algorithms. Upper panels show measured (red) and simulated (green) optical depths of $\mathrm{BrO}$ while lower panels show fit residuals.

$$
\begin{aligned}
\tilde{\boldsymbol{x}}_{i+1} & =\tilde{\boldsymbol{x}}_{\mathrm{a}}+\left(\tilde{\mathbf{K}}_{i}^{T} \tilde{\mathbf{K}}_{i}+\lambda_{i+1}^{2} \mathbf{L}^{T} \mathbf{L}\right)^{-1} \\
& \times \tilde{\mathbf{K}}_{i}^{T}\left(\hat{\boldsymbol{y}}-\hat{\boldsymbol{F}}\left(\boldsymbol{x}_{i}\right)+\tilde{\mathbf{K}}_{i}\left(\tilde{\boldsymbol{x}}_{i}-\tilde{\boldsymbol{x}}_{\mathrm{a}}\right)\right),
\end{aligned}
$$

The above discussed strategy for choosing the regularization parameter represents an extension of the L-curve method to non-linear problems relying on the idea that a weaker regularization is required if the solution approaches to the true atmospheric state. More details on the described regularization technique can be found in Doicu et al. (2002). The Gauss-Newton iterative process is stopped if the non-linear residuals obtained at two subsequent iterative steps differ by less than $1 \%$. Typically $3-5$ iterations are required to achieve the convergence.

\section{General settings}

An intercomparison of the above discussed retrieval methods, their implementation details, and initial settings is presented in Table 1.

All three retrieval algorithms discussed in this study use somewhat different spectral windows exploiting, however, the same absorption bands of BrO. The widest spectral interval ranging from 337 to $357 \mathrm{~nm}$ used by the DLR retrieval is followed by a somewhat shorter range between 338 and $357.25 \mathrm{~nm}$ exploited in the MPI Mainz algorithm. The shortest interval from 338 to $356.2 \mathrm{~nm}$ is used in the IUP Bremen retrieval.

The MPI Mainz algorithm uses limb radiances measured at all tangent heights below $32 \mathrm{~km}$ whereas both DLR and IUP Bremen retrievals do not consider measurements at tangent heights below $9 \mathrm{~km}$. Furthermore, the uppermost tangent height in the IUP Bremen algorithm is set to about
$29 \mathrm{~km}$. To reduce an influence of the solar Fraunhofer structure and instrument calibration uncertainties, all limb radiances in the selected tangent height range are normalized by the limb measurement at the reference tangent height (reference spectrum) which is set to about $35 \mathrm{~km}$ for all retrieval algorithms.

The spectral fitting in all retrieval algorithms is done considering the spectral signatures of $\mathrm{BrO}, \mathrm{O}_{3}$, and $\mathrm{NO}_{2}$. Example spectral fits at a tangent height of $21 \mathrm{~km}$ for IUP Bremen and MPI Mainz retrievals are presented in Fig. 4. The results are shown for a measurement performed on 10 October 2003, over Aire-sur-l' Adour (see Table 2).

Throughout this study, the absorption cross sections of $\mathrm{BrO}$ obtained by the time-windowing Fourier transform spectroscopy (TW-FTS) technique (Fleischmann et al., 2004), the $\mathrm{O}_{3}$ and $\mathrm{NO}_{2}$ cross sections measured by the SCIAMACHY PFM Satellite Spectrometer (Bogumil et al., 2003), and the $\mathrm{O}_{4}$ cross section from Greenblatt et al. (1990) are used. However, the spectral contribution of $\mathrm{O}_{4}$ is considered only in the forward models of the IUP Bremen and DLR algorithms with no fitting of $\mathrm{O}_{4}$ amount during the retrieval process.

The forward models used in both IUP Bremen and MPI Mainz retrieval algorithms are initialized with a climatological data base (similar to Haley et al., 2004; McLinden et al., 2010) which contains monthly averaged vertical distributions of ozone, $\mathrm{NO}_{2}$, and $\mathrm{BrO}$ for $10^{\circ}$ latitude bins. The pressure and temperature information originates from the operational analysis model of the European Centre for MediumRange Weather Forecasts (ECMWF) with a spatial resolution of $1.5^{\circ}$ (both latitude and longitude) and a temporal resolution of $6 \mathrm{~h}$. The DLR algorithm uses vertical distributions of ozone and $\mathrm{NO}_{2}$ as well as pressure and temperature profiles from the climatological database (see references above) 
Table 1. Comparison of the retrieval algorithms: implementation details and initial settings.

\begin{tabular}{|c|c|c|c|}
\hline & IUP Bremen & DLR & MPI Mainz \\
\hline Solution method & $\begin{array}{l}\text { Global fit approach with a } \\
\text { pre-processing step }\end{array}$ & Global fit approach & $\begin{array}{l}\text { DOAS technique with wavelength dependent } \\
\text { slant columns of ozone }\end{array}$ \\
\hline Spectral range & $338-356.2 \mathrm{~nm}$ & $337-357 \mathrm{~nm}$ & $338-357.25 \mathrm{~nm}$ \\
\hline Tangent height range & $\sim 9-29 \mathrm{~km}$ & $\sim 9-32 \mathrm{~km}$ & $\sim-3-32 \mathrm{~km}$ \\
\hline Reference tangent height & \multicolumn{3}{|c|}{$\sim 35 \mathrm{~km}$} \\
\hline $\begin{array}{l}\text { Radiative transfer model } \\
\text { (RTM) }\end{array}$ & $\begin{array}{l}\text { SCIATRAN 2.2: an approximative spherical } \\
\text { model incorporating a fully spherical treat- } \\
\text { ment for the single scattering and the CDI } \\
\text { approximation (Rozanov et al., 2001) to ac- } \\
\text { count for the multiple scattering contribution }\end{array}$ & $\begin{array}{l}\text { Discrete-ordinate method with matrix expo- } \\
\text { nential (Doicu and Trautmann, 2009). Fully } \\
\text { spherical treatment for the single scattering } \\
\text { and source function integration technique to } \\
\text { account for the multiple scattering. }\end{array}$ & $\begin{array}{l}\text { McArtim: A fully spherical model using the } \\
\text { backward Monte-Carlo method }\end{array}$ \\
\hline RTM is used to calculate & $\begin{array}{l}\text { simulated limb spectra and weighting func- } \\
\text { tions for all considered atmospheric species } \\
\text { used at both pre-processing and main inver- } \\
\text { sion steps }\end{array}$ & $\begin{array}{l}\text { simulated limb spectra and weighting func- } \\
\text { tions for all considered atmospheric species }\end{array}$ & $\begin{array}{l}\text { box air mass factors used at vertical inversion } \\
\text { step }\end{array}$ \\
\hline $\begin{array}{l}\text { Considered atmospheric } \\
\text { species }\end{array}$ & $\begin{array}{l}\text { Forward modeling: } \mathrm{BrO}, \mathrm{O}_{3}, \mathrm{NO}_{2}, \mathrm{O}_{4} \\
\text { Retrieval: } \mathrm{BrO}, \mathrm{O}_{3}, \mathrm{NO}_{2}\end{array}$ & & $\begin{array}{l}\text { Forward modeling and spectroscopic retrieval: } \\
\mathrm{BrO}, \mathrm{O}_{3}, \mathrm{NO}_{2} \\
\text { Vertical inversion: } \mathrm{BrO}\end{array}$ \\
\hline $\begin{array}{l}\text { Temperature dependence of } \\
\text { cross sections }\end{array}$ & \multicolumn{2}{|c|}{$\begin{array}{l}\text { fully accounted for by using temperature dependent cross sections of all considered species } \\
\text { in the radiative transfer calculations (temperature profiles from ECMWF (IUP Bremen) or } \\
\text { climatological (DLR) data bases are used) }\end{array}$} & $\begin{array}{l}\mathrm{O}_{3} \text { cross sections at } 203,223 \text {, and } 243 \mathrm{~K} \text { used } \\
\text { at spectroscopic retrieval stage, both } \mathrm{NO}_{2} \text { and } \\
\text { BrO cross sections at } 223 \mathrm{~K}\end{array}$ \\
\hline $\begin{array}{l}\text { Pressure dependence of cross } \\
\text { sections }\end{array}$ & \multicolumn{3}{|c|}{ not accounted for } \\
\hline Spectral corrections & $\begin{array}{l}\text { shift, } I_{0} \text {-correction for } \mathrm{O}_{3} \text {, Ring, eta, } \\
\text { differential logarithmic eta, tilt }\end{array}$ & shift & $\begin{array}{l}\text { shift, } I_{0} \text {-corrected } \mathrm{O}_{3} \text { cross section, Ring, eta, } \\
\text { zeta, } \frac{1}{I_{0}(\lambda)}, \frac{\lambda}{I_{0}(\lambda)}\end{array}$ \\
\hline Polynomial & linear & cubic & fourth order \\
\hline Regularization & $\begin{array}{l}\text { weak statistical regularization, smoothness } \\
\text { constraint }\end{array}$ & $\begin{array}{l}\text { optimal regularization parameter using L- } \\
\text { curve method }\end{array}$ & statistical regularization \\
\hline Treatment of the non-linearity & \multicolumn{2}{|c|}{ Gauss-Newton iterative scheme } & not accounted for \\
\hline Assumptions & \multicolumn{2}{|c|}{$\begin{array}{l}\text { - all broad-band spectral features are approximated by a low order polynomial } \\
\text { - local linearity around the previous guess value at each iterative step } \\
\text { - at the pre-processing step vertical profiles } \\
\text { of atmospheric species are obtained by } \\
\text { scaling a priori profiles }\end{array}$} & $\begin{array}{l}\text { - global linearity with respect to BrO } \\
\text { - box air mass factors are calculated at one } \\
\text { wavelength ( } 344.2 \mathrm{~nm}) \\
\text { - slant columns are independent of the wave- } \\
\text { length (except for ozone) }\end{array}$ \\
\hline $\begin{array}{l}\text { Advantages and } \\
\text { disadvantages }\end{array}$ & \multicolumn{2}{|c|}{$\begin{array}{l}\text { + most accurate treatment of the spectral signatures of atmospheric species doing full ra- } \\
\text { diative transfer calculations at each iterative step } \\
+ \text { vertical profiles of all relevant species are retrieved simultaneously } \\
\text { - retrieval is less stable because of a large number of parameters, more complicated regular- } \\
\text { ization technique is required } \\
\text { - the approach is quite slow as it requires a lot of radiative transfer calculations }\end{array}$} & $\begin{array}{l}\text { + no need for radiative transfer calculations } \\
\text { and knowledge of a priori profiles in the } \\
\text { spectroscopic retrieval } \\
+ \text { computational efficiency: separate evalua- } \\
\text { tion of spectra from different tangent } \\
\text { heights, box air mass factors at one spectral } \\
\text { point } \\
\text { - slant columns are independent of the wave- } \\
\text { length (except for ozone) } \\
\text { - temperature independent BrO cross section } \\
\text { - box air mass factors depend on the assumed } \\
\text { ozone profile }\end{array}$ \\
\hline
\end{tabular}

whereas a constant a priori profile (in VMR units) is used for $\mathrm{BrO}$. Vertical distributions of $\mathrm{O}_{4}$ used in the forward models of the IUP Bremen and DLR algorithms are calculated from the corresponding vertical profiles of the air density. All retrievals use a constant surface albedo that is set to 0.3 in both IUP Bremen and MPI Mainz algorithms and to 0.5 in the DLR retrieval. The IUP Bremen algorithm assumes a background aerosol loading according to the LOWTRAN aerosol parameterization (Kneizys et al., 1996) whereas in both MPI Mainz and DLR retrievals an aerosol free atmosphere is assumed. The influence of different aerosol settings on the retrieval results is discussed below in Sect. 7.3. The influence of clouds is neglected in all retrievals. This is justified by the fact that for the considered limb measurements the bulk of the observed signal originates from the tangent point area. Only a small portion of light which has traveled through the atmospheric layers below the tangent point is observed by the instrument. Furthermore, at middle and high latitudes, due to the strong Rayleigh scattering only a small portion of light penetrates into the lower atmosphere where clouds occur. In 
Table 2. Balloon-borne measurements performed with DOAS, SAOZ, and TRIPLE instruments as well as coincident SCIAMACHY limb observations. The information is partially from Table 1 in Dorf et al. (2006).

\begin{tabular}{|c|c|c|c|c|c|c|c|}
\hline \multicolumn{4}{|c|}{ Balloon-borne measurements } & \multicolumn{4}{|c|}{ Coincident SCIAMACHY limb observations } \\
\hline Instrument & $\begin{array}{l}\text { Date, } \\
\text { time (UTC) }\end{array}$ & $\begin{array}{l}\text { Location of the } \\
\text { launch site }\end{array}$ & $\begin{array}{l}\text { SZA } \\
\text { range }\end{array}$ & $\begin{array}{l}\text { Orbit number, date, } \\
\text { time (UTC) }\end{array}$ & $\begin{array}{l}\text { Location of tangent } \\
\text { point }(\mathrm{TP})\end{array}$ & $\begin{array}{l}\text { SZA } \\
\text { at TP }\end{array}$ & $\begin{array}{l}\text { Altitude } \\
\text { range, } \mathrm{km}\end{array}$ \\
\hline \multirow[t]{2}{*}{ DOAS } & 23 March 2003 & Kiruna & \multirow[t]{2}{*}{$79^{\circ}-95^{\circ}$} & 5545, 23 March 2003, 11:07:42 & $75.3^{\circ} \mathrm{N}, 15.8^{\circ} \mathrm{E}$ & $74^{\circ}$ & $18-28$ \\
\hline & $14: 47-17: 35$ & $67.9^{\circ} \mathrm{N}, 21.1^{\circ} \mathrm{E}$ & & 5558, 24 March 2003, 09:01:18 & $56.2^{\circ} \mathrm{N}, 25.6^{\circ} \mathrm{E}$ & $57^{\circ}$ & $19-29$ \\
\hline \multirow[t]{2}{*}{ DOAS } & 9 October 2003 & Aire-sur-l'Adour & \multirow[t]{2}{*}{$66^{\circ}-88^{\circ}$} & 8407,9 October 2003, 09:51:44 & $41.1^{\circ} \mathrm{N}, \quad 7.7^{\circ} \mathrm{E}$ & $51^{\circ}$ & $17-31$ \\
\hline & $15: 39-17: 09$ & $43.7^{\circ} \mathrm{N}, 0.3^{\circ} \mathrm{W}$ & & 8421,10 October $2003,09: 20: 14$ & $40.8^{\circ} \mathrm{N}, 15.5^{\circ} \mathrm{E}$ & $51^{\circ}$ & $25-33$ \\
\hline \multirow[t]{2}{*}{ DOAS } & 24 March 2004 & Kiruna & \multirow[t]{2}{*}{$72^{\circ}-95^{\circ}$} & 10798, 24 March 2004, 10:36:04 & $66.3^{\circ} \mathrm{N}, \quad 9.0^{\circ} \mathrm{E}$ & $65^{\circ}$ & $12-33$ \\
\hline & $13: 55-17: 35$ & $67.9^{\circ} \mathrm{N}, 21.1^{\circ} \mathrm{E}$ & & 10811, 25 March 2004, 08:25:08 & $62.4^{\circ} \mathrm{N}, 38.4^{\circ} \mathrm{E}$ & $62^{\circ}$ & $20-26$ \\
\hline \multirow[t]{2}{*}{ DOAS } & 17 June 2005 & Teresina & \multirow[t]{2}{*}{$61^{\circ}-94^{\circ}$} & 17240,17 June $2005,11: 54: 16$ & $5.5^{\circ} \mathrm{S}, 41.2^{\circ} \mathrm{W}$ & $43^{\circ}$ & $25-30$ \\
\hline & $18: 32-21: 07$ & $5.1^{\circ} \mathrm{S}, 42.9^{\circ} \mathrm{W}$ & & 17255,18 June $2005,13: 03: 14$ & $5.5^{\circ} \mathrm{S}, 48.5^{\circ} \mathrm{W}$ & $43^{\circ}$ & $8-33$ \\
\hline \multirow[t]{2}{*}{ DOAS } & 7 September 2009 & Kiruna & \multirow[t]{2}{*}{$76^{\circ}-94^{\circ}$} & 39326, 7 September 2009, 9:59:06 & $64.6^{\circ} \mathrm{S}, 16.6^{\circ} \mathrm{E}$ & $59^{\circ}$ & $9-34$ \\
\hline & $15: 05-18: 15$ & $67.9^{\circ} \mathrm{N}, 21.1^{\circ} \mathrm{E}$ & & 39340,8 September $2009,9: 25: 32$ & $71.0^{\circ} \mathrm{S}, 32.4^{\circ} \mathrm{E}$ & $66^{\circ}$ & $10-34$ \\
\hline \multirow[t]{2}{*}{$\mathrm{SAOZ}$} & 1 October 2002 & Aire-sur-l'Adour & \multirow{2}{*}{$\begin{array}{l}83.4^{\circ} \\
\text { at } 20 \mathrm{~km}\end{array}$} & 3068,1 October $2002,10: 13: 39$ & $44.3^{\circ} \mathrm{N}, \quad 5.1^{\circ} \mathrm{E}$ & $50^{\circ}$ & $13-29$ \\
\hline & $16: 35-17: 25$ & $43.7^{\circ} \mathrm{N}, 0.3^{\circ} \mathrm{W}$ & & 3082,2 October $2002,09: 42: 10$ & $43.8^{\circ} \mathrm{N}, 12.8^{\circ} \mathrm{E}$ & $50^{\circ}$ & $13-29$ \\
\hline \multirow[t]{2}{*}{$\mathrm{SAOZ}$} & 30 March 2003 & Kiruna & \multirow{2}{*}{$\begin{array}{l}85.8^{\circ} \\
\text { at } 20 \mathrm{~km}\end{array}$} & 5645, 30 March 2003, 10:49:17 & $70.0^{\circ} \mathrm{N}, \quad 9.9^{\circ} \mathrm{E}$ & $67^{\circ}$ & $5-29$ \\
\hline & $16: 01-16: 53$ & $67.9^{\circ} \mathrm{N}, 21.1^{\circ} \mathrm{E}$ & & 5658, 31 March 2003, 08:38:01 & $66.9^{\circ} \mathrm{N}, 39.1^{\circ} \mathrm{E}$ & $63^{\circ}$ & $5-23$ \\
\hline \multirow[t]{2}{*}{ SAOZ } & 31 January 2004 & Bauru & \multirow{2}{*}{$\begin{array}{l}81.2^{\circ} \\
\text { at } 20 \mathrm{~km}\end{array}$} & 10040, 31 January 2004, 12:06:55 & $20.2^{\circ} \mathrm{S}, 36.7^{\circ} \mathrm{W}$ & $36^{\circ}$ & $25-30$ \\
\hline & $20: 54-21: 46$ & $22.4^{\circ} \mathrm{S}, 49.0^{\circ} \mathrm{W}$ & & 10055,1 February $2004,13: 15: 48$ & $19.8^{\circ} \mathrm{S}, 43.9^{\circ} \mathrm{W}$ & $36^{\circ}$ & $15-21$ \\
\hline \multirow[t]{2}{*}{$\mathrm{SAOZ}$} & 5 February 2004 & Bauru & \multirow{2}{*}{$\begin{array}{l}75.0^{\circ} \\
\text { at } 20 \mathrm{~km}\end{array}$} & 10112,5 February $2004,12: 51: 35$ & $25.8^{\circ} \mathrm{S}, 48.9^{\circ} \mathrm{W}$ & $38^{\circ}$ & $5-21$ \\
\hline & $20: 25-21: 12$ & $22.4^{\circ} \mathrm{S}, 49.0^{\circ} \mathrm{W}$ & & 10127,6 February $2004,13: 59: 47$ & $23.0^{\circ} \mathrm{S}, 65.4^{\circ} \mathrm{W}$ & $37^{\circ}$ & $25-29$ \\
\hline \multirow[t]{2}{*}{ TRIPLE } & 24 September 2002 & Aire-sur-l'Adour & \multirow[t]{2}{*}{$49^{\circ}-66^{\circ}$} & 2954, 23 September 2002, 11:06:31 & $40.2^{\circ} \mathrm{N}, \quad 9.5^{\circ} \mathrm{W}$ & $45^{\circ}$ & $21-29$ \\
\hline & 08:12-10:07 & $43.7^{\circ} \mathrm{N}, 0.3^{\circ} \mathrm{W}$ & & 2968,24 September $2002,10: 32: 50$ & $47.3^{\circ} \mathrm{N}, \quad 1.5^{\circ} \mathrm{E}$ & $50^{\circ}$ & $16-33$ \\
\hline \multirow[t]{2}{*}{ TRIPLE } & 6 March 2003 & Kiruna & \multirow[t]{2}{*}{$78^{\circ}-85^{\circ}$} & 5288, 5 March 2003, 12:13:18 & $76.6^{\circ} \mathrm{N}, \quad 3.4^{\circ} \mathrm{E}$ & $83^{\circ}$ & $16-28$ \\
\hline & $06: 32-07: 59$ & $67.9^{\circ} \mathrm{N}, 21.1^{\circ} \mathrm{E}$ & & 5301, 6 March 2003, 10:04:29 & $66.0^{\circ} \mathrm{N}, 16.5^{\circ} \mathrm{E}$ & $73^{\circ}$ & $5-31$ \\
\hline \multirow[t]{2}{*}{ TRIPLE } & 9 June 2003 & Kiruna & \multirow[t]{2}{*}{$45^{\circ}-49^{\circ}$} & 6652,8 June $2003,19: 01: 32$ & $68.1^{\circ} \mathrm{N}, 20.9^{\circ} \mathrm{E}$ & $81^{\circ}$ & $5-31$ \\
\hline & 07:59-09:07 & $67.9^{\circ} \mathrm{N}, 21.1^{\circ} \mathrm{E}$ & & 6661,9 June $2003,10: 18: 15$ & $68.1^{\circ} \mathrm{N}, 15.3^{\circ} \mathrm{E}$ & $46^{\circ}$ & $5-34$ \\
\hline
\end{tabular}

tropics, where high clouds are often present, their impact still remains small because of a very low $\mathrm{BrO}$ abundance below about $18 \mathrm{~km}$.

The finite vertical instantaneous field of view of the SCIAMACHY instrument is accounted for in both IUP Bremen and MPI Mainz algorithms but neglected in the DLR retrieval. The horizontal extension of the field of view is ignored in all three approaches. Refraction effects are fully accounted for in the radiative transfer models of both IUP Bremen and DLR retrievals. In the McArtim model used by the MPI Mainz algorithm the refractive bending of the line of sight is accounted for by using the effective tangent height.

All retrievals are done at fixed equidistant altitude grids with vertical increments of $3 \mathrm{~km}, 1.75 \mathrm{~km}$, and $1 \mathrm{~km}$ in MPI Mainz, DLR, and IUP Bremen algorithms, respectively.

\section{Sensitivity of limb retrievals}

A commonly used approach to characterize retrieval algorithms that employ the optimal estimation type inversion is to analyze the theoretical precisions and the averaging kernels. In general, these retrieval characteristics are specific to the measurement setup, atmospheric composition, illumination conditions, algorithm implementation, and retrieval parameter settings.

The theoretical precision describes the total retrieval error (i.e., the sum of the noise and smoothing errors) and is given by the square root of the diagonal elements of the a posteriori covariance matrix (see Rodgers, 2000 for details). For IUP Bremen retrieval the latter is written as

$\mathbf{S}=\left(\hat{\mathbf{K}}^{T} \mathbf{S}_{\varepsilon}^{-1} \hat{\mathbf{K}}+\mathbf{R}\right)^{-1}$

where the same notations as in Sect. 3.4.2 are used.

For observations of the scattered solar light performed by space-borne instruments in limb viewing geometry, the averaging kernels in the relevant altitude region are distinctly peaked at altitudes where the bulk of the information is originating from. The shape of the averaging kernels provides information on the vertical sensitivity and resolution of the measurement-retrieval system as well as on the contribution of the a priori information to the retrieved profiles. In this study we analyze the averaging kernels specific to the 

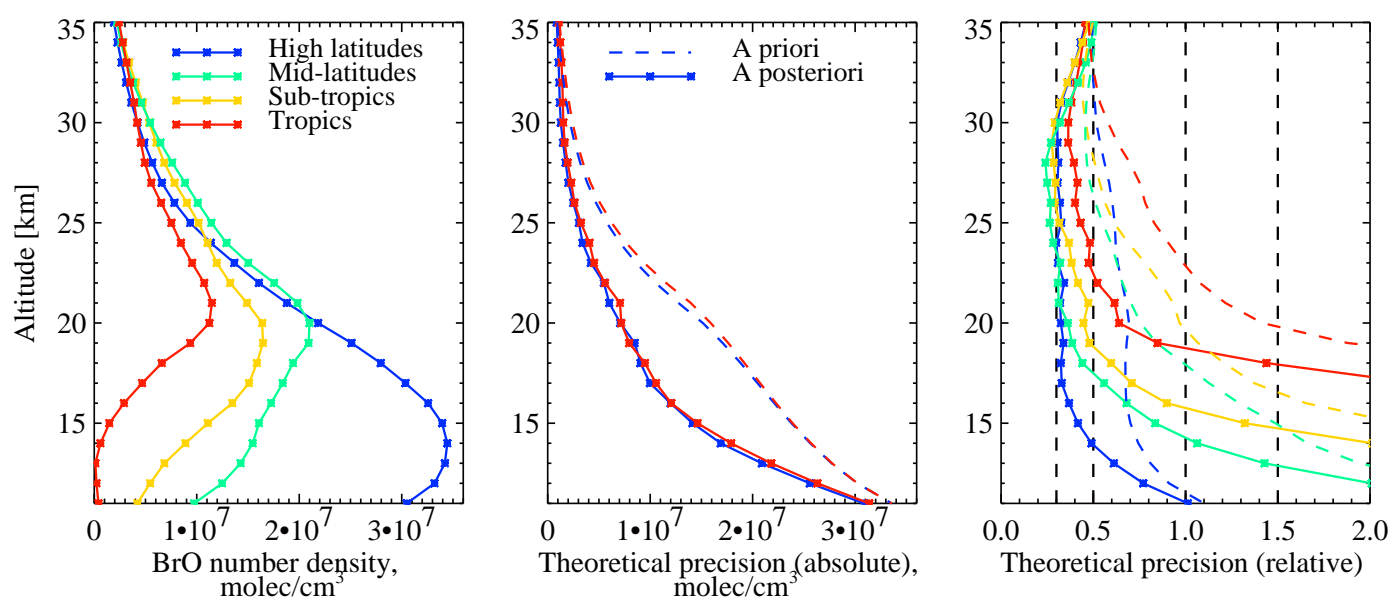

Fig. 5. Retrieved vertical profiles of $\mathrm{BrO}$ and theoretical precision of the retrieval typical for the IUP Bremen algorithm. Left panel: vertical profiles of BrO typical for high-latitude spring, mid-latitude fall, subtropical summer, and tropical winter seasons. Middle panel: theoretical precisions (solid lines) and a priori constraints (dashed lines) for high-latitude (blue) and tropical (red) retrievals. Right panel: same as in the middle panel but in relative units.

retrieval of the absolute differences with respect to the a priori state:

$\boldsymbol{x}=\boldsymbol{x}_{\mathrm{a}}+\mathbf{A}_{k}\left(\boldsymbol{x}_{\mathrm{t}}-\boldsymbol{x}_{\mathrm{a}}\right)$,

where $\boldsymbol{x}, \boldsymbol{x}_{\mathrm{t}}$, and $\boldsymbol{x}_{\mathrm{a}}$ are retrieved, true, and a priori state vectors, respectively.

Figure 5 presents example vertical profiles of $\mathrm{BrO}$ obtained at different latitudes and theoretical precision of the retrieval when using the IUP Bremen algorithm. The left panel shows vertical profiles of $\mathrm{BrO}$ typical for high-latitude spring, mid-latitude fall, subtropical summer, and tropical winter seasons. In the middle panel, the theoretical precision of the retrieval (solid lines) and a priori constraints (dashed lines) are shown. The latter are given by the square roots of the diagonal elements of the inverse constraint matrix, i.e., inverse of matrix $\mathbf{R}$ as given by Eq. (41). For an un-smoothed retrieval the a priori constraints are equal to the a priori standard deviations. As the theoretical precisions are nearly the same for all latitude regions, they are only shown for the high latitudes and tropics. The overall altitude dependence of the precision is determined by the a priori constraints. The highest reduction of the variance due to measurements (with respect to a priori) is observed between 14 and $21 \mathrm{~km}$. When expressed in relative units, as shown in the right panel of Fig. 5, the precision is highest at high latitudes where $\mathrm{BrO}$ is most abundant. Here, the relative retrieval precision is about $30 \%$ above $16 \mathrm{~km}$ and degrades below. Towards equator, the relative precisions in the lower atmosphere rapidly degrade because of decreasing $\mathrm{BrO}$ number densities. As expected, the lowest $\mathrm{BrO}$ concentrations and, hence, the worst relative retrieval precisions are observed in tropics below $19 \mathrm{~km}$.

In the left panel of Fig. 6 the averaging kernels typical for the IUP Bremen retrieval algorithm are presented. As the averaging kernels for different latitude regions are very similar
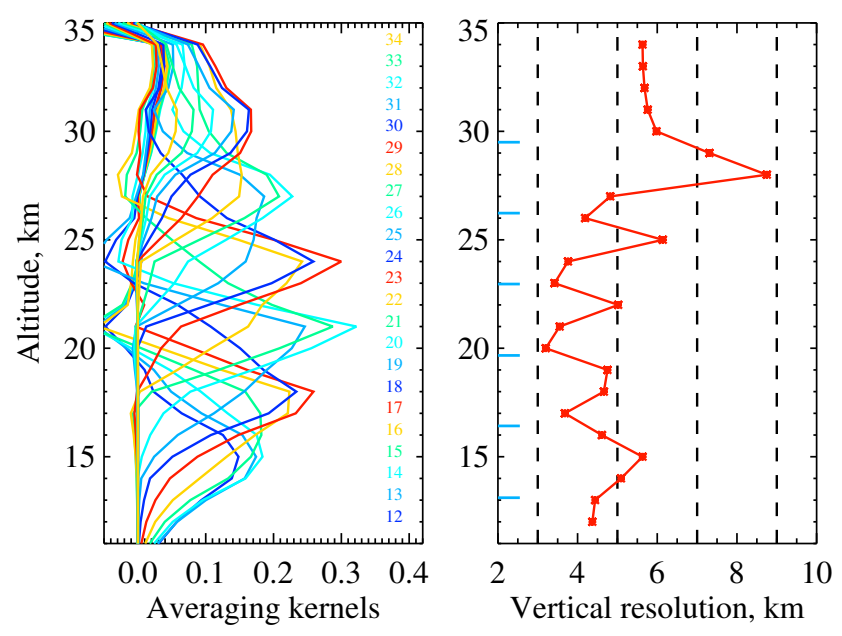

Fig. 6. Averaging kernels (left panel) and the vertical resolution (right panel) typical for the IUP Bremen retrieval. The colored numbers on the right-hand side of the averaging kernel plot denote the altitudes which the averaging kernels are calculated for. The thick blue lines in the left-hand side of the vertical resolution plot depict positions of the measurement tangent heights.

only the results for the high latitudes are shown. The colored numbers on the right-hand side of the averaging kernel plot denote the altitudes which the averaging kernels are calculated for. Between about 16 and $27 \mathrm{~km}$ the averaging kernels for altitudes close to measurement tangent heights show well pronounced peaks near the tangent point altitudes. This indicates a good sensitivity and a good vertical resolution of the retrieval at these altitudes. In contrast, the averaging kernels for the intermediate altitude levels are substantially broader with much less distinct peaks indicating the redistribution of 

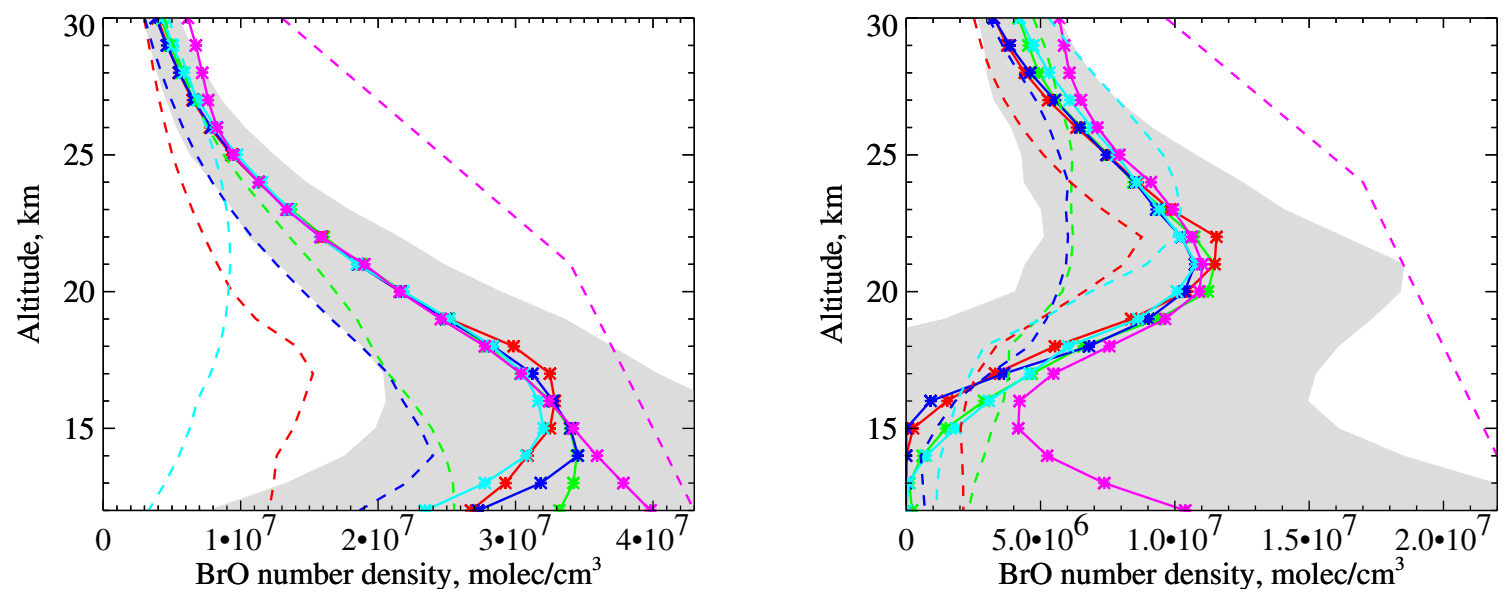

Fig. 7. Dependence on a priori information for typical retrievals at high latitudes (left panel) and in the tropics (right panel). Dashed lines of different colors depict a priori profiles used for the retrieval (see text for details). For each a priori the corresponding retrieved profile is shown in the same color by a solid line with asterisks. Grey areas show the uncertainty regions of the retrieved profiles. The results are obtained using the IUP Bremen retrieval.

the information (strong influence of the neighboring altitude levels) and, thus, a lower vertical resolution at these altitudes. Below $16 \mathrm{~km}$ and above $27 \mathrm{~km}$ the averaging kernels become wider and their peaks are displaced from the nominal altitudes. This indicates a partial loss of sensitivity and increased influence of the smoothing constraints. The negative lobe around $35 \mathrm{~km}$ seen for all averaging kernels is due to the influence of the residual $\mathrm{BrO}$ signature in the reference measurement (i.e., non-zero $\mathrm{BrO}$ amount around the tangent height of the reference measurement) upon the retrieval results.

The vertical resolution of the retrieval is usually characterized by the width of the averaging kernels. In recent publications (e.g., Haley et al., 2004; Sofieva et al., 2004; Krecl et al., 2006) the averaging kernel width is commonly estimated using the so-called spread of the averaging kernel as introduced by Backus and Gilbert (1970). However, as discussed by Rodgers (2000), spread does not provide a satisfactory general-purpose definition of resolution for functions which decay more slowly than $\mathrm{O}\left\{\left(z-z^{\prime}\right)^{-3 / 2}\right\}$. Here, $z-z^{\prime}$ characterizes the distance to the nominal altitude of the averaging kernel. Thus, a negative lobe exhibited by each particular averaging kernel near the tangent point altitude of the reference measurement causes the spread to be unsuitable for the characterization of the vertical resolution. In this study, we use the full width at half height of the averaging kernel as a measure of the vertical resolution of the retrieval. This is the most straightforward method allowing the influence of the negative lobe to be eliminated. The vertical resolution of the IUP Bremen retrieval is shown in the right panel of Fig. 6. The thick blue lines in the left-hand side of the plot depict positions of the measurement tangent heights. The best vertical resolution of typically $3.5-4 \mathrm{~km}$ is achieved at the altitude levels which are close to the tangent point altitudes of the measurements whereas the vertical resolution for intermediate altitudes is substantially lower (typically $5-6 \mathrm{~km}$ ) indicating increased vertical smoothing. The highest vertical resolution is achieved in the altitude range between 16 and $24 \mathrm{~km}$. Above $27 \mathrm{~km}$ the usage of stronger smoothing constraints results in a decrease of the vertical resolution to 6$9 \mathrm{~km}$.

Summarizing the discussion above, the best sensitivity altitude range can be identified as 16 to $26 \mathrm{~km}$ whereas at altitude levels above and below the sensitivity of the retrieval decreases. It is noteworthy that both theoretical precisions and averaging kernels discussed above depend on the signal to noise ratio in the measured limb spectra. The presented results are valid for the most typical quality of the measurements and can differ for unusual observation conditions. The obtained results are only applicable to the parameter settings as described in Sects. 3.4 and 4 and may change if the settings are changed.

The influence of the a priori information on the retrieved profiles can be analyzed performing multiple retrievals of the same limb observation using different a priori profiles. Figure 7 presents results of such analysis for two different latitude regions. The retrieved profiles are shown by solid lines with symbols whereas dashed lines represent the corresponding a priori profiles. The grey areas show the uncertainty regions of the retrieved profiles. The a priori profile shown by the magenta line is artificially generated without any relation to the nature whereas the other profiles are obtained running different chemical transport models (including outdated ones) or compiling observation results. As expected from the sensitivity studies above, for the high-latitude profile the dependence on the a priori information is negligible down to $15 \mathrm{~km}$. Below, the differences between retrievals increase with the decreasing altitude. Whereas the retrieved 
profiles at $14 \mathrm{~km}$ still agree within about $15 \%$, already at $13 \mathrm{~km}$ they are clearly different. However, it is worth noting here that even at $12 \mathrm{~km}$ the influence of the a priori information is far below the retrieval uncertainty. The investigation for a tropical observation presented in the right panel of Fig. 7 shows that in the high sensitivity region between 17 and $27 \mathrm{~km}$ the results are very similar to those at high latitudes exhibiting no significant influence of the a priori information. Above 27 and below $17 \mathrm{~km}$ disagreement between $\mathrm{BrO}$ profiles retrieved using different a priori information increases indicating a partial loss of sensitivity. Below $15 \mathrm{~km}$ the retrieval results are strongly affected by the a priori information and even the shape of the vertical profiles becomes different. However, similar to the high-latitude observation, even at $12 \mathrm{~km}$, where the profiles retrieved using different a priori information are quite different, they are still in agreement within the retrieval uncertainty. In general, these results reveal that within the sensitivity range no significant bias due to the a priori information is expected. The results presented here are obtained with the IUP Bremen retrieval. While for the MPI Mainz algorithm a similarly weak influence of the a priori information is expected, the DLR retrieval is found to lose its sensitivity below $18-20 \mathrm{~km}$. The DLR data below these altitudes are not recommended for use.

\section{Model simulations}

In this section, simulated limb spectra are considered which are obtained running different radiative transfer models for pre-defined atmospheric scenarios. The comparison of simulated data includes results from three models, namely, SCIATRAN, McArtim, and VECTOR. The former two are incorporated in the IUP Bremen and MPI Mainz retrieval algorithms, respectively, whereas the latter is used in $\mathrm{BrO}$ retrieval algorithms not considered in this study (Sioris et al., 2006; McLinden et al., 2010). The radiative transfer model incorporated in the DLR retrieval algorithm could not be investigated, because this model is not available as a stand along software and no changes in the operational processor are allowed.

The SCIATRAN radiative transfer model is run in the approximative spherical mode. The approach is based on the integration of the single scattering contribution and multiple scattering source function along the line of sight in a spherical atmosphere. The multiple scattering source function is calculated for each point along the line of sight using a pseudo-spherical model. In doing so, the solar zenith angle and viewing direction are set in accordance with a spherical ray tracing. A detailed description of the employed approach can be found in Rozanov et al. (2001). VECTOR (McLinden et al., 2002a) is similarly to SCIATRAN an approximative spherical model incorporating a fully spherical treatment for the single scattering and a well established successive order of scattering approach (Lenoble, 1985) to account for the multiple scattering contribution. McArtim (Deutschmann et al., 2011) is a fully spherical model which employs the backward Monte-Carlo method (Marchuk et al., 1980) to account for both singly and multiply scattered light.

The simulations discussed in this section are performed using the same simplified initial settings for all radiative transfer models, namely, (i) all cross sections at $223 \mathrm{~K}$, (ii) aerosol free atmosphere, (iii) constant surface albedo of 0.3 , (iv) no refraction, and (v) no field of view integration.

As discussed in Sect. 3, all retrieval algorithms discussed in this study work with logarithms of the normalized limb radiance. Contributions of interfering absorbers are separated from the measured signal based on their unique spectral signatures and, thus, are not expected to affect the retrieval significantly. For this reason comparisons of simulated data are performed for the optical depth of $\mathrm{BrO}$, which directly affects retrieved vertical profiles, rather than for the limb radiance itself. The $\mathrm{BrO}$ optical depth is calculated from the limb radiances simulated using the participating radiative transfer models including and neglecting $\mathrm{BrO}$ absorption:

$\tau_{\mathrm{BrO}}=\ln I_{\text {without } \mathrm{BrO}}-\ln I_{\text {with BrO }}$.

Figure 8 shows a comparison of $\mathrm{BrO}$ optical depths simulated using different radiative transfer models (left panels) and absolute differences in simulated optical depths with respect to McArtim results (right panels) at different tangent heights. The simulations are performed for observation conditions typical for high-latitude spring stratosphere. At lower tangent heights the optical depths of $\mathrm{BrO}$ simulated by different models agree very well. The remaining differences are below $1 \%$ for both 13.8 and $22.3 \mathrm{~km}$ tangent heights. For upper tangent heights (represented by $35.9 \mathrm{~km}$ in the plot) the disagreement increases to about $5 \%$ between SCIATRAN and McArtim and about $7 \%$ between VECTOR and McArtim which is, however, still far below the retrieval uncertainty (30-40\%, see Sect. 5). A similar comparison for observation conditions typical for tropical winter stratosphere is presented in Fig. 9. Here, the agreement between different models is even better than for high latitudes. At lower tangent heights optical depths simulated by all radiative transfer models agree within $0.5 \%$. For upper tangent heights (represented by $34.9 \mathrm{~km}$ in the plot), the agreement between SCIATRAN and McArtim remains within $1 \%$ whereas the relative difference between VECTOR and McArtim results increases to about $4 \%$. Thus, relative differences in the optical depths simulated by different radiative transfer models are found to be relatively small and the retrieval results are not expected to be significantly affected by the usage of different models.

Quantitatively, the effect of differences in $\mathrm{BrO}$ optical depths upon the resulting vertical profiles is estimated by performing synthetic retrievals. As above, synthetic limb spectra are calculated with SCIATRAN, VECTOR, and McArtim models. A Gaussian noise is added to each limb spectrum assuming a signal to noise ratio of 670 . This is similar to the signal to noise ratio of the measured limb spectra estimated 

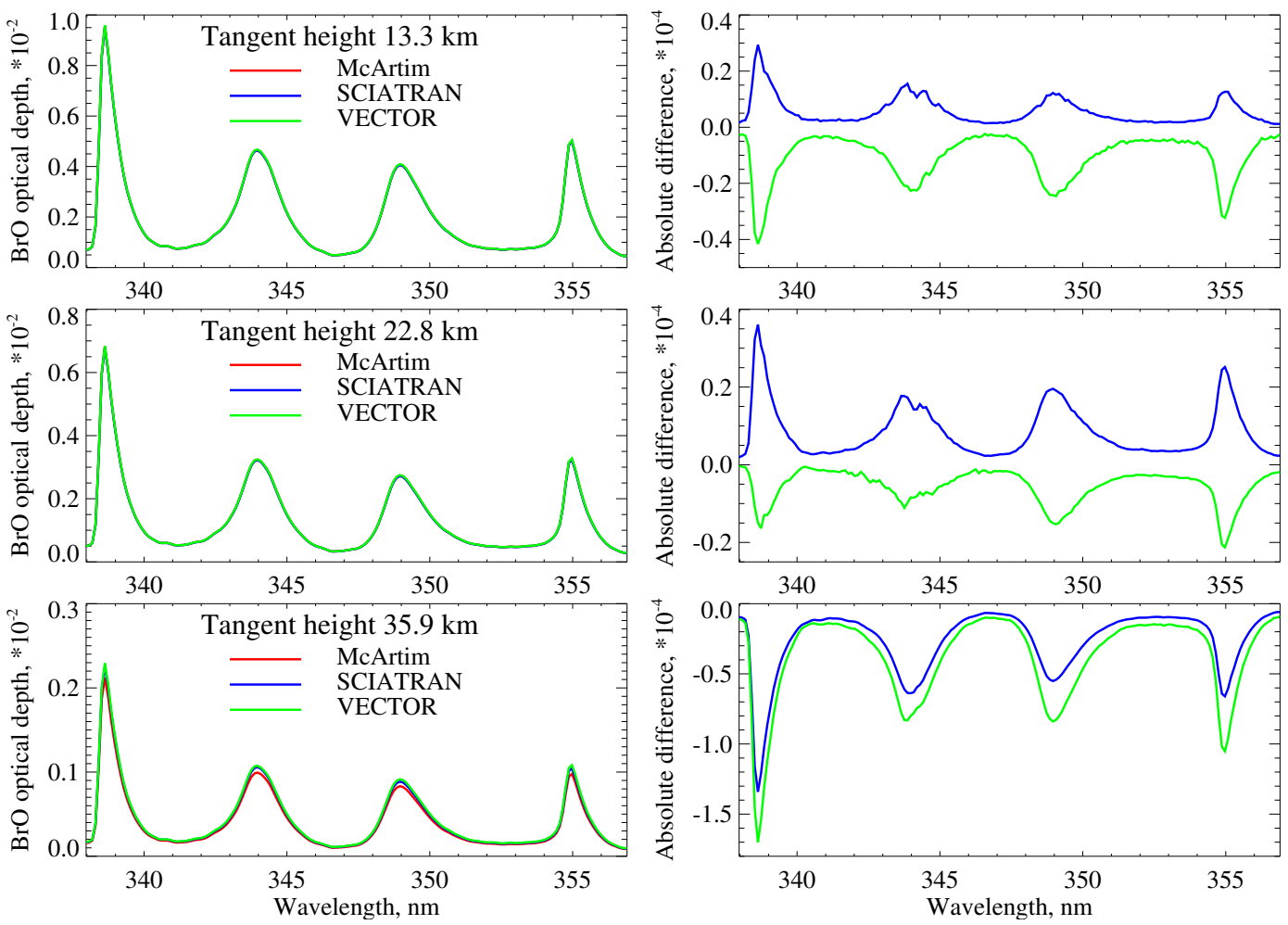

Fig. 8. Optical depths of BrO simulated using different radiative transfer models (left panels) and absolute differences in simulated optical depths with respect to McArtim results (right panels) at different tangent heights. The simulations are performed for an observation geometry typical for high-latitude spring stratosphere.

from fit residuals. The synthetic retrievals are performed with the IUP Bremen and MPI Mainz algorithms. The DLR retrieval is not considered here as changes in input parameters needed to perform synthetic retrievals are not allowed in the operational processor. To obtain significant statistics the retrievals are done for 100 different noise realizations.

Results of the synthetic retrievals performed with the IUP Bremen algorithm for an observation scenario typical for high-latitude spring season are shown in Fig. 10. Mean vertical profiles of $\mathrm{BrO}$ shown in the left panel by solid color lines with asterisks are retrieved from synthetic limb spectra simulated with different models. For each simulation the retrieval is performed for all noise realizations and the resulting profiles are averaged. The true and a priori profiles are shown with black solid and dashed lines, respectively. In the right panel relative deviations of the mean BrO profiles with respect to the true profile are shown with solid lines and the standard deviations are shown with dashed lines. One sees that the inversion of all simulations yields very similar results. Above $15 \mathrm{~km}$, vertical profiles of $\mathrm{BrO}$ retrieved from different simulations agree within $7 \%$ both with each other and with the true profile. As discussed in Sect. 5, below $16 \mathrm{~km}$ the smoothing error of the retrieval increases with decreasing altitude. For true profiles which are much higher than a priori at $16-17 \mathrm{~km}$ and differing less below, this results in an overestimation of $\mathrm{BrO}$ amounts at lower altitudes (see Fig. 7 for a priori influence). In Fig. 10 this effect appears as a shift of the profile maximum. Nevertheless, the relative difference remains always within $15 \%$. The standard deviations range from 20 to $50 \%$ and, as expected, are very similar for all three radiative transfer models. The results obtained from the same synthetic spectra but using the MPI Mainz retrieval algorithm are shown in Fig. 11. Here the same notations as in Fig. 10 are used. Generally, the same behavior as for the IUP Bremen retrieval is observed. The mean retrieved profiles agree with each other and with the true profile within $10 \%$ nearly everywhere. It is worth noting here that these differences are far below the typical retrieval precision, see Sect. 5. Thus, we conclude that differences in the radiative transfer models do not cause significant discrepancies in the retrieved $\mathrm{BrO}$ profiles.

Results of a similar investigation but for an observation scenario typical for the tropical winter season are shown in Fig. 12 for the IUP Bremen and in Fig. 13 for the MPI Mainz retrievals. Here, the retrieved profiles agree with each other and with the true profile typically within $10 \%$ above $17 \mathrm{~km}$ for the IUP Bremen and above $19 \mathrm{~km}$ for the MPI Mainz retrievals. As a result of a decreased sensitivity, the IUP Bremen retrieval shows a positive bias below $17 \mathrm{~km}$ for all simulations while the MPI Mainz results below $19 \mathrm{~km}$ tend to 

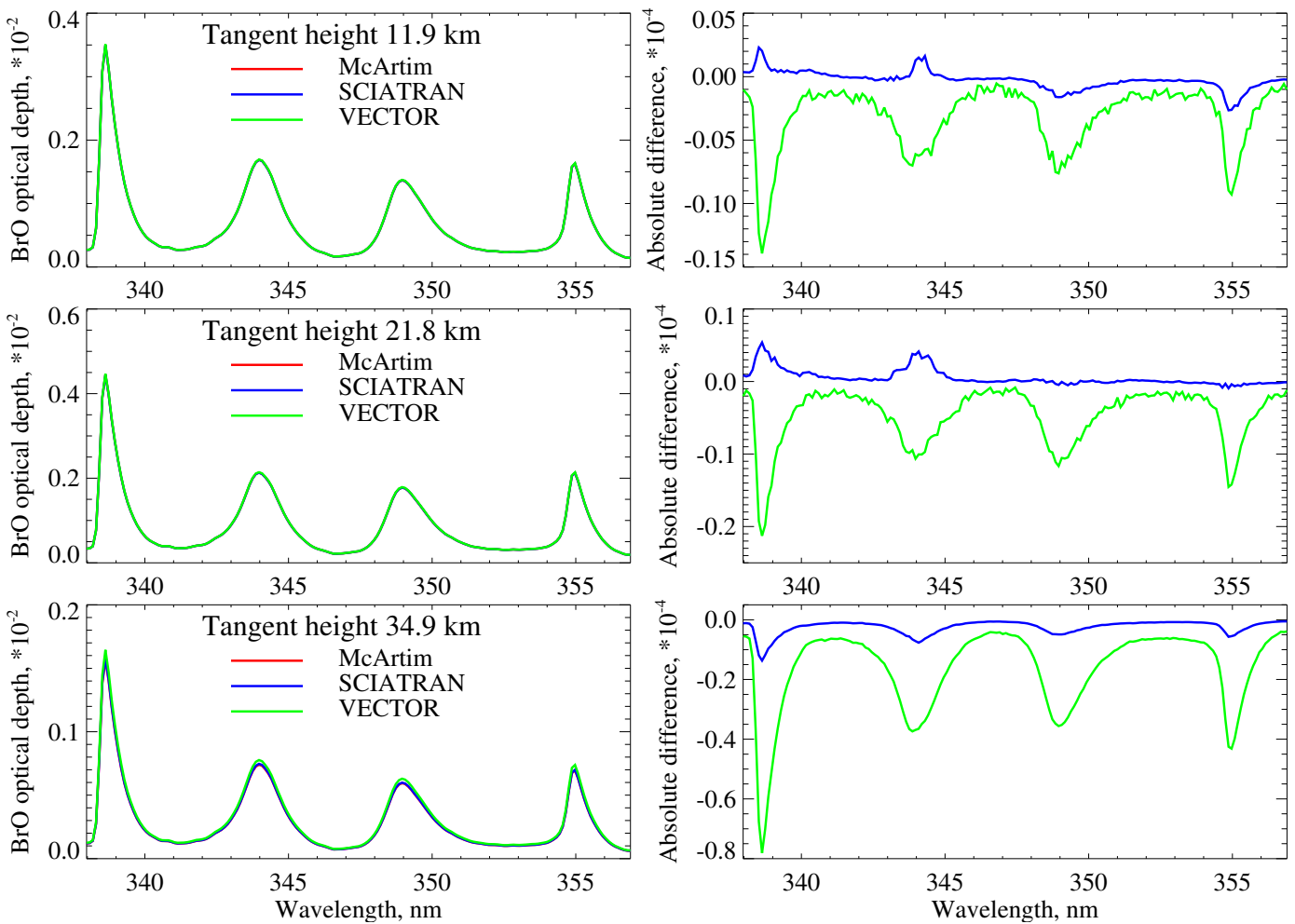

Fig. 9. Same as in Fig. 8 but for an observation geometry typical for tropical winter stratosphere.

the a priori. The standard deviations are similar for all models ranging from 40 to $60 \%$ down to $19-20 \mathrm{~km}$ and rapidly increasing below. This is consistent with the theoretical precision of the retrieval discussed in Sect. 5. Similar to the high latitudinal scenario, we conclude that, at least above $17 \mathrm{~km}$, the differences in the radiative transfer models do not cause significant discrepancies in the retrieved $\mathrm{BrO}$ profiles. It should be noted that the absolute errors in the tropical retrieval results below $17 \mathrm{~km}$ are of the same order of magnitude as for the high latitudes.

\section{Major uncertainties}

In this section we consider major sources of uncertainties in retrieved vertical profiles of $\mathrm{BrO}$ which are relevant to the comparisons presented below. Main topics to be investigated here are the effects of different absorption cross sections of $\mathrm{BrO}$, temperature dependence of the cross sections, and stratospheric aerosol loading. Influence of the surface albedo on the retrieval results is found to be insignificant.

\subsection{Absorption cross sections of $\mathrm{BrO}$}

As described below in more details, most of the comparisons in this study are done using $\mathrm{BrO}$ profiles obtained from DOAS (see Sect. 9.1) and SAOZ (see Sect. 9.2) balloonborne instruments observing the direct solar light transmitted through the Earth's atmosphere. Whereas all SCIAMACHY retrievals considered in this study are performed using $\mathrm{BrO}$ absorption cross sections from Fleischmann et al. (2004), either at all temperatures as in both IUP Bremen and DLR algorithms or at $223 \mathrm{~K}$ as in the MPI Mainz retrieval, both DOAS and SAOZ balloon-borne observations are processed using the $\mathrm{BrO}$ cross section at $228 \mathrm{~K}$ as obtained by Wahner et al. (1988). Figure 14 shows $\mathrm{BrO}$ absorption cross sections from Fleischmann et al. (2004), which is referred to as the Fleischmann cross section below, at $223 \mathrm{~K}$ and from Wahner et al. (1988), which is referred to as the Wahner cross section below, at $228 \mathrm{~K}$ with red and blue curves, respectively. The left panel shows the spectral window between 346 and $360 \mathrm{~nm}$ as used in the retrieval of the balloon-borne DOAS measurements (Dorf et al., 2006) whereas the right panel shows the $331-370 \mathrm{~nm}$ spectral range as used in the retrieval of the balloon-borne SAOZ measurements (Pundt et al., 2002). The cross sections are shown in the differential form, i.e., a cubic polynomial is subtracted from both cross sections. The plot reveals that the wavelength calibration and the magnitudes of some $\mathrm{BrO}$ absorption bands in Fleischmann and Wahner cross sections are distinctly different.

While the wavelength misalignment can be accounted for using an improved calibration or including the shift and squeeze parameters in the spectral fit procedure, the difference in the magnitudes of absorption bands propagates 

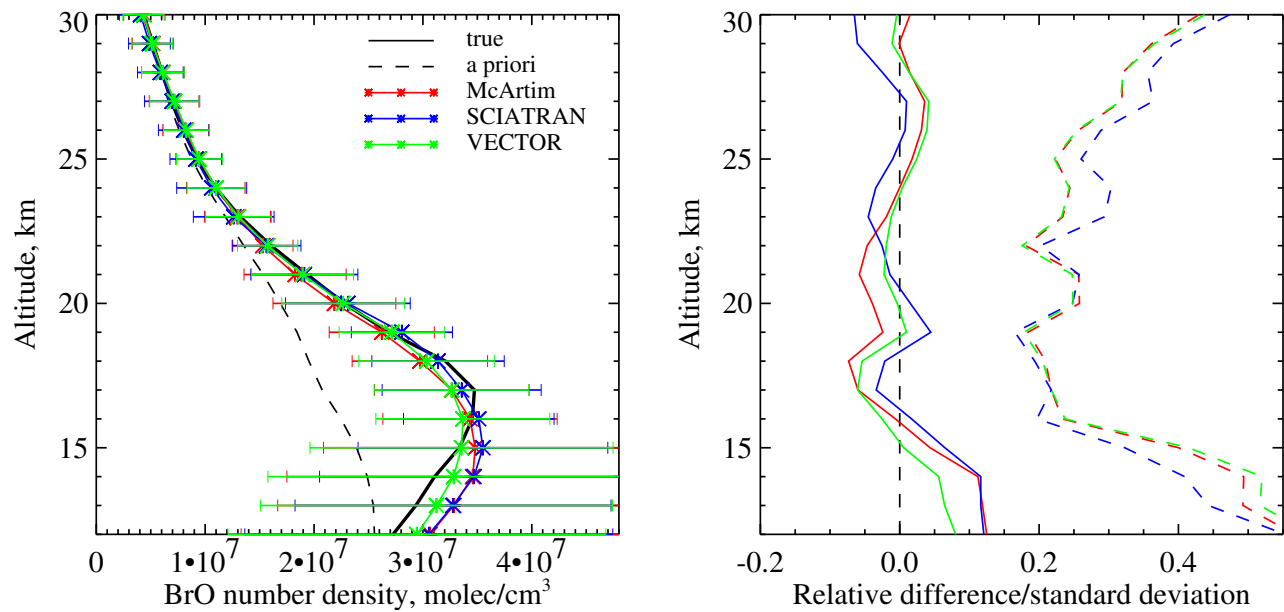

Fig. 10. Synthetic retrievals for an observation geometry typical for high-latitude spring season. Left panel: mean vertical profiles of BrO retrieved with the IUP Bremen algorithm using synthetic limb spectra simulated with different radiative transfer models (colored solid lines with asterisks). The true and a priori profiles are shown with black solid and dashed lines, respectively. Right panel: relative deviations from the true profile (solid lines) and standard deviations (dashed lines) for different retrievals.
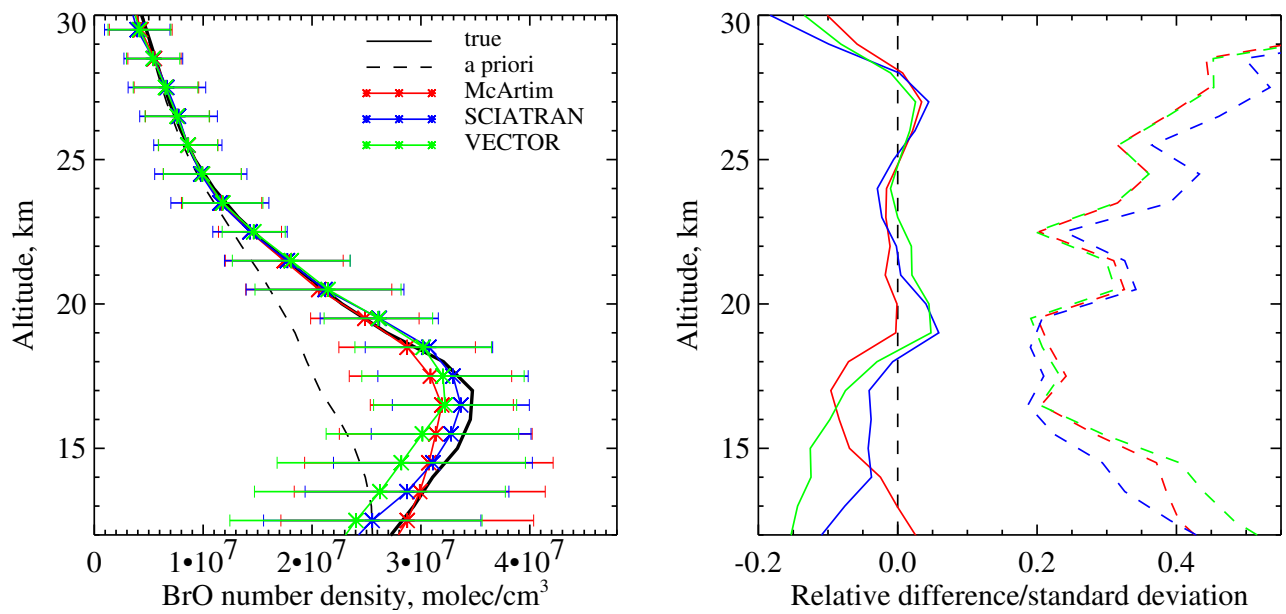

Fig. 11. Same as in Fig. 10 but retrieved with the MPI Mainz algorithm.

directly into the retrieval results. Thus, resulting vertical profiles of $\mathrm{BrO}$ differ when different absorption cross sections are used. The effect upon the retrieval results depends on the spectral interval used for the retrieval and can be estimated fitting one $\mathrm{BrO}$ cross section to the other using the amplitude, shift, and squeeze as the fit parameters. Figure 15 shows the fit results with the Wahner cross section at $228 \mathrm{~K}$ fitted to the Fleischmann cross section at $223 \mathrm{~K}$. The scaling factor of 0.894 is obtained when performing the fit in the short spectral range $(346-360 \mathrm{~nm})$ whereas in the long spectral range (331-370) the amplitudes of both cross sections are nearly the same (scaling factor of 1.014 is obtained).

If the temperature dependence of the $\mathrm{BrO}$ cross section is not considered in the retrieval process the scaling factor for the absorption cross section propagates directly to the resulting $\mathrm{BrO}$ profiles. Thus, the scaling factor provides a rough estimate of the retrieval uncertainty due to differences in $\mathrm{BrO}$ absorption cross sections. Summarizing the results above, one should expect the $\mathrm{BrO}$ amounts resulting from the balloon-borne DOAS measurements to be about $10 \%$ higher when retrieved using the Fleischmann cross sections. In contrast, for $\mathrm{BrO}$ profiles retrieved from the balloon-borne SAOZ measurements nearly the same results are expected for both cross sections.

\subsection{Temperature dependence of $\mathrm{BrO}$ cross sections}

As pointed out above, both DOAS/SAOZ retrievals and MPI Mainz algorithm use a $\mathrm{BrO}$ cross section at a fixed temperature in the retrieval procedure. The temperature is assumed to be $223 \mathrm{~K}$ when using the Fleischmann cross section (MPI Mainz) and $228 \mathrm{~K}$ for the Wahner cross section 

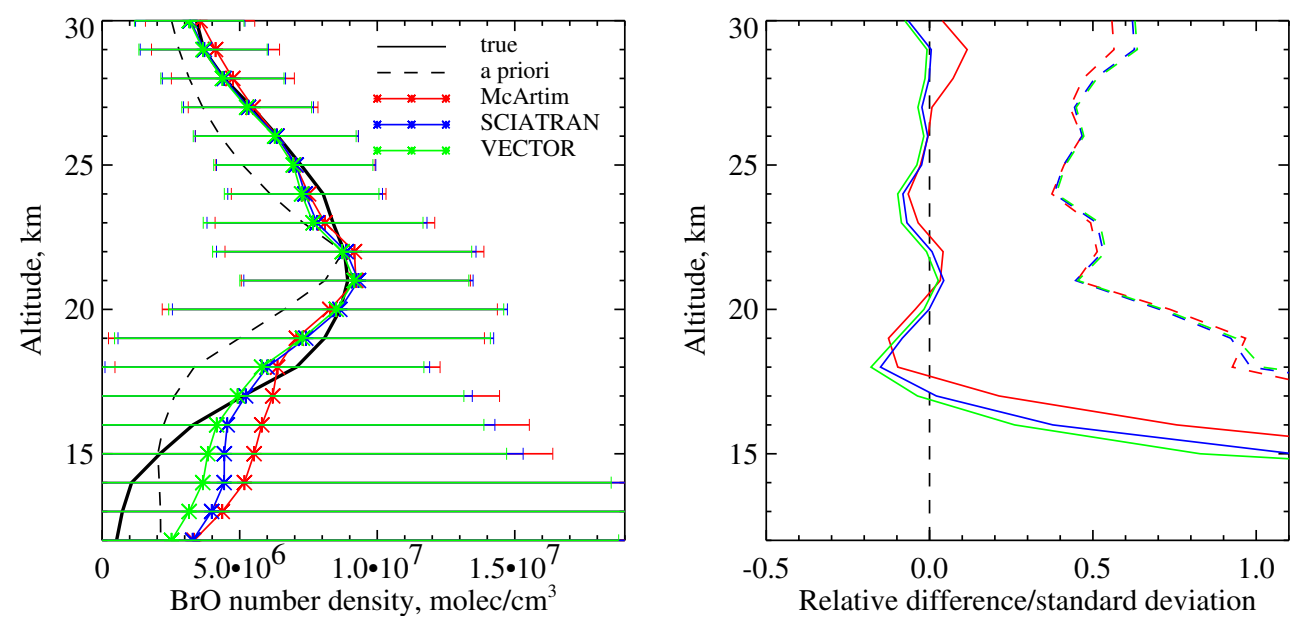

Fig. 12. Same as in Fig. 10 but for an observation geometry typical for tropical winter season.
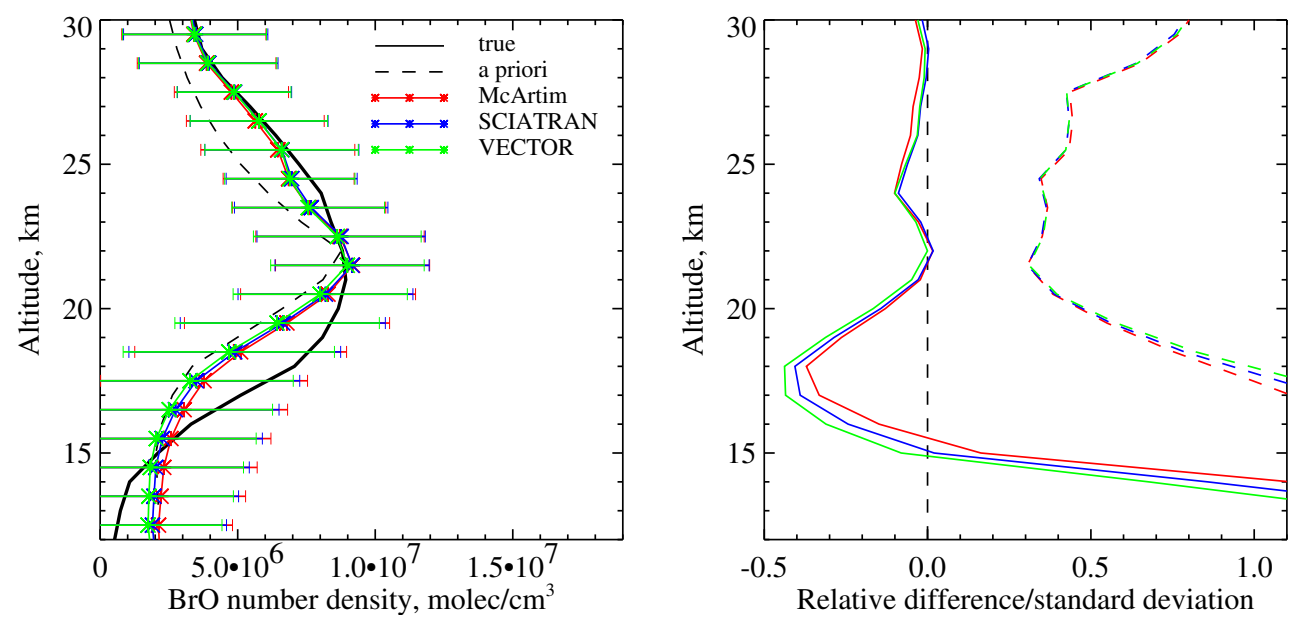

Fig. 13. Same as in Fig. 12 but retrieved with the MPI Mainz algorithm.

(DOAS/SAOZ), see Sect. 7.1 for details. In this section, synthetic retrievals are used to investigate the error which is expected when the temperature dependence of the $\mathrm{BrO}$ cross section is neglected. First, limb spectra are simulated for some example atmospheric conditions using temperature dependent $\mathrm{BrO}$ cross sections from Fleischmann et al. (2004). The retrieval is performed then using only the cross section at $223 \mathrm{~K}$. The simulations are performed using the SCIATRAN radiative transfer model and the synthetic retrievals are done employing the IUP Bremen algorithm. The left panel of Fig. 16 shows vertical profiles of the temperature obtained from the operational analysis model of the European Centre for Medium-Range Weather Forecasts (ECMWF) for example locations and seasons. To obtain a data set which is more or less representative for the entire set of comparisons presented below, the following locations and seasons are selected: Northern Sweden during high-latitude spring, Southern France during mid-latitude fall, Southern Brasil during subtropical summer, and North Western Brasil during tropical winter. The results are shown in blue, green, orange, and red, respectively. The corresponding $\mathrm{BrO}$ profiles used for simulations (i.e., true profiles in this study) are shown in the left panel of Fig. 5 by the same colors. The right panel of Fig. 16 shows the relative differences between the retrieval results obtained using $\mathrm{BrO}$ cross section at $223 \mathrm{~K}$ and true profiles. The plot reveals that the use of a constant $\mathrm{BrO}$ cross section at $223 \mathrm{~K}$ results in higher $\mathrm{BrO}$ amounts in the retrieved profiles for all considered scenarios. With exception of the tropical profile below $16 \mathrm{~km}$, the relative differences are typically below $10 \%$. For the high-latitude observation the difference is about $2 \%$ at $15 \mathrm{~km}$ increasing to $5-10 \%$ above $19 \mathrm{~km}$ whereas the relative difference for other observations is nearly zero at $30 \mathrm{~km}$ increasing to $5-10 \%$ below $23 \mathrm{~km}$. High relative differences below $16 \mathrm{~km}$ for a tropical observation are not meaningful because of a very low $\mathrm{BrO}$ content at these altitudes. 

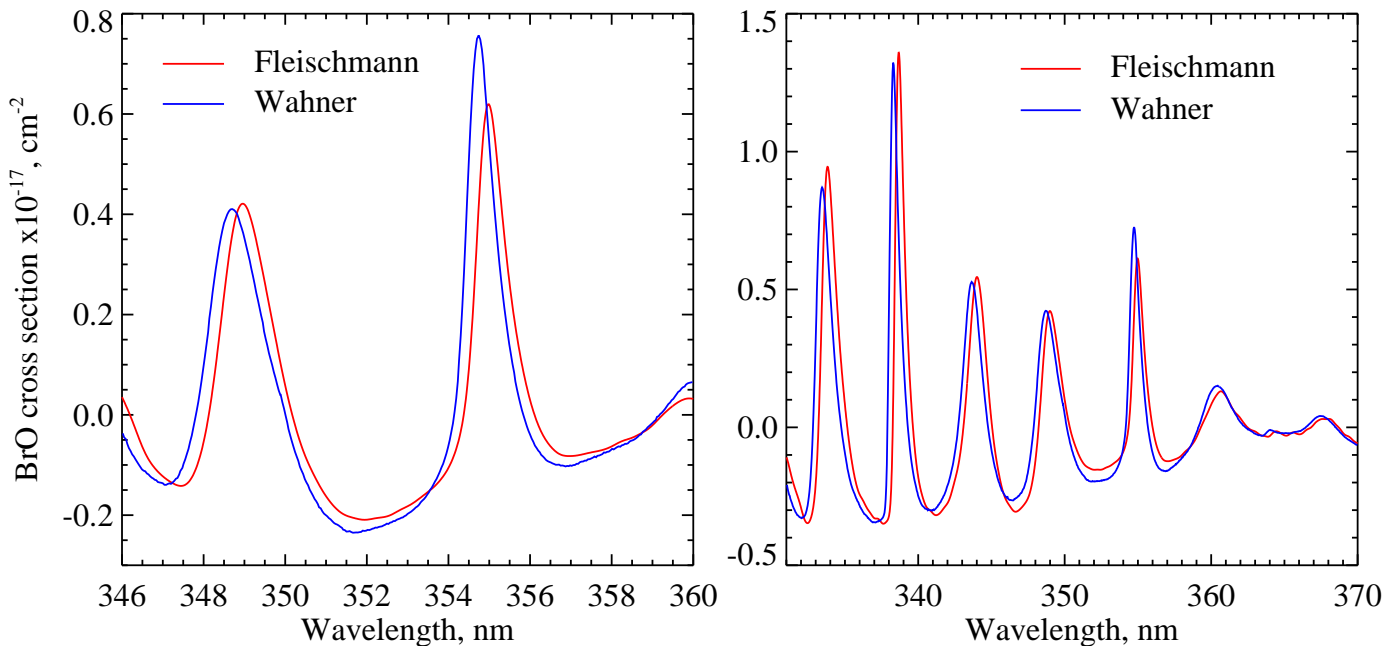

Fig. 14. BrO cross section at $223 \mathrm{~K}$ according to Fleischmann et al. (2004) shown by the red curve and at $228 \mathrm{~K}$ according to Wahner et al. (1988) shown by the blue curve. Left panel: $346-360 \mathrm{~nm}$ spectral interval as used in the retrieval of the balloon-borne DOAS measurements. Right panel: $331-370 \mathrm{~nm}$ spectral interval as used in the retrieval of the balloon-borne SAOZ measurements.
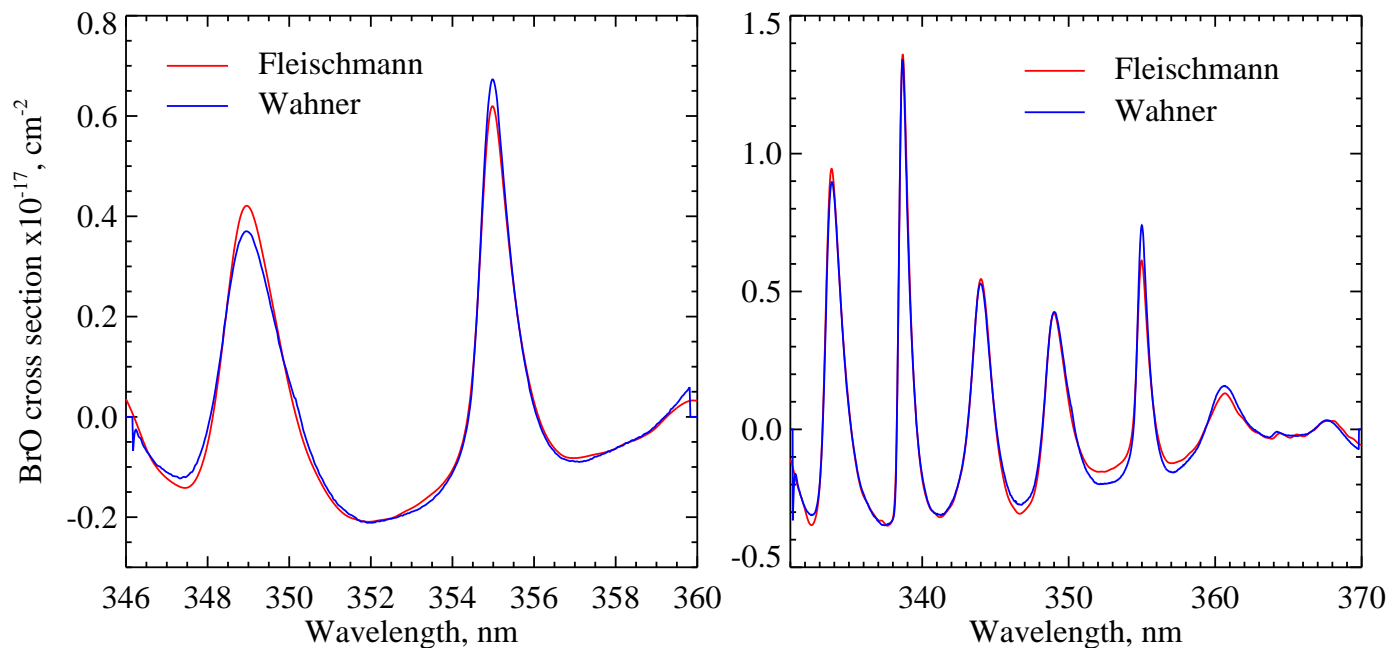

Fig. 15. Same as in Fig. 14 but with the Wahner BrO absorption cross section at $228 \mathrm{~K}$ (blue curve) fitted to the Fleischmann cross section at $223 \mathrm{~K}$ (red curve).

\subsection{Stratospheric aerosols}

In this section the influence of the stratospheric aerosol on the retrieved vertical profiles of $\mathrm{BrO}$ is investigated. Similar to the previous section, this is done using the synthetic retrievals. First, a set of limb observations is simulated assuming various stratospheric aerosol loading scenarios. The simulated spectra are used then to retrieve vertical profiles of $\mathrm{BrO}$ assuming an aerosol free atmosphere. This means that for each aerosol loading scenario the retrieval error is analyzed which arises if the contribution of stratospheric aerosols is completely neglected in the retrieval process. The simulations are performed for a background, moderate volcanic, and high volcanic aerosol loading according to the LOWTRAN aerosol model (Kneizys et al., 1996) as well as for a background aerosol loading according to the ECSTRA aerosol model (Fussen and Bingen, 1999).

Figure 17 illustrates influence of the stratospheric aerosols on the retrieved vertical profiles of $\mathrm{BrO}$ for an example limb observation performed over Northern Sweden during highlatitude spring. In the left panel of the figure the true vertical profile of $\mathrm{BrO}$ (i.e., used for simulations) is shown with the black line whereas the color lines depict the retrieved profiles obtained for different aerosol loading scenarios. The relative differences with respect to the true profile are shown in the right panel of the figure. The plot reveals that the 

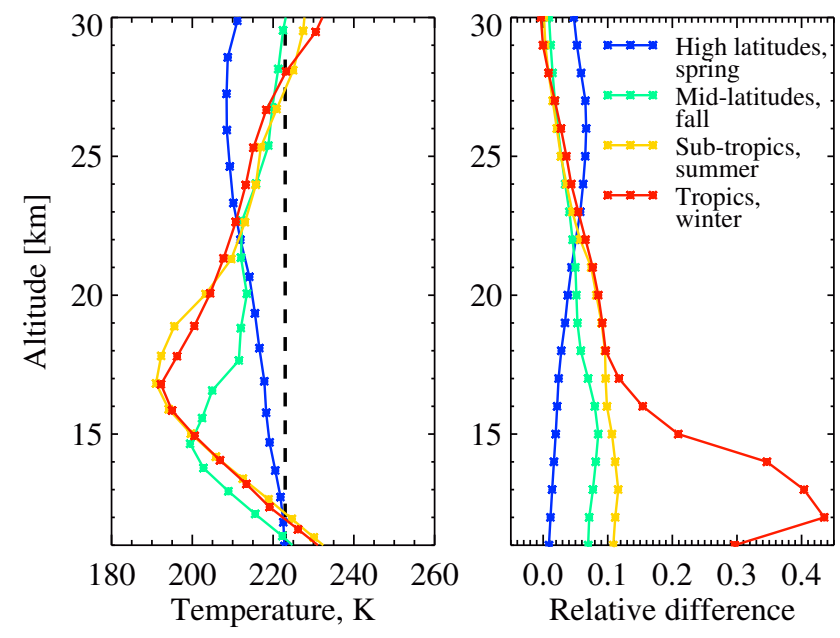

Fig. 16. Influence of the temperature dependence of the $\mathrm{BrO}$ absorption cross section on retrieved profiles. Left panel: examples of temperature profiles for high-latitude spring (blue), mid-latitude fall (green), subtropical summer (orange), and tropical winter (red). The dashed black line shows a temperature of $223 \mathrm{~K}$. Right panel: relative differences between $\mathrm{BrO}$ profiles retrieved assuming a constant $\mathrm{BrO}$ cross section at $223 \mathrm{~K}$ and corresponding true profiles. The results are obtained with the IUP Bremen algorithm.

$\mathrm{BrO}$ amount in the stratosphere is typically underestimated if stratospheric aerosols are not considered in the retrieval. For an unpolluted atmosphere (i.e., background aerosols), however, the effect is rather small with the relative differences never exceeding $15 \%$. For volcanic scenarios, the retrieval errors become significant reaching about $60 \%$ between 17 and $19 \mathrm{~km}$ for a high volcanic aerosol scenario.

Similar results for the tropical region represented by an example limb observation performed over North Western Brasil during tropical winter are shown in Fig. 18. Here, the relative differences are generally larger because of much lower $\mathrm{BrO}$ amounts in tropics especially below about $17 \mathrm{~km}$. Nevertheless, for an unpolluted atmosphere, the relative differences above $18 \mathrm{~km}$ are still within about $10 \%$ rapidly increasing with decreasing altitude. Similar to the high latitudes, the relative differences for volcanic aerosol scenarios are quite high indicating a strong influence of the stratospheric aerosols on the retrieval results.

These results show that variations of aerosol loading around the background level do not introduce any significant bias in the retrieved data. Contrarily, retrievals for a highly increased aerosol loading, e.g., as observed directly after the Kasatochi volcanic eruption in August 2008, can be substantially biased. An improvement can be achieved including stratospheric aerosols in the retrieval scheme (Bourassa et al., 2007; Ernst et al., 2009; Rozanov et al., 2011). This is, however, outside the scope of our study. As non of the considered retrievals includes any aerosol correction procedure, their sensitivity to the stratospheric aerosols is expected to be similar.

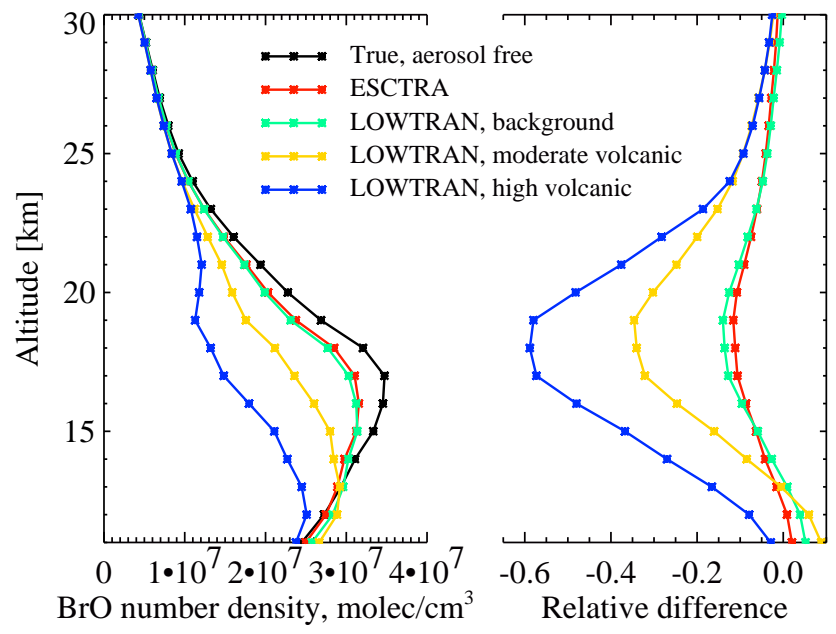

Fig. 17. Influence of stratospheric aerosols on the retrieved vertical profiles of $\mathrm{BrO}$ for a typical observation over Northern Sweden during high-latitude spring. Left panel: true vertical profile of $\mathrm{BrO}$ (black line) and retrieval results for different aerosol loading scenarios (color lines). Right panel: relative differences between $\mathrm{BrO}$ profiles retrieved for different aerosol loading scenarios and the true profile. The results are obtained with the IUP Bremen algorithm.

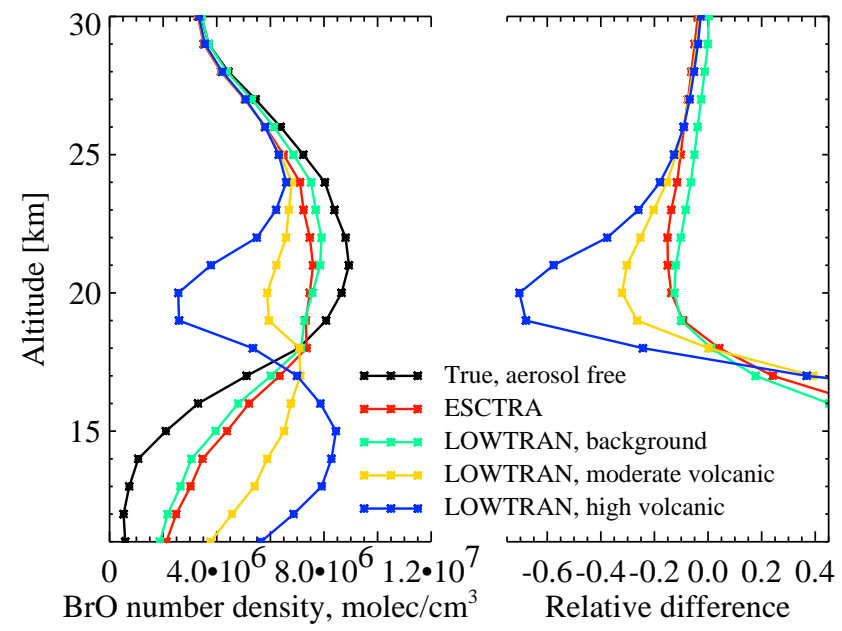

Fig. 18. Same as in Fig. 17 but for a typical observation over North Western Brasil during tropical winter.

\section{Intercomparison of SCIAMACHY BrO products}

In this section, vertical profiles of BrO retrieved with IUP Bremen, DLR, and MPI Mainz algorithms are compared to each other for one SCIAMACHY orbit. For this purpose the orbit 10811 from 25 March 2004 is selected that contains one of the measurements collocated with the balloon-borne observations discussed below in Sect. 9 (see Table 2).

Vertical distributions of $\mathrm{BrO}$ retrieved with all three algorithms are presented in the left panels of Fig. 19. The relative differences between the results from different retrievals 

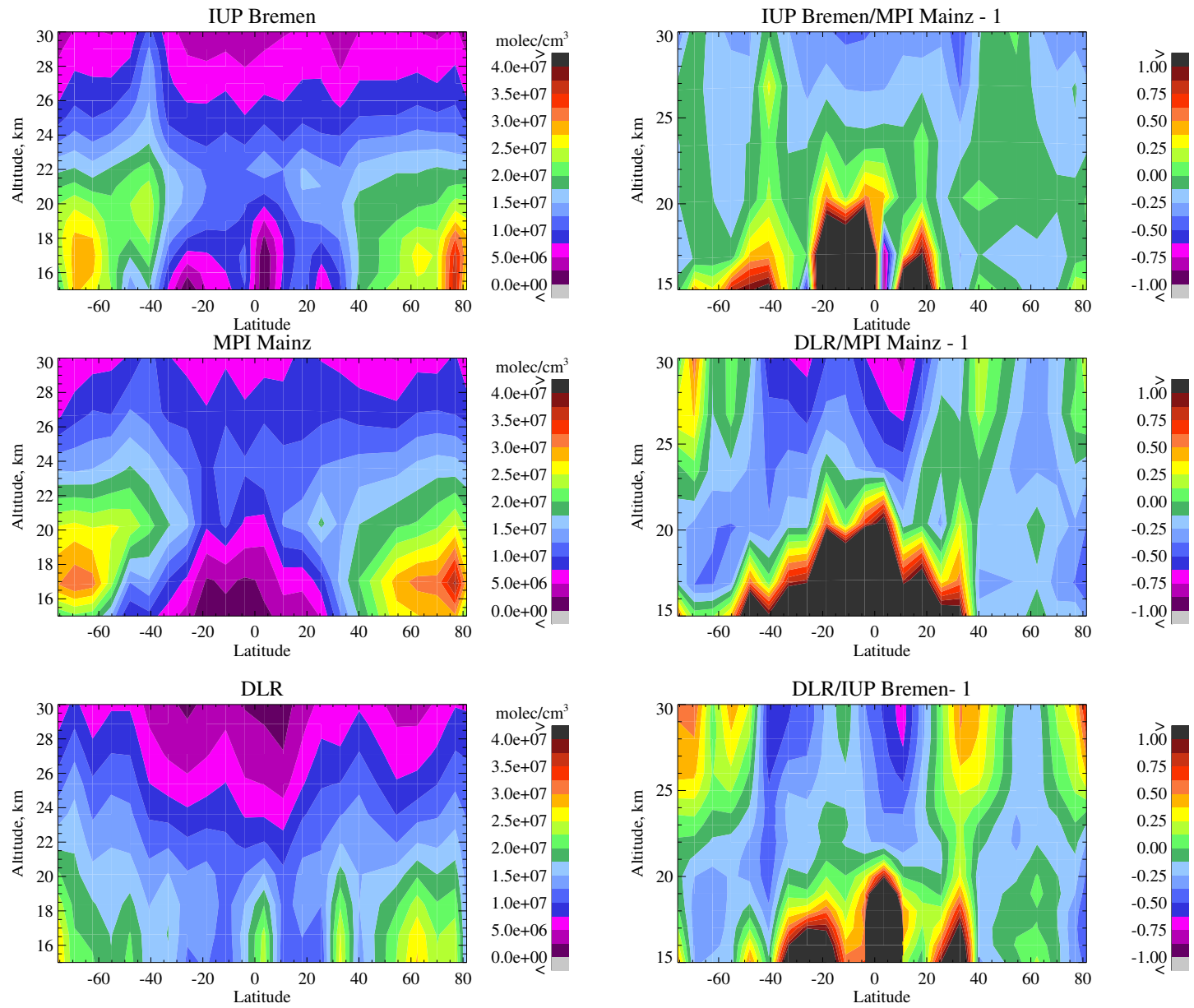

Fig. 19. Intercomparison of three SCIAMACHY BrO products for a selected orbit (Orbit 10811, 25 March 2004). Left panels: BrO vertical distributions retrieved form SCIAMACHY limb measurements with different algorithms. Right panels: relative differences in the retrieved $\mathrm{BrO}$ profiles.

are shown in the right panel of the figure. The common features seen by all retrievals are high $\mathrm{BrO}$ amounts in the lower atmosphere at high latitudes and values about 1$1.5 \times 10^{7}$ molec $\mathrm{cm}^{-3}$ between 20 and $24 \mathrm{~km}$ in the tropics. The IUP Bremen and MPI Mainz results show a very similar latitudinal behavior with peak values decreasing and peak altitude increasing when moving form the high latitudes to the tropics. Because of a coarser vertical sampling, the vertical structures in the MPI Mainz results look smoother and peak altitudes in the tropics are higher as compared to the IUP Bremen retrieval. An increase in both IUP Bremen and MPI Mainz results seen at about $40^{\circ} \mathrm{S}$ is most probably because the satellite crosses the South-Atlantic Anomaly during this particular measurement. The relative differences between both results, shown in the upper right panel, are mostly within $\pm 12.5 \%$ (one color step) in the high sensitivity range. The high differences seen in the tropical troposphere are due to large retrieval errors (more then $100 \%$ ) in this altitude range. In comparison to both IUP Bremen and
MPI Mainz products, the DLR results look slightly different showing higher values above 26 and lower values below $22 \mathrm{~km}$ at high latitudes, as well as lower values above $22 \mathrm{~km}$ in the tropics. Nevertheless, the relative differences with respect to both IUP Bremen and MPI Mainz results, shown in the middle and lower right panels, respectively, are mostly below $25 \%$. The high amounts of $\mathrm{BrO}$ obtained from the DLR retrieval in the tropical troposphere are explained by high values in the a priori $\mathrm{BrO}$ profiles and a low retrieval sensitivity in this region. The a priori $\mathrm{BrO}$ profiles used by the retrieval algorithms are shown in Fig. 20. As discussed in Sect. 4, IUP Bremen and MPI Mainz retrievals employ a latitude dependent climatological information whereas the DLR algorithm uses a constant a priori profile (in VMR units). 

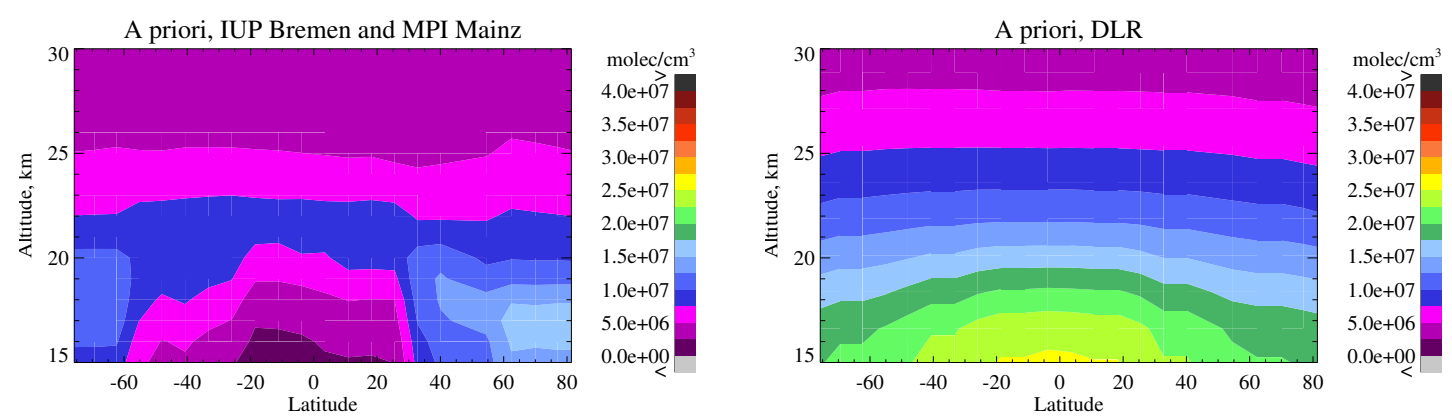

Fig. 20. A priori information used for the retrievals shown in Fig. 19
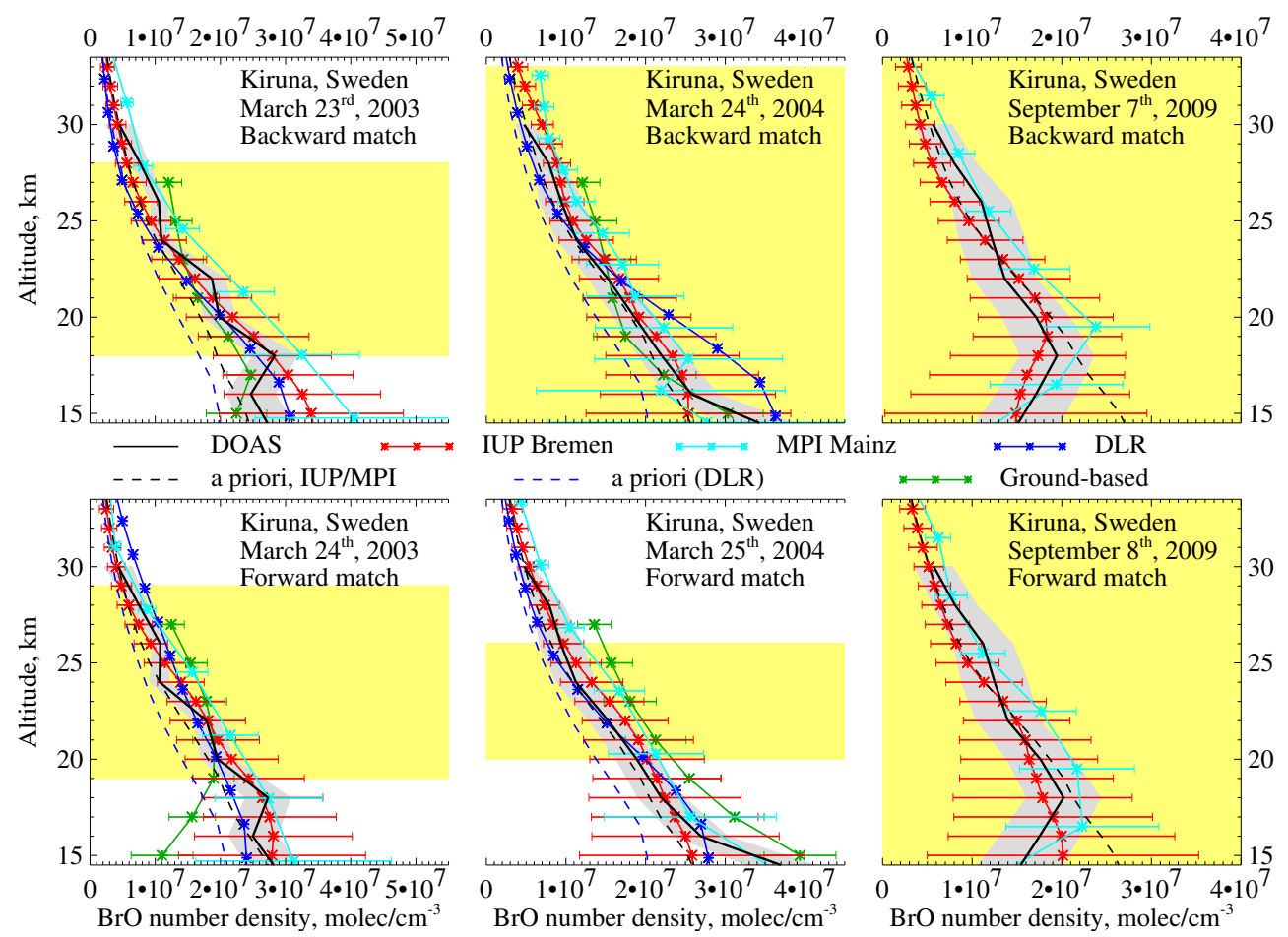

Fig. 21. Comparison of BrO vertical distributions retrieved from SCIAMACHY limb measurements using different retrieval algorithms to coinciding balloon-borne DOAS observations. When available, ground-based UV-visible BrO profiles from the Harestua station are also shown. All balloon launches are in Kiruna (high latitude). Left panels: 23 March 2003. Middle panels: 24 March 2004. Right panels: 7 September 2009. Gray shadings depict the uncertainties of DOAS results $(1-\sigma)$. Yellow areas mark vertical ranges where according to trajectory model calculations both instruments probe the same air mass.

\section{Comparisons to balloon-borne observations}

In this section, BrO vertical profiles retrieved with IUP Bremen, DLR, and MPI Mainz algorithms from SCIAMACHY limb measurements are compared with the results obtained from the coinciding balloon-borne observations. In total, $12 \mathrm{BrO}$ profiles from DOAS, SAOZ, and TRIPLE balloonborne instruments are considered. The former two are remote sensing instruments while the latter performs in situ measurements. The full list of coincidences is presented in Table 2. Since an overview of the balloon-borne instruments involved in the comparison, corresponding retrieval methods, and error estimations are already published by Dorf et al. (2006), only a short description of each instrument is presented below.

As the exact location of the air mass probed by balloon payloads is strongly determined by weather conditions and astronomical parameters, it is very difficult to match the temporal and spatial factors of the balloon measurements directly with individual satellite measurements. A partial compensation of the remaining temporal and spatial mismatches can be achieved applying trajectory calculations (Lumpe et al., 2002). Employing a trajectory model, the air mass probed by the balloon payload can be traced to the 

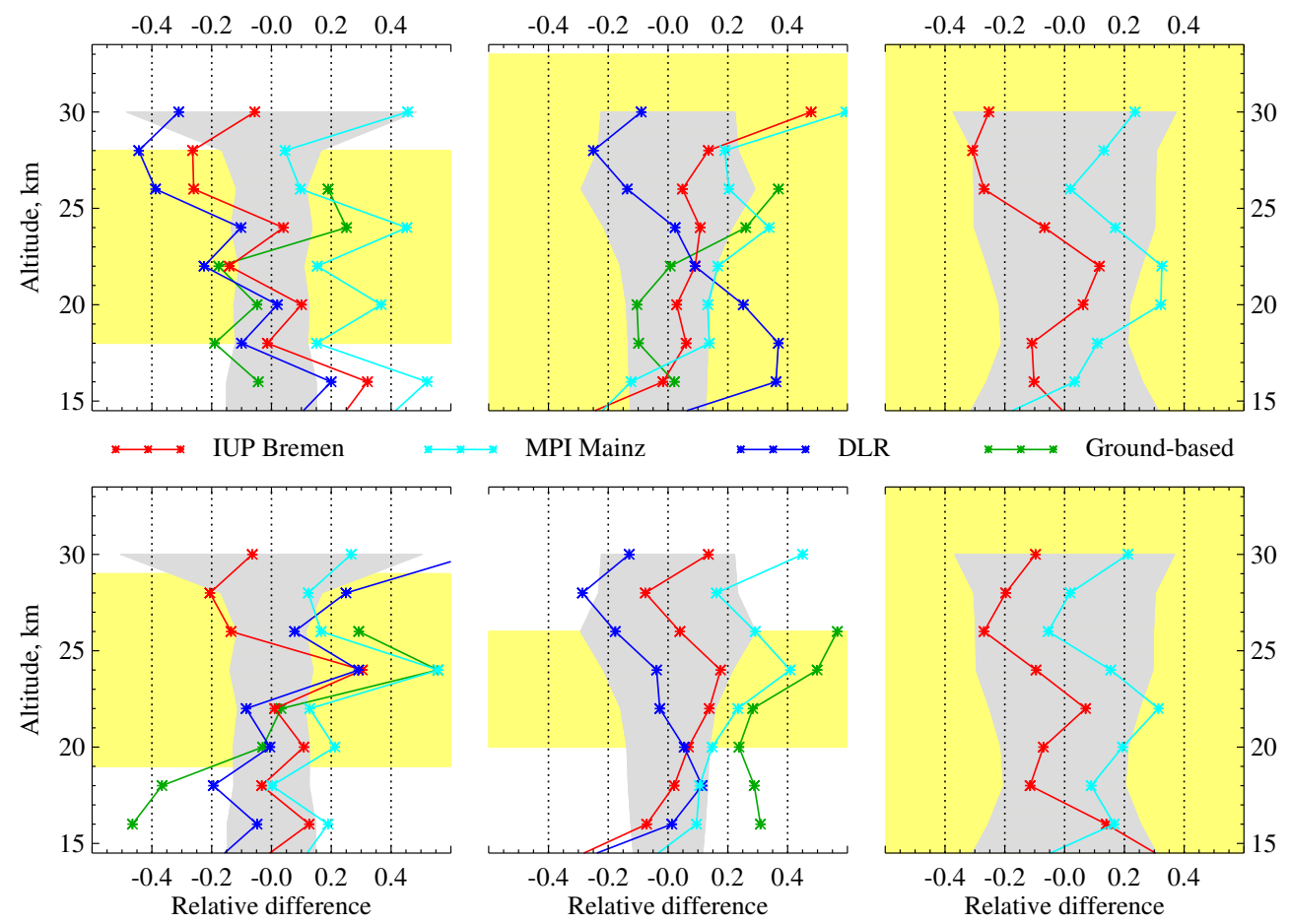

Fig. 22. Same as in Fig. 21 but for relative differences with respect to balloon-borne DOAS results, e.g., IUP Bremen/DOAS-1, etc.
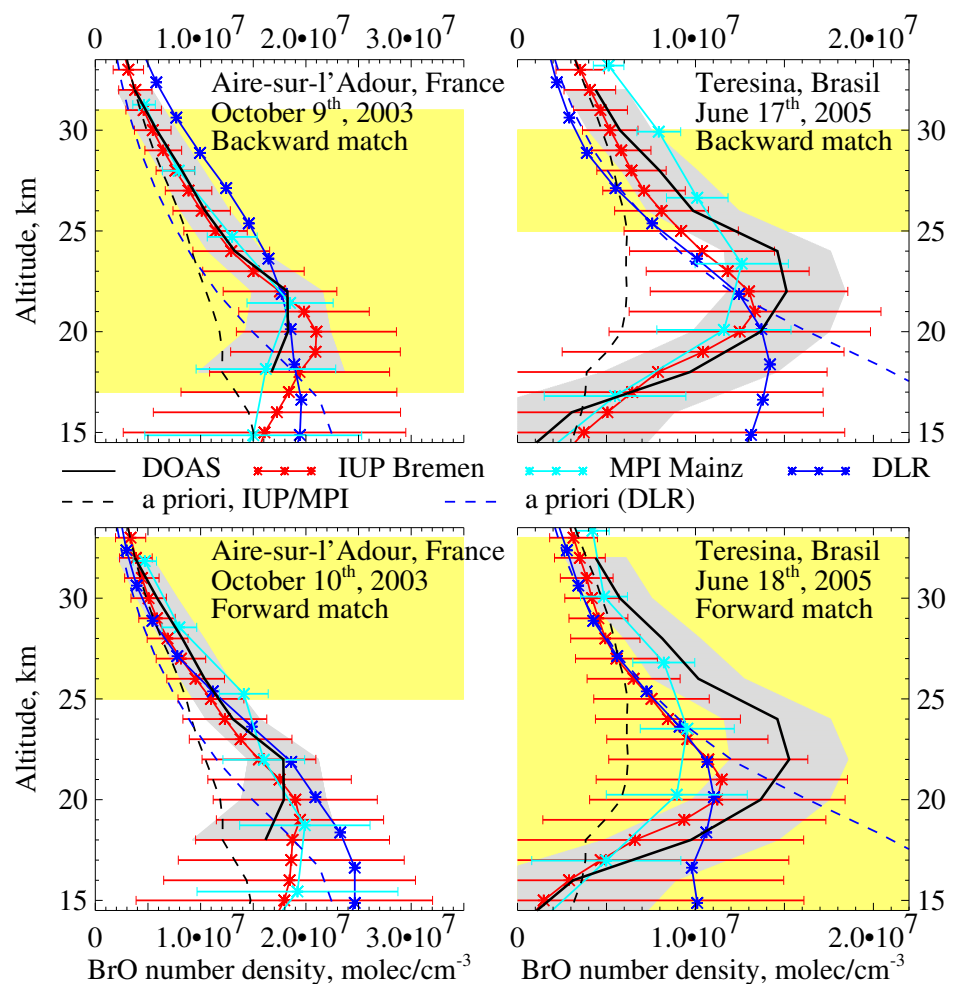

Fig. 23. Comparison of $\mathrm{BrO}$ vertical distributions retrieved from SCIAMACHY limb measurements using different retrieval algorithms to coinciding balloon-borne DOAS observations. Left panels: balloon launch in Aire-sur-l'Adour (mid-latitude) on 9 October 2003. Right panels: balloon launch in Teresina (tropics) on 17 June 2005. Gray shadings depict the uncertainties of DOAS results (1- $\sigma$ ). Yellow areas mark vertical ranges where according to trajectory model calculations both instruments probe the same air mass. 

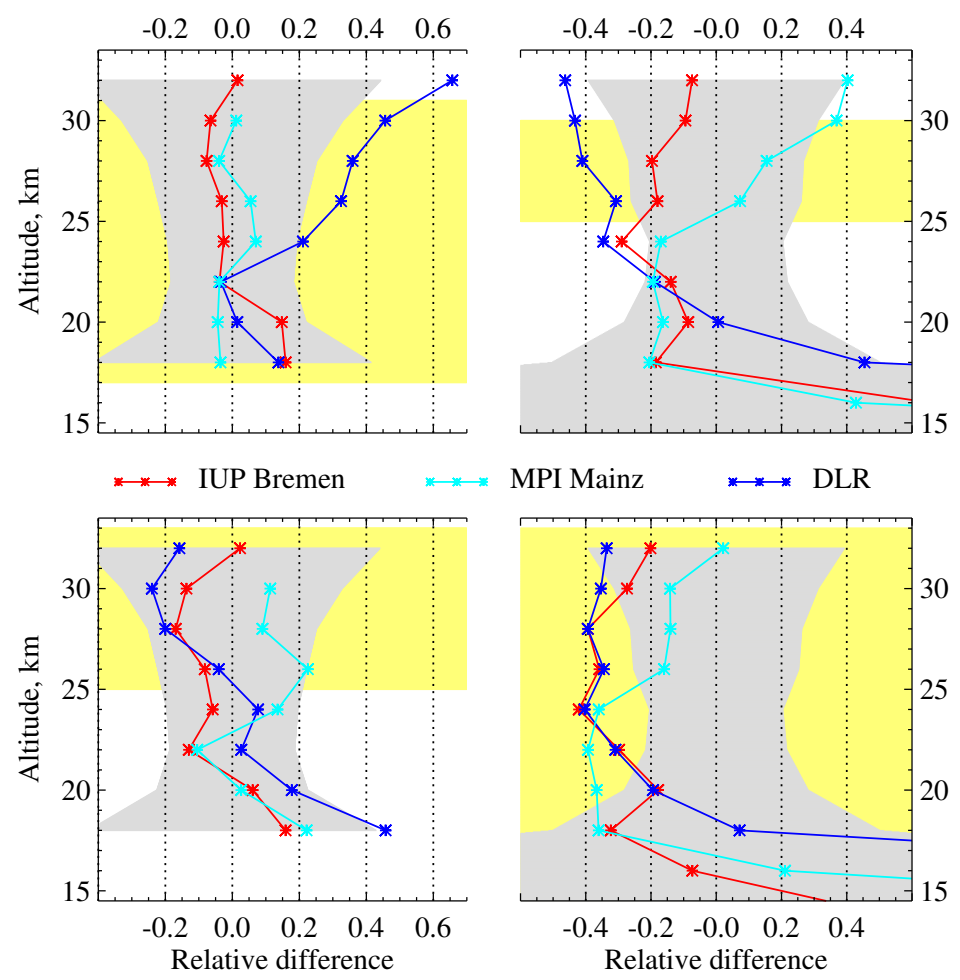

Fig. 24. Same as in Fig. 23 but for relative differences with respect to balloon-borne DOAS results, e.g., IUP Bremen/DOAS-1, etc.

past and/or to the future from the balloon measurement time to found an appropriate match with a satellite measurement. This yields two coincidences for each balloon flight referred to as forward and backward matches, which correspond to the air mass tracing into the future and into the past with respect to the balloon-borne measurement, respectively. For all comparisons discussed in this section, trajectory calculations are performed at FU Berlin. Details on the trajectory model are presented by Langematz et al. (1987). A temporal misalignment between different observations means usually that the measurements are performed under different illumination conditions that, for photochemically active species, results in different observed concentrations even when probing the same air mass. This is accounted for by using a photochemical model in a similar manner as discussed e.g. by Bracher et al. (2005); Butz et al. (2006); Dorf et al. (2006). Thereby, BrO amounts observed by a balloonborne instrument are converted to the illumination conditions which are appropriate for the matching satellite measurement. Photochemical corrections for DOAS observations are performed by the scientific team of the University of Heidelberg as described by Dorf et al. (2006). All results from SAOZ and where needed from TRIPLE are photochemically corrected at the Environment Canada similar to McLinden et al. (2010). The uncertainty associated to all balloon measurements shown below is represented by $1-\sigma$ range.

\subsection{DOAS}

The spectra of the direct solar light transmitted through the Earth's atmosphere are collected on board the azimuthcontrolled LPMA/DOAS (Limb Profile Monitor of the Atmosphere/Differential Optical Absorption Spectroscopy) balloon payload. Vertical profiles of $\mathrm{BrO}$ are retrieved with the DOAS technique in the wavelength range from $346 \mathrm{~nm}$ to $360 \mathrm{~nm}$. The $\mathrm{BrO}$ reference is the absolute cross-section measured by Wahner et al. (1988) with the wavelength calibration taken from laboratory measurements. Details on the measurement setup and the retrieval technique are presented by Ferlemann et al. (1998, 2000), Harder et al. (1998, 2000) and Dorf et al. (2006). This study uses BrO profiles obtained during five balloon flights which were performed in the framework of the SCIAMACHY validation campaign over Kiruna in Sweden, Aire-sur-l'Adour in France, and Teresina in Brazil (see Table 2). Only the measurements during the balloon ascent are considered.

As mentioned above, $\mathrm{BrO}$ vertical distributions retrieved by three algorithms (IUP Bremen, MPI Mainz, and DLR) from SCIAMACHY limb measurements are compared with coinciding balloon-borne DOAS observations. The results for high latitudes (balloon launches at Kiruna, see Table 2) are shown in Figs. 21 and 22 for profiles and relative differences, respectively. For each balloon flight forward (lower panels) and backward (upper panels) matches are compared. 

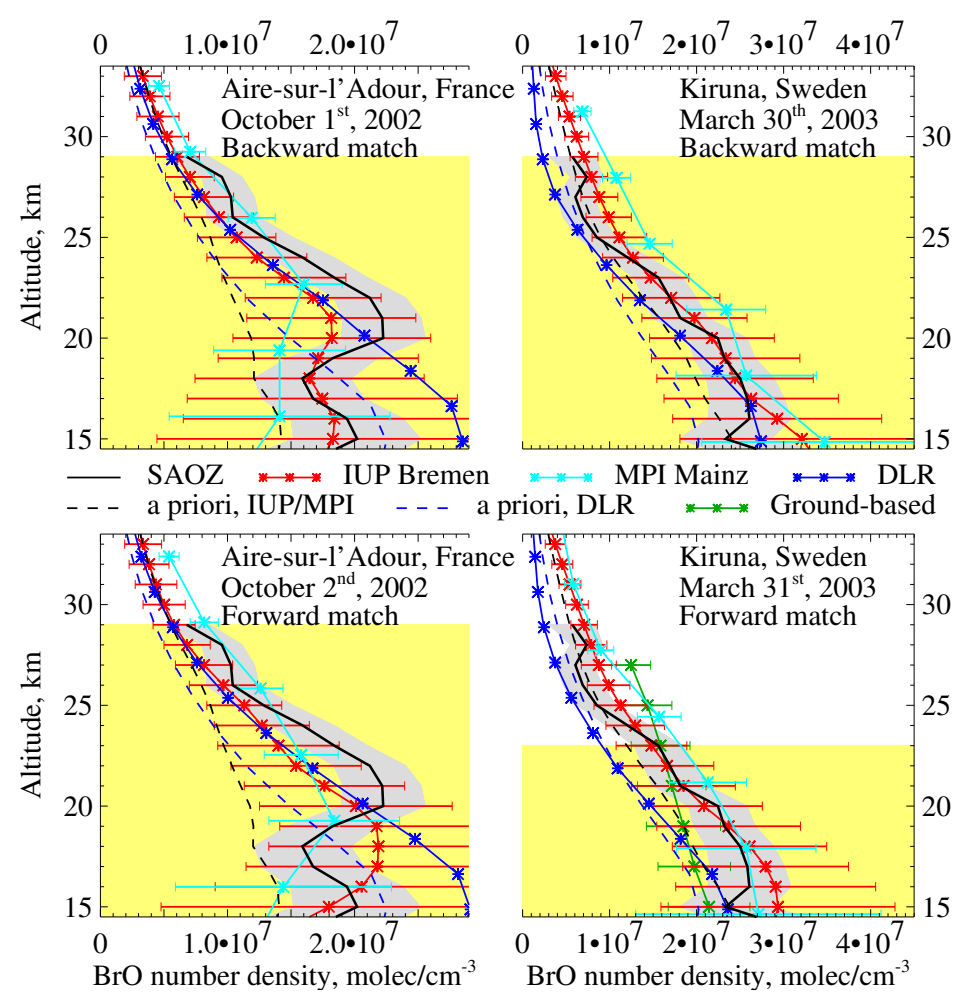

Fig. 25. Comparison of BrO vertical distributions retrieved from SCIAMACHY limb measurements using different retrieval algorithms to coinciding balloon-borne SAOZ observations. When available, ground-based UV-visible BrO profiles from the Harestua station are also shown. Left panels: balloon launch in Aire-sur-l'Adour (mid-latitude) on 1 October 2002. Right panels: balloon launch in Kiruna (high latitude, outside the polar vortex) on 30 March 2003. Gray shadings depict the uncertainties of SAOZ results (1- $\sigma$ ). Yellow areas mark vertical ranges where according to trajectory model calculations both instruments probe the same air mass.

The vertical profiles of $\mathrm{BrO}$ retrieved from SCIAMACHY limb measurements with the IUP Bremen, DLR, and MPI Mainz algorithms are shown in red, blue, and cyan, respectively. Both IUP Bremen and MPI Mainz retrievals use the same a priori information shown with black dashed lines whereas the DLR a priori profiles are depicted by dashed blue lines. The coinciding balloon-borne DOAS retrievals are shown by black solid lines and their uncertainties are depicted by grey areas. Yellow areas mark vertical ranges where, according to trajectory model calculations, both SCIAMACHY and balloon-borne instruments are considered to probe the same air mass (for match criteria see e.g. Dorf et al., 2006). Where available, BrO profiles retrieved from the ground-based zenith sky UV-visible observations performed at Harestua in Norway $\left(60^{\circ} \mathrm{N}, 11^{\circ} \mathrm{E}\right)$ are shown in green. These retrievals are performed at the Belgian Institute for Space Aeronomy (IASB-BIRA) in Brussels using a profiling algorithm described by Hendrick et al. (2009). The ground-based observations are selected according to the closest match principle, i.e., no trajectory calculations are performed. For all considered observations, the vertical profiles of $\mathrm{BrO}$ obtained from SCIAMACHY limb measurements using different retrieval algorithms agree with the balloon-borne DOAS results typically within $20 \%$. All retrievals agree within error bars nearly everywhere. In most comparisons the MPI Mainz retrieval shows slightly higher values while the DLR profile clearly deviates from other retrievals below $20 \mathrm{~km}$ on 24 March 2004 . Where available, ground-based measurements fit well into the overall picture showing, however, too low values below $18 \mathrm{~km}$ on 24 March 2003, and slightly higher values at all altitudes on 25 March 2004. A more statistically significant comparison between SCIAMACHY (IUP Bremen) and ground-based UV-visible BrO retrievals can be found in Hendrick et al. (2009).

Figures 23 and 24 show a similar comparison but for midlatitudes and tropics (balloon launches at Aire-sur-l'Adour and Teresina, respectively, see Table 2). The layout of plots is the same as in Figs. 21 and 22. At mid-latitudes all results agree within $20 \%$ in the entire altitude range except for DLR retrieval on 9 October 2004. The latter shows 30-45\% higher $\mathrm{BrO}$ amounts above $24 \mathrm{~km}$. A quite different behavior is observed in the tropics. Here, for the backward match, the results of both IUP Bremen and MPI Mainz retrievals agree with balloon-borne DOAS profiles within $20 \%$ nearly everywhere while the DLR retrieval shows lower values above $24 \mathrm{~km}$. For the forward match, all SCIAMACHY retrievals agree to each other within error bars in the entire altitude 

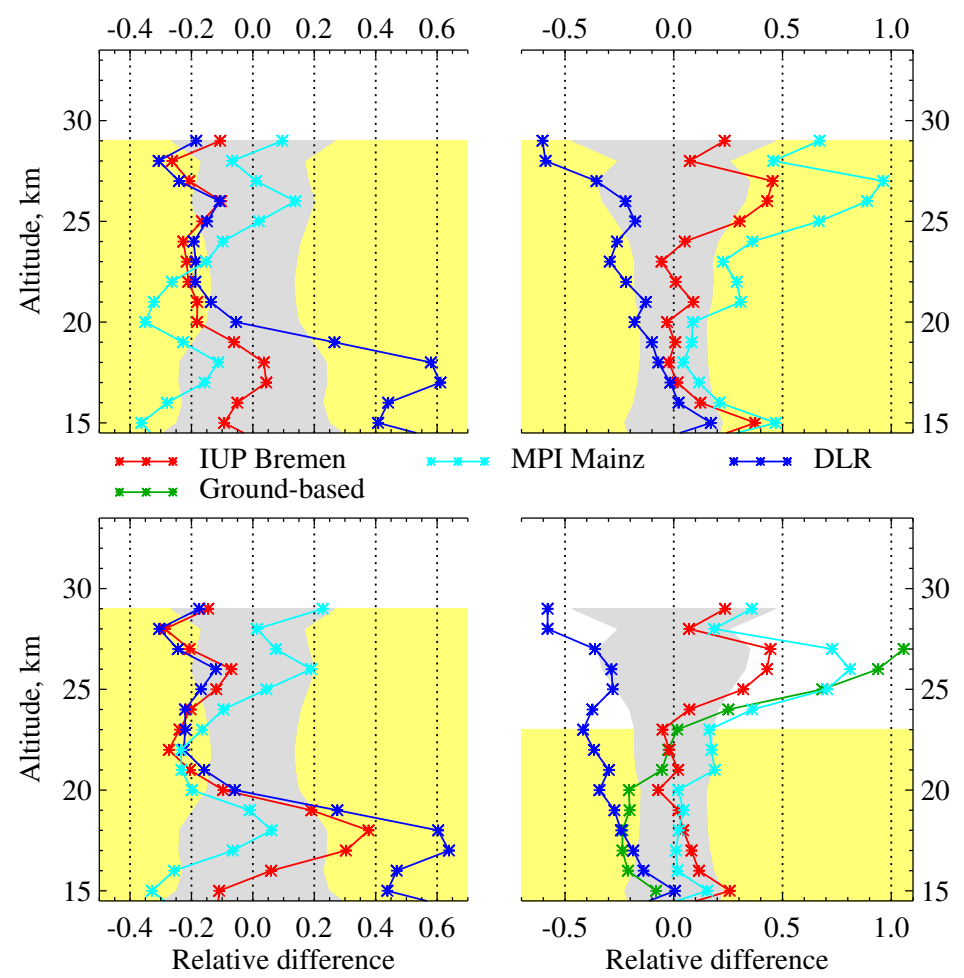

Fig. 26. Same as in Fig. 25 but for relative differences with respect to balloon-borne SAOZ results, e.g., IUP Bremen/SAOZ-1, etc.

range but show $20-40 \%$ lower BrO amounts as compared to balloon-borne DOAS results.

\subsection{SAOZ}

Similar to the DOAS instrument discussed in the previous section, the SAOZ-BrO (Systeme d'Analyse par Observations Zenithales) sonde is a balloon payload comprising an optical spectrometer which operates in the $320-400 \mathrm{~nm}$ spectral range. The SAOZ has no Sun tracker but uses instead a light collector of $360^{\circ}$ azimuth and $-5^{\circ} \%+15^{\circ}$ elevation field of view. Although using this experimental setup both direct and scattered solar light is collected and passed to the detector, it is clear that for daylight cloud free conditions the contribution of the scattered light is negligible and the instrument can be considered as measuring only the direct solar light transmitted through the atmosphere. The vertical profiles of $\mathrm{BrO}$ considered in this study are retrieved from the observations performed during late afternoon balloon ascents. In total, four balloon flights performed over Aire-surl'Adour in France, Kiruna in Sweden, and Bauru in Brazil are considered (see Table 2). The LATMOS-CNRS research group in France has operated the instrument during all flights and performed the retrievals. A detailed description of the instrument setup and of the retrieval method can be found in Pundt et al. (2002) and references therein.
In Figs. 25-28 $\mathrm{BrO}$ vertical distributions retrieved from SCIAMACHY limb observations with IUP Bremen, DLR, and MPI Mainz algorithms are compared to coinciding SAOZ measurements. The comparisons are performed for the forward (lower panels) and backward (upper panels) matches for each of the four flights listed in Table 2. The results are presented in the same manner as discussed in Sect. 9.1 for balloon-borne DOAS measurements (see Figs. 21-24).

In general, the results agree within error bars for all observations. Best agreement is achieved for the observations over Kiruna (outside the polar vortex) shown in the right panel of Fig. 25 displaying a maximum concentration around $16-18 \mathrm{~km}$ consistent with the $\mathrm{BrO}$ profile climatology published by Pundt et al. (2002). The IUP Bremen and SAOZ retrievals typically agree within $10 \%$ for this flight whereas the MPI Mainz and DLR results are slightly higher or lower, respectively. For the flight at mid-latitude (Airesur-l'Adour) shown in the left panel of Fig. 25, all SCIAMACHY retrievals yield slightly lower BrO concentrations between 20 and $25 \mathrm{~km}$ compared to that of SAOZ. The maximum of $\mathrm{BrO}$ concentration around $20-22 \mathrm{~km}$ seen by the SAOZ is consistent with that shown by the DOAS during the same season (Fig. 23) as well as with the climatology published by Pundt et al. (2002) whereas the absolute concentrations are slightly higher than that from DOAS. All SCIAMACHY retrievals agree very well above $20 \mathrm{~km}$ and disperse 

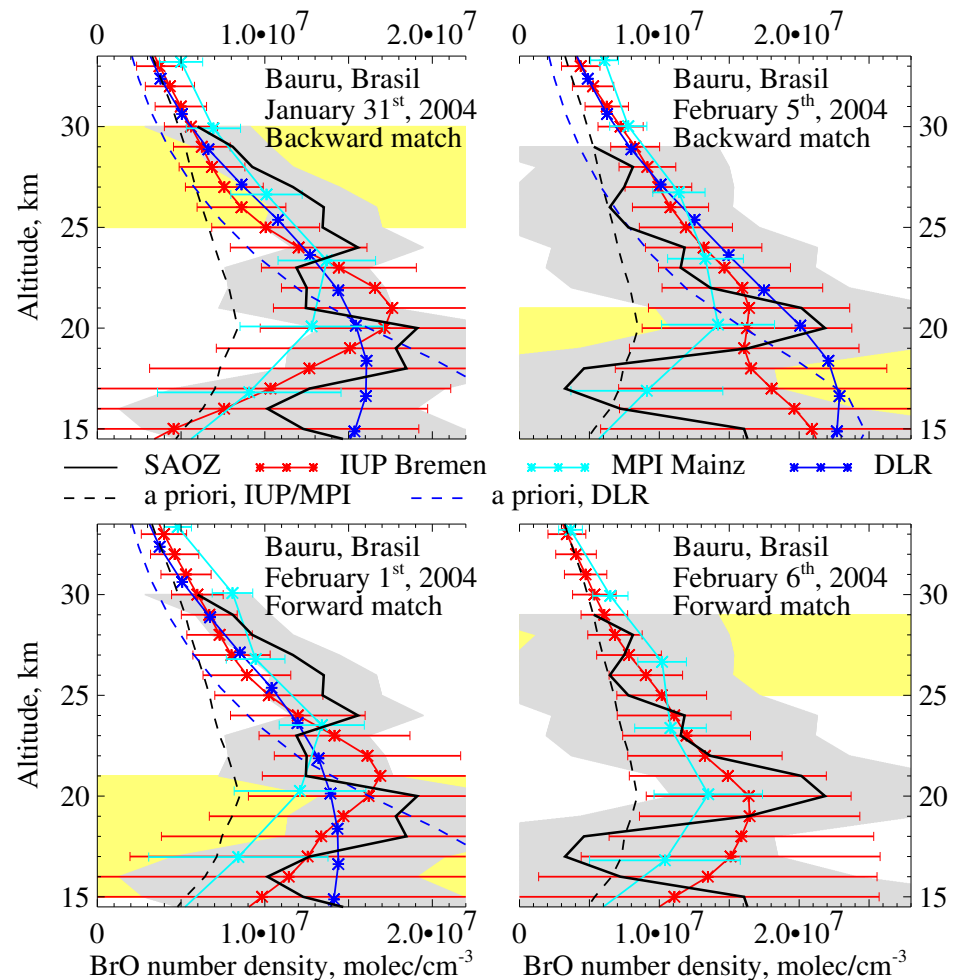

Fig. 27. Comparison of BrO vertical distributions retrieved from SCIAMACHY limb measurements using different retrieval algorithms to coinciding balloon-borne SAOZ observations. All balloon launches are in Bauru (tropics). Left panels: 31 January 2004. Right panels: 5 February 2004. Gray shadings depict the uncertainties of SAOZ results $(1-\sigma)$. Yellow areas mark vertical ranges where according to trajectory model calculations both instruments probe the same air mass.

with the decreasing altitude below still remaining, however, in agreement within error bars. The situation is more complex in Bauru in the tropics where the SAOZ precision is reduced because of the higher SZA at the time of the ascent, particularly on 5 February. Two BrO profiles are available (Fig. 27), only 6 days apart, but in very different meteorological and stratospheric conditions. The analysis of stratospheric conditions was done by the $\mathrm{SAOZ}$ team based on the simultaneous $\mathrm{NO}_{2}$ profiles also measured by SAOZ (results are not shown here). The first observation on 31 January showing a minimum $\mathrm{BrO}$ at the tropopause is carried out in a cloud free region while the second, displaying a minimum $\mathrm{BrO}$ higher up at $18-19 \mathrm{~km}$ is performed over a very active convection area. Furthermore, according to potential vorticity maps (not shown here) the first observation is performed within $\mathrm{NO}_{2}$ poor equatorial air above $24 \mathrm{~km}$ and $\mathrm{NO}_{2}$ rich filament from mid-latitude around $22-23 \mathrm{~km}$. In contrast, the second profile observed on 5 February shows a strong advection from mid-latitude above $24 \mathrm{~km}$ carrying $\mathrm{NO}_{2}$ enriched air (by $40 \%$ compared to the first flight). Though of broader resolution, the SCIAMACHY BrO profiles are also showing similar changes between the two days. Those changes in stratospheric composition are making the comparison more difficult than at higher latitudes. However, within their respective error bars, the SCIAMACHY and $\mathrm{SAOZ}$ results are consistent.

\subsection{TRIPLE}

The TRIPLE multi-instrument balloon payload comprises four in situ instruments from which only the $\mathrm{ClO} / \mathrm{BrO}$ detection system operated by Forschungszentrum Jülich $\mathrm{GmbH}$ is of interest for the current study. The detection of $\mathrm{BrO}$ is performed using the chemical-conversion resonance fluorescence technique during the balloon ascent or descent. The technique starts to suffer from oxygen absorption of the bromine resonance fluorescence radiation at $138.8 \mathrm{~nm}$ at altitudes below $20 \mathrm{~km}$ while at pressures below $10 \mathrm{hPa}$ the measurement suffers from significant wall loss of $\mathrm{Br}$ atoms. Therefore measurements are restricted to the pressure regime between about 100 and $10 \mathrm{hPa}$. A detailed description of the measurement technique and data analysis can be found in Brune et al. (1989), McKinney et al. (1997) and Woyke et al. (1999). This study uses BrO profiles obtained during 3 balloon flights which were performed in the framework of the SCIAMACHY validation campaigns over Kiruna in Sweden and Aire-sur-l'Adour in France (see Table 2). The error bars indicated in the figures correspond to statistical errors as a result of measurement noise. The absolute error of the $\mathrm{BrO}$ 

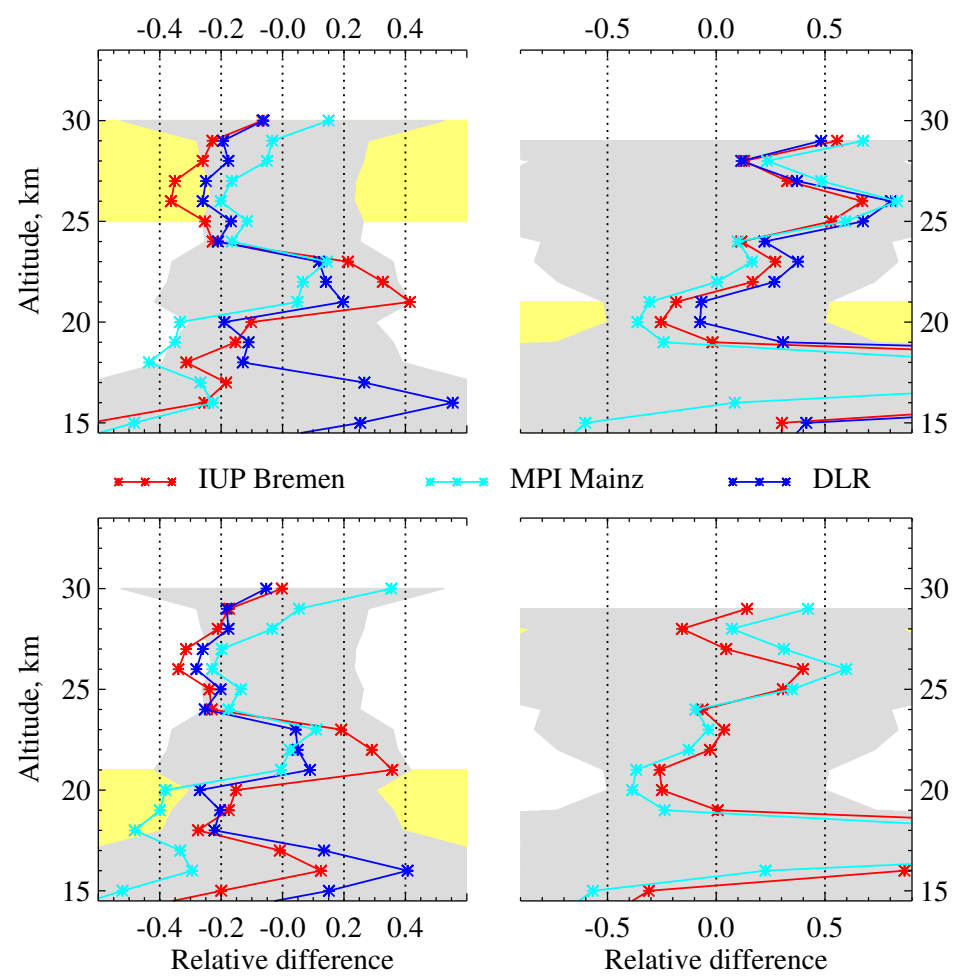

Fig. 28. Same as in Fig. 27 but for relative differences with respect to balloon-borne SAOZ results, e.g., IUP Bremen/SAOZ-1, etc.

in situ measurements is given as $35 \%$ or 3 pptv, whatever is higher.

In Figs. 29 and 30, BrO vertical distributions retrieved from SCIAMACHY limb observations with IUP Bremen, DLR, and MPI Mainz algorithms are compared to coinciding TRIPLE measurements. The comparisons are performed for the forward (lower panels) and backward (upper panels) matches for each of the three flights listed in Table 2. The results are presented in the same manner as discussed in Sect. 9.1 for balloon-borne DOAS measurements (see Figs. 21-24). For the Aire-sur-l'Adour flight on 24 September 2002, shown in the left panels, BrO profiles retrieved from SCIAMACHY limb and balloon-borne TRIPLE measurements are in reasonable agreement down to $23 \mathrm{~km}$. Below, a dip in the in situ measurement is obvious which however is consistent with parallel tracer measurements of $\mathrm{CH}_{4}, \mathrm{~N}_{2} \mathrm{O}, \mathrm{CCl}_{3} \mathrm{~F}$, and $\mathrm{CCl}_{2} \mathrm{~F}_{2}$ by the cryogenic whole air sampler BONBON (e.g. Engel et al., 1997) on the same payload. SCIAMACHY results are typically higher as compared to $\mathrm{BrO}$ concentrations detected by TRIPLE. For the Kiruna flight on 6 March 2003, shown in the middle panels, a similar result as for Aire-sur-l'Adour is obtained. Here, different SCIAMACHY retrievals agree within error bars in the entire altitude range showing, however, substantially higher $\mathrm{BrO}$ concentrations than those detected by TRIPLE. A quite different behavior is observed for the Kiruna flight on 9 June 2003, shown in the right panels. Here, the vertical profiles of BrO retrieved from SCIAMACHY limb and balloon-borne TRIPLE measurements are in a good agreement down to $22 \mathrm{~km}$. Below, the TRIPLE instrument detects higher BrO amounts than seen by SCIAMACHY. Different SCIAMACHY retrievals agree within error bars in the entire altitude range for both forward and backward matches.

\section{Conclusions}

In this study we present three different retrieval algorithms developed to gain vertical profiles of $\mathrm{BrO}$ from SCIAMACHY limb measurements. Two of the considered algorithms (IUP Bremen and MPI Mainz) are precision optimized scientific retrievals whereas the third one (DLR) is designed as a speed optimized operational processor. Discussing the theoretical basis of the retrievals we have shown that apparently completely different DOAS and global fit approaches are obtained from the same logarithmic formulation of the inverse problem using specific assumptions. This finding clarifies how concepts widely used in the DOAS community, e.g., $I_{0}$-corrected cross sections or tilt, can be implemented in the framework of the global fit technique.

Analyzing the sensitivity of SCIAMACHY limb BrO retrievals we have found that the best retrieval sensitivity is achieved between 16 and $26 \mathrm{~km}$ and a typical vertical 

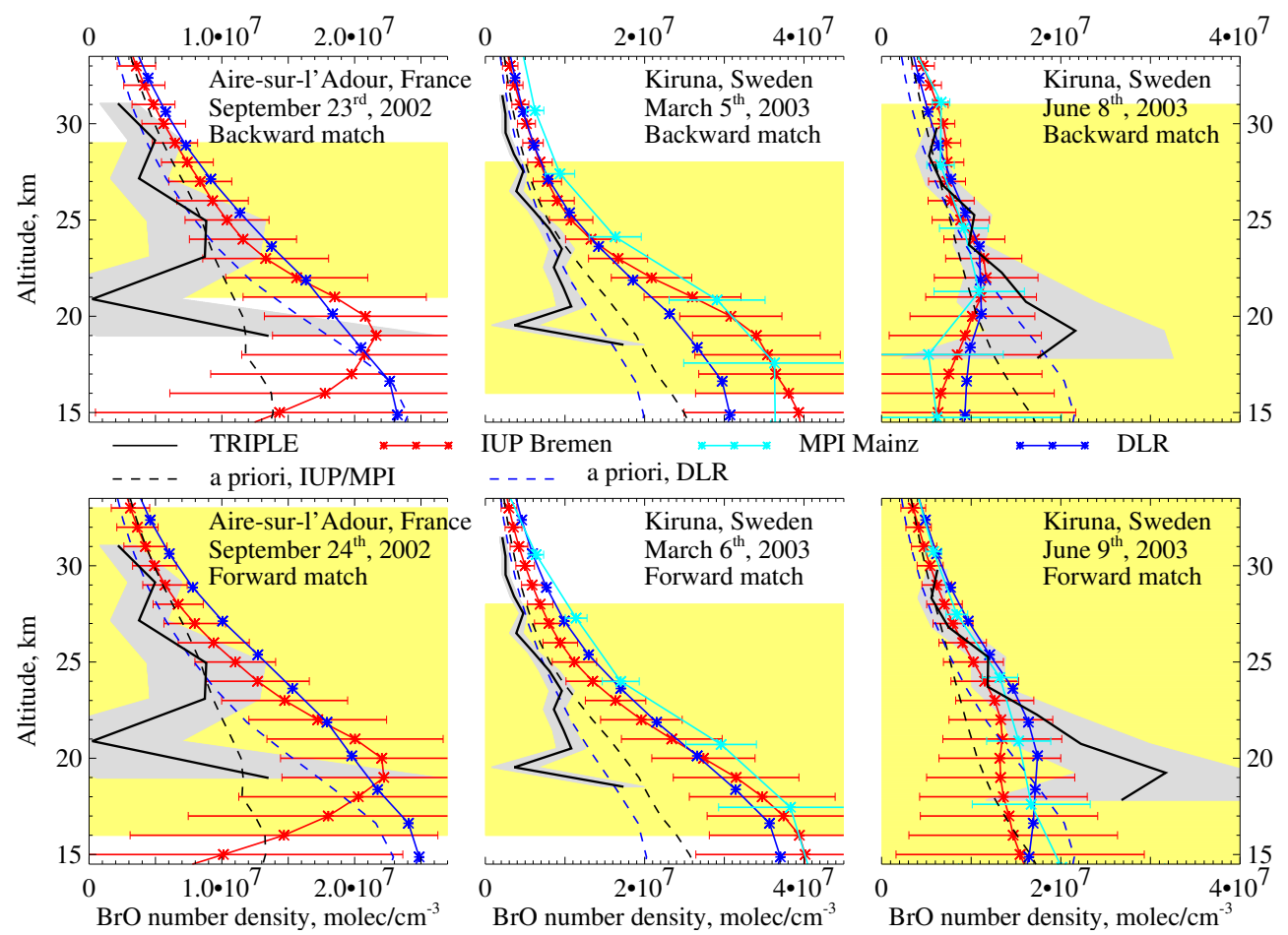

Fig. 29. Comparison of $\mathrm{BrO}$ vertical distributions retrieved from SCIAMACHY limb measurements using different retrieval algorithms to coinciding balloon-borne TRIPLE observations. Left panels: balloon launch in Aire-sur-l'Adour (mid-latitude) on 24 September 2002. Middle panels: balloon launch in Kiruna (high latitude) on 6 March 2003. Right panels: balloon launch in Kiruna on 9 June 2003. Gray shadings depict the statistical error of the TRIPLE results $(1-\sigma)$. The absolute error is on the order of $35 \%$ (see text). Yellow areas mark vertical ranges where according to trajectory model calculations both instruments probe the same air mass.
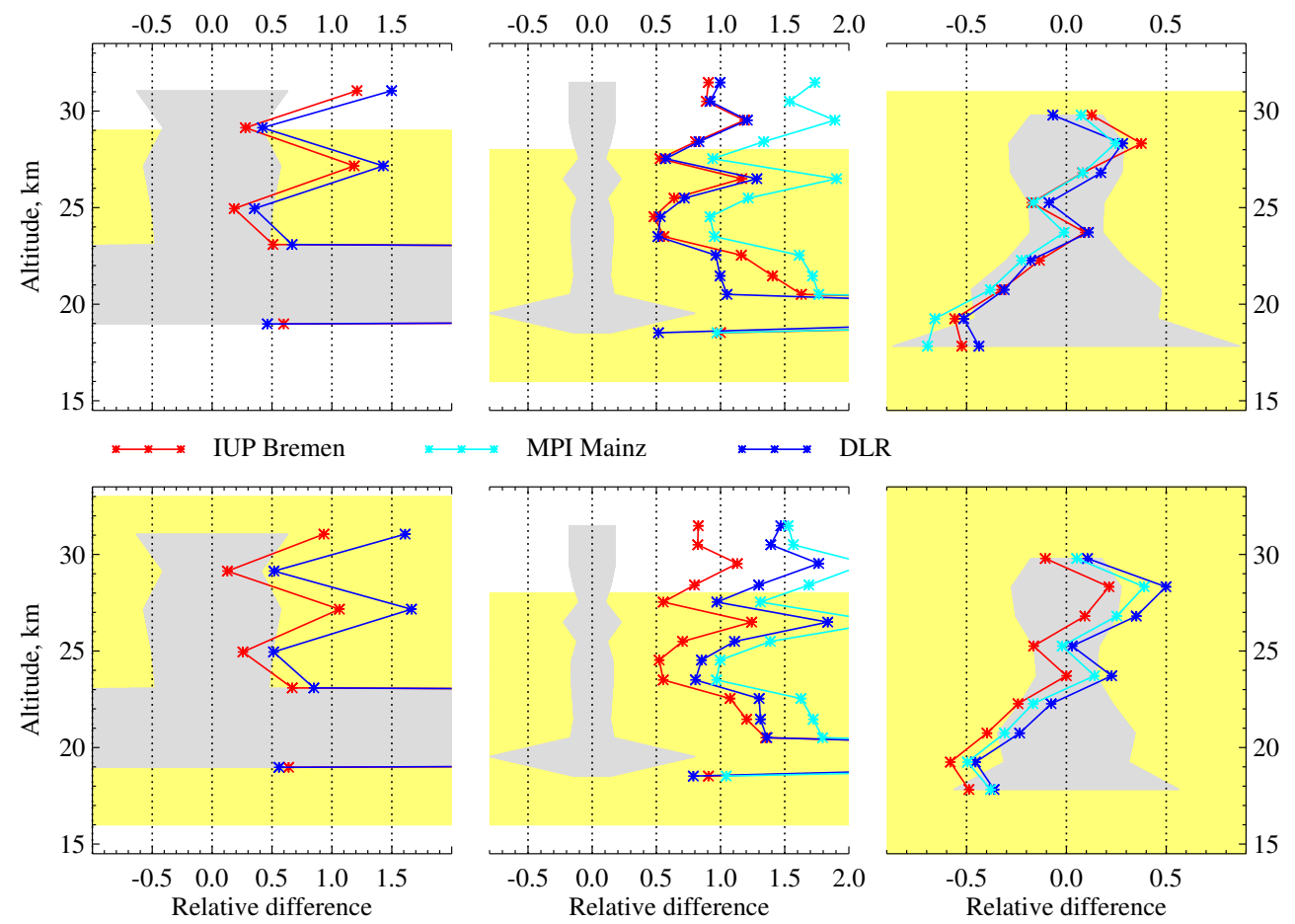

Fig. 30. Same as in Fig. 29 but for relative differences with respect to balloon-borne TRIPLE results, e.g., IUP Bremen/TRIPLE-1, etc. 
Table 3. Comparison summary.

\begin{tabular}{|c|c|c|c|c|c|}
\hline & \multirow[t]{2}{*}{ Flight } & \multicolumn{3}{|c|}{$\begin{array}{c}\text { Mean relative difference } \\
\text { for backward/forward match, } \%\end{array}$} & \multirow[t]{2}{*}{$\begin{array}{c}\text { Mean uncertainty of } \\
\text { balloon-borne results, \% }\end{array}$} \\
\hline & & IUP Bremen & MPI Mainz & DLR & \\
\hline \multirow[t]{6}{*}{ High latitudes } & DOAS, 23 March 2003 & $14 / 15$ & $21 / 24$ & $21 / 14$ & $13 / 13$ \\
\hline & DOAS, 24 March 2004 & $12 / 11$ & $24 / 27$ & $20 / 7$ & $19 / 20$ \\
\hline & DOAS, 7 September 2009 & $16 / 13$ & $17 / 15$ & $-1-$ & $28 / 27$ \\
\hline & SAOZ, 30 March 2003 & $15 / 8$ & $39 / 9$ & $23 / 25$ & $23 / 17$ \\
\hline & TRIPLE, 6 March 2003* & $76 / 78$ & $126 / 141$ & $76 / 115$ & $16 / 16$ \\
\hline & TRIPLE, 6 June 2003 & $27 / 25$ & $28 / 25$ & $24 / 26$ & $36 / 28$ \\
\hline \multirow[t]{3}{*}{ Mid-latitudes } & DOAS, 9 October 2003 & $8 / 13$ & $4 / 14$ & $22 / 16$ & $26 / 27$ \\
\hline & SAOZ, 1 October 2002 & $14 / 19$ & $18 / 15$ & $27 / 29$ & $19 / 19$ \\
\hline & TRIPLE, 24 September 2002* & $63 / 53$ & $-1-$ & $82 / 89$ & $52 / 49$ \\
\hline \multirow[t]{3}{*}{ Tropics } & DOAS, 17 June 2005 & $16 / 29$ & $20 / 27$ & $38 / 53$ & $28 / 49$ \\
\hline & SAOZ, 31 January 2004 & $25 / 18$ & $12 / 35$ & $19 / 21$ & $30 / 54$ \\
\hline & SAOZ, 5 February 2004 & $137 / 21$ & $68 / 35$ & $183 /-$ & $184 / 123$ \\
\hline
\end{tabular}

* For this flight only altitudes above $22 \mathrm{~km}$ are considered.

resolution of the retrieval ranges between about $3 \mathrm{~km}$ in the vicinity of measurement tangent point altitudes and $5 \mathrm{~km}$ at intermediate altitude levels. In the high sensitivity altitude range the retrieval results are found to be almost independent of the a priori information. Employing numerical simulations and synthetic retrievals we have investigated the influence of different implementations of radiative transfer modeling upon the retrieval results and found it to be negligible (among the considered models). Performing synthetic retrievals, influence of different $\mathrm{BrO}$ cross sections and their temperature dependence as well as of stratospheric aerosols is analyzed. Whereas the effect of the former two is found to be in the order of $10 \%$, improperly considered high volcanic aerosol loading may lead to significant errors (up to $60 \%$ ) in the retrieved $\mathrm{BrO}$ profiles.

Comparisons of $\mathrm{BrO}$ profiles retrieved from SCIAMACHY measurements using different algorithms demonstrate a reliability of SCIAMACHY retrievals. The results from different algorithms agree with each other within error bars nearly everywhere. In comparison to balloon-borne observations a very good agreement is obtained at high and mid-latitudes (balloon flights in Kiruna and Aire-surl'Adour) with both DOAS and SAOZ results. Comparisons to TRIPLE do not provide any consistent picture. While for two of three flights $\mathrm{BrO}$ amounts seen by SCIAMACHY are systematically higher than those detected by TRIPLE, a good agreement is observed down to $22 \mathrm{~km}$ for the third flight. Below this altitude an opposite behavior is seen with SCIAMACHY BrO concentrations lower than those from TRIPLE. For the tropical DOAS flight, $\mathrm{BrO}$ amounts retrieved from SCIAMACHY are systematically somewhat lower than those from balloon-borne DOAS. As only one tropical profile is available from the DOAS instrument, no general conclusions on the agreement quality can be made. Due to complicated meteorological and stratospheric conditions only an overall consistency can be stated for tropical SAOZ observations. Nevertheless, also in comparison to balloon-borne observations we conclude that the results are in agreement within error bars nearly everywhere. The comparison results are summarized in Table 3. The values represent percentage differences averaged over all matching altitudes (yellow areas in Figs. 21-30). Averaging is done for absolute values of the differences. The last column contains uncertainties for balloon-borne instruments averaged over all matching altitudes as above.

It is important to highlight that the usage of different $\mathrm{BrO}$ cross sections and different handling of their temperature dependence in both SCIAMACHY and DOAS/SAOZ retrievals implicates the following biases in the results. If the $\mathrm{BrO}$ cross section from Fleischmann et al. (2004) rather than that from Wahner et al. (1988) was used for the interpretation of the balloon-borne measurements, the DOAS results would be about $10 \%$ higher while the SAOZ results would remain nearly the same. If the temperature dependence of the $\mathrm{BrO}$ cross section was neglected, the IUP Bremen and DLR results would increase by about $10 \%$. The TRIPLE measurements are unaffected by the cross section issues. These biases are, however, below the overall uncertainty of the comparisons and do not affect the conclusions above.

In general, SCIAMACHY limb observations performed since August 2002 provide a unique data set for studying and monitoring the evolution of bromine content in the stratosphere which is needed in the framework of the Montreal Protocol. 


\section{Appendix A}

\section{Inverse problem at the spectroscopic retrieval stage of the standard DOAS technique}

The purpose of this section is to demonstrate how the fit equations used at the spectroscopic retrieval stage of the standard DOAS technique can be obtained from the logarithmic formulation of the inverse problem as given by Eq. (9) and which assumptions need to be done to obtain these.

As the retrievals employing the standard DOAS technique do not use the weighting functions in the spectral fitting procedure exploiting the absorption cross sections of atmospheric species instead, an appropriate modification of the inverse problem is required. This can be done employing the Beer-Lambert law under assumption that the absorption by atmospheric species of interest is weak:

$$
\begin{aligned}
\left\{\boldsymbol{F}_{j}(\boldsymbol{x})\right\}_{l} & =I_{j}\left(\lambda_{1}\right)=I_{\mathrm{e}}\left(\lambda_{1}\right) \exp \left(-\sum_{i=1}^{N_{i}}\left\{\mathbf{A}_{\mathbf{j}}\right\}_{l, i} H_{i}\right. \\
& \left.\times \sum_{k=1}^{N_{k}} \sigma_{k}\left(\lambda_{1}\right) n_{k, i}-\tau_{\text {other }}\left(\lambda_{1}\right)\right) .
\end{aligned}
$$

Here, $I_{j}\left(\lambda_{1}\right)$ and $I_{\mathrm{e}}\left(\lambda_{1}\right)$ represent the limb radiance at a tangent height $h_{j}$ and the extraterrestrial radiance, respectively, $\lambda_{1}$ is the wavelength, $\sigma_{k}\left(\lambda_{1}\right)$ are the absorption cross sections of atmospheric species included in the fitting procedure, $n_{k, i}$ are the corresponding concentrations in the $i$-th altitude layer $\left(n_{k, i}=\{\boldsymbol{x}\}_{N(k-1)+i}\right),\left\{\mathbf{A}_{j}\right\}_{l, i}$ is the effective light path enhancement in the $i$-th altitude layer at wavelength $\lambda_{1}$ which is also referred to as the box air mass factor, $H_{i}$ is the geometrical thickness of the $i$-th altitude layer, and $\tau_{\text {other }}\left(\lambda_{1}\right)$ is the total optical depth of atmospheric parameters exhibiting only broad-band spectral signatures (e.g., Rayleigh scattering, aerosol extinction). In the framework of the standard DOAS technique, atmospheric parameters contributing to $\tau_{\text {other }}$ are not included in the fitting procedure. Instead, this term is approximated by a low order polynomial, $P_{\lambda}$.

Using the Beer-Lambert law given by Eq. (A1) and taking into account Eq. (3), the elements of the weighting function matrix can be obtained as follows:

$$
\begin{aligned}
\left\{\mathbf{K}_{j}\right\}_{l, N_{i}(k-1)+i} & =\left.\frac{\partial\left\{\boldsymbol{F}_{j}(\boldsymbol{x})\right\}_{l}}{\partial\{\boldsymbol{x}\}_{N_{i}(k-1)+i}}\right|_{\boldsymbol{x}=\boldsymbol{x}_{\mathrm{a}}} \\
& =\left\{\mathbf{A}_{j}\right\}_{l, i} H_{i} \sigma_{k}\left(\lambda_{1}\right)\left\{\mathbf{F}_{\mathbf{j}}\left(\boldsymbol{x}_{\mathrm{a}}\right)\right\}_{l} .
\end{aligned}
$$

Here, curly brackets are used to denote elements of vectors or matrices. Employing Eq. (A2), taking into account Eq. (7), and introducing notations $\hat{\boldsymbol{x}} \equiv \boldsymbol{x}-\boldsymbol{x}_{\mathrm{a}}$ and $\hat{\mathbf{A}}_{j} \equiv \mathbf{A}_{j}-\mathbf{A}_{\text {ref }}$, the second term on the right hand side of Eq. (9) can be rewritten as

$$
\left\{\hat{\mathbf{K}}_{j} \hat{\boldsymbol{x}}\right\}_{l}=\sum_{k=1}^{N_{k}} \sum_{i=1}^{N_{i}}\left\{\hat{\mathbf{A}}_{\mathbf{j}}\right\}_{l, i} H_{i} \sigma_{k}\left(\lambda_{1}\right)\{\hat{\boldsymbol{x}}\}_{N_{i}(k-1)+i}
$$

Assuming the trace gas cross sections $\sigma_{k}(\lambda)$ do not change with the altitude, i.e., using for each species a representative cross section at a fixed pressure and temperature, the absorption cross sections can be taken out of the second summation in Eq. (A3). Assuming further the box air mass factors $\hat{\mathbf{A}}_{j}$ to be independent of the wavelength, Eq. (A3) can be rewritten as follows:

$$
\begin{aligned}
\left\{\hat{\mathbf{K}}_{j} \hat{\boldsymbol{x}}\right\}_{l} & =\sum_{k=1}^{N_{k}} \sigma_{k}\left(\lambda_{1}\right) \sum_{i=1}^{N_{i}}\left\{\hat{\mathbf{A}}_{\mathbf{j}}\right\}_{i} H_{i}\{\hat{\boldsymbol{x}}\}_{N_{i}(k-1)+i} \\
& =\left\{\mathbf{S}^{\sigma} \boldsymbol{c}\right\}_{l}-\left\{\mathbf{S}^{\sigma} \boldsymbol{c}_{\mathrm{a}}\right\}_{l},
\end{aligned}
$$

where $\mathbf{S}^{\sigma}$ is a matrix containing the absorption cross sections of all atmospheric species included in the fit,

$$
\left\{\mathbf{S}^{\sigma}\right\}_{l, k}=\sigma_{k}\left(\lambda_{1}\right),
$$

and vector $\boldsymbol{c}$ contains so-called slant columns for each retrieved species:

$\{\boldsymbol{c}\}_{k}=\sum_{i=1}^{N_{i}}\left\{\hat{\mathbf{A}}_{j}\right\}_{i} H_{i}\{\boldsymbol{x}\}_{N_{i}(k-1)+i}$.

Under these assumptions, the logarithm of the normalized radiance can be represented as a sum of the absorption cross sections of the atmospheric species weighted by the corresponding slant columns:

$$
\left\{\hat{\boldsymbol{F}}_{\boldsymbol{j}}(\boldsymbol{x})\right\}_{l}=\ln \frac{I_{j}\left(\lambda_{1}\right)}{I_{\mathrm{ref}}\left(\lambda_{1}\right)}=\sum_{k=1}^{N_{k}}\{\boldsymbol{c}\}_{k} \sigma_{k}\left(\lambda_{1}\right)-P_{\lambda} .
$$

Substituting then Eq. (A4) into the logarithmic representation of the inverse problem as given by Eq. (9) and taking into account that, according to Eq. (A7),

$\hat{\boldsymbol{F}}_{\boldsymbol{j}}\left(\boldsymbol{x}_{\mathrm{a}}\right)=\mathbf{S}^{\sigma} \boldsymbol{c}_{\mathrm{a}}-P_{\lambda}$,

the modified inverse problem is formulated as follows:

$\hat{\boldsymbol{y}}_{j}=\mathbf{S}^{\sigma} \boldsymbol{c}+\mathbf{W}_{j}^{\mathrm{sc}} \boldsymbol{s}+P_{\lambda}$

Here, the fitting parameter vectors $\boldsymbol{c}$ and $s$ are obtained applying the least square fit technique.

The formulation of the inverse problem given by Eq. (A9) yields the main fitting equation used at the spectroscopic retrieval stage of the standard DOAS technique. The equation is obtained from the logarithmic representation of the general inverse problem, as given by Eq. (9), assuming (i) absorption by atmospheric species to be weak, (ii) absorption cross sections of atmospheric species to be independent of the altitude, (iii) box air mass factors and slant columns to be independent of the wavelength, and (iv) all broad-band spectral features to be approximated by a polynomial. 


\section{Appendix B}

\section{Accounting for the $I_{0}$ effect in the framework of the standard DOAS and global fit techniques}

An expression allowing the $I_{0}$ effect to be accounted for in the fit procedure can be derived using the similar formulation as for Eq. (16) but considering both scattering and absorption processes when calculating the radiance:

$R_{i}=\ln \frac{\mathbf{L}\left\{I^{\mathrm{hr}}\left(\lambda, h_{i}\right)\right\}}{\mathbf{L}\left\{I^{\mathrm{hr}}\left(\lambda, h_{\mathrm{ref}}\right)\right\}}-\ln \frac{I^{\operatorname{lr}}\left(\lambda, h_{i}\right)}{I^{\operatorname{lr}}\left(\lambda, h_{\mathrm{ref}}\right)}$.

Here, the total correction, $R_{i}$, comprises both $I_{0}$ and tilt effects. Expressing the limb radiance as a product of the extraterrestrial and atmospheric parts, $I\left(\lambda, h_{i}\right)=I_{\mathrm{e}}(\lambda) I_{\mathrm{a}}\left(\lambda, h_{i}\right)$, and employing the functional Taylor series expansion with respect to the absorber concentrations around the zero absorption, the limb radiance can be rewritten as

$I\left(\lambda, h_{i}\right)=I_{\mathrm{e}}(\lambda)\left[I_{\mathrm{sc}}\left(\lambda, h_{i}\right)+J\left(\lambda, h_{i}\right)\right]$,

where $I_{\mathrm{sc}}\left(\lambda, h_{i}\right)$ describes the contribution of the scattering processes only and

$$
J(\lambda, h)=\left.\int_{\text {BOA }}^{\text {TOA }} \frac{\delta I_{\mathrm{a}}\left(\lambda, h_{i}\right)}{\delta n(z)} d z\right|_{n(z)=0} n(z) d z
$$

represents the absorption term. Here, for the sake of simplicity, only one absorbing atmospheric species with a concentration profile $n(z)$ is accounted for. The absorption is assumed to be weak.

Substituting Eq. (B2) into Eq. (B1) and expending the logarithms in Taylor series with respect to the absorption term one obtains:

$$
\begin{aligned}
R_{i} & \approx \ln \frac{\mathbf{L}\left\{I_{\mathrm{e}}^{\mathrm{hr}}\left(\lambda, h_{i}\right) I_{\mathrm{sc}}^{\mathrm{hr}}\left(\lambda, h_{i}\right)\right\}}{\mathbf{L}\left\{I_{\mathrm{e}}^{\mathrm{hr}}\left(\lambda, h_{\mathrm{ref}}\right) I_{\mathrm{sc}}^{\mathrm{hr}}\left(\lambda, h_{\mathrm{ref}}\right)\right\}} \\
& +\frac{\mathbf{L}\left\{I_{\mathrm{e}}^{\mathrm{hr}}(\lambda) J^{\mathrm{hr}}\left(\lambda, h_{i}\right)\right\}}{\mathbf{L}\left\{I_{\mathrm{e}}^{\mathrm{hr}}(\lambda) I_{\mathrm{sc}}^{\mathrm{hr}}\left(\lambda, h_{i}\right)\right\}}-\frac{\mathbf{L}\left\{I_{\mathrm{e}}^{\mathrm{hr}}(\lambda) J^{\mathrm{hr}}\left(\lambda, h_{\mathrm{ref}}\right)\right\}}{\mathbf{L}\left\{I_{\mathrm{e}}^{\mathrm{hr}}(\lambda) I_{\mathrm{sc}}^{\mathrm{hr}}\left(\lambda, h_{\mathrm{ref}}\right)\right\}} \\
& -\ln \frac{I_{\mathrm{sc}}^{\mathrm{lr}}\left(\lambda, h_{i}\right)}{I_{\mathrm{sc}}^{\mathrm{lr}}\left(\lambda, h_{\mathrm{ref}}\right)}-\frac{J^{\mathrm{lr}}\left(\lambda, h_{i}\right)}{I_{\mathrm{sc}}^{\mathrm{lr}}\left(\lambda, h_{i}\right)}+\frac{J^{\mathrm{lr}}\left(\lambda, h_{\mathrm{ref}}\right)}{I_{\mathrm{sc}}^{\mathrm{lr}}\left(\lambda, h_{\mathrm{ref}}\right)},
\end{aligned}
$$

Clearly, the difference of the logarithmic terms on the righthand side of Eq. (B4) is equal to the tilt correction as defined by Eq. (16). As the sun-normalized limb radiance in a nonabsorbing atmosphere, $I_{\mathrm{sc}}(\lambda, h)$, has only a smooth spectral dependence, in the second and third terms in Eq. (B4) it can be moved from the integral operator in the denominator to the integral operator in the numerator without introducing a significant error. Thus, Eq. (B4) can be rewritten as

$$
\begin{aligned}
R_{i} & \approx t_{i}-\left[\tilde{J}^{\mathrm{lr}}\left(\lambda, h_{i}\right)-\tilde{J}^{\mathrm{lr}}\left(\lambda, h_{\mathrm{ref}}\right)\right] \\
& +\frac{\mathbf{L}\left\{I_{\mathrm{e}}^{\mathrm{hr}}(\lambda)\left[\tilde{J}^{\mathrm{hr}}\left(\lambda, h_{i}\right)-\tilde{J}^{\mathrm{hr}}\left(\lambda, h_{\mathrm{ref}}\right)\right]\right\}}{\mathbf{L}\left\{I_{\mathrm{e}}^{\mathrm{hr}}(\lambda)\right\}},
\end{aligned}
$$

where $\tilde{J}(\lambda, h) \equiv \frac{J(\lambda, h)}{I_{\mathrm{sc}}(\lambda, h)}$.

Employing the Beer-Lambert law (see Appendix A for details), the atmospheric part of the radiance can be written as

$I_{\mathrm{a}}(\lambda, h)=I_{\mathrm{sc}}(\lambda, h) \exp \left[-\int \sigma(\lambda, s) n(s) d s\right]$,

where $\sigma(\lambda, s)$ is the cross section of the absorbing atmospheric species and the integration is performed along the light path. For a weak absorption, Eq. (B6) can be rewritten as

$$
I_{\mathrm{a}}(\lambda, h)=I_{\mathrm{sc}}(\lambda, h)\left[1-\int \sigma(\lambda, z) n(z) \frac{\partial s}{\partial z} d z\right] .
$$

This equation can be used then to calculate the variational derivative in Eq. (B3) leading to

$\tilde{J}\left(\lambda, h_{i}\right)=\int_{\text {BOA }}^{\text {TOA }} \sigma(\lambda, z) \frac{\partial s}{\partial z} n(z) d z=\sigma(\lambda) c_{i}$,

where the absorption cross section $\sigma(\lambda)$ is assumed to be independent of the altitude and the slant column is defined as

$c_{i} \equiv \int_{\text {BOA }}^{\text {TOA }} \frac{\partial s}{\partial z} n(z) d z$.

Employing Eq. (B8) the total correction, $R_{i}$, as given by Eq. (B5) can be represented as

$$
R_{i} \approx t_{i}+\left(c_{i}-c_{\mathrm{ref}}\right)\left[\frac{\mathbf{L}\left\{I_{\mathrm{e}}^{\mathrm{hr}}(\lambda) \sigma^{\mathrm{hr}}(\lambda)\right\}}{\mathbf{L}\left\{I_{\mathrm{e}}^{\mathrm{hr}}(\lambda)\right\}}-\sigma^{\operatorname{lr}}(\lambda)\right] .
$$

The second term on the right-hand side of this equation is referred to as the $I_{0}$-correction. In the framework of the standard DOAS technique this correction is accounted for replacing in the spectral fit procedure the pre-convolved cross section, $\sigma^{\operatorname{lr}}(\lambda)$, by the so-called $I_{0}$-corrected cross section:

$\hat{\sigma}(\lambda)=\frac{\mathbf{L}\left\{\mathrm{I}_{\mathrm{e}}^{\mathrm{hr}}(\lambda) \sigma^{\mathrm{hr}}(\lambda)\right\}}{\mathbf{L}\left\{I_{\mathrm{e}}^{\mathrm{hr}}(\lambda)\right\}}$.

In the framework of the global fit method, the $I_{0}$-correction is commonly calculated as a difference of the total correction, $R_{i}$, and the tilt spectrum, $t_{i}$. 


\section{Appendix C}

\section{Inverse problem at the pre-processing stage of the global fit approach}

The purpose of this section is to demonstrate how the fit equations used at the pre-processing stage of the global fit approach can be obtained from the logarithmic formulation of the inverse problem as given by Eq. (9) and which assumptions are needed to obtain these.

As mentioned in Sect. 3.4.2, at the pre-processing step of the global fit approach the spectral fit is performed for each tangent height independently. However, a limb observation at a single tangent height does not contain enough information to retrieve vertical profiles. Therefore, the second term in the right-hand side of Eq. (9) containing the weighting functions of atmospheric species needs to be simplified. To this end let us first write an explicit equation for the $l$ th component (i.e., the value at the wavelength $\lambda_{1}$ ) of vector $\hat{\mathbf{K}}_{j}\left(\boldsymbol{x}-\boldsymbol{x}_{\mathrm{a}}\right)$ taking into account that the state vector usually contains number densities of atmospheric species at discrete altitude levels:

$$
\begin{aligned}
\mathcal{K}_{l} & \equiv\left\{\hat{\mathbf{K}}_{j}\left(\boldsymbol{x}-\boldsymbol{x}_{\mathrm{a}}\right)\right\}_{l} \\
& =\sum_{k=1}^{N_{k}} \sum_{i=1}^{N_{i}}\left\{\hat{\mathbf{K}}_{j}\right\}_{l, N_{i}(k-1)+i}\left\{\boldsymbol{x}-\boldsymbol{x}_{\mathrm{a}}\right\}_{N_{i}(k-1)+i} .
\end{aligned}
$$

Here, curly brackets are used to denote elements of vectors or matrices, $N_{k}$ is the total number of atmospheric species included in the fit, and $N_{i}$ is the number of the discrete altitude layers. This expression can be simplified assuming relative variations of trace gas number densities to be the same at all altitude layers, i.e., the retrieved vertical profile for each atmospheric species of interest is assumed to be obtained by scaling its a priori profile:

$$
\begin{gathered}
\{\boldsymbol{x}\}_{N_{i}(k-1)+i}=\{\hat{\boldsymbol{p}}\}_{k}\left\{\boldsymbol{x}_{\mathrm{a}}\right\}_{N_{i}(k-1)+i}, \\
i=1, \ldots, N_{i}, \quad k=1, \ldots, N_{k} .
\end{gathered}
$$

Here, $\hat{\boldsymbol{p}}$ is a vector containing the scaling factors for the vertical profiles of the retrieved atmospheric species (one scaling factor per species), i.e., the vector consists of only $N_{k}$ elements. Substituting Eq. (C2) into the right-hand side of Eq. (C1) the following relationship is obtained:

$$
\begin{aligned}
\mathcal{K}_{l} & =\sum_{k=1}^{N_{k}}\{\hat{\boldsymbol{p}}-\mathbf{1}\}_{k} \sum_{i=1}^{N_{i}}\left\{\hat{\mathbf{K}}_{j}\right\}_{l, N_{i}(k-1)+i}\left\{\boldsymbol{x}_{\mathrm{a}}\right\}_{N_{i}(k-1)+i} \\
& \equiv \sum_{k=1}^{N_{k}}\left\{\mathbf{W}_{j}^{\mathrm{par}}\right\}_{k, l}\{\boldsymbol{p}\}_{k},
\end{aligned}
$$

where $\mathbf{1}$ is a unity vector with $N_{k}$ elements, $\boldsymbol{p}=\hat{\boldsymbol{p}}-\mathbf{1}$, and $\mathbf{W}_{j}^{\mathrm{par}}$ is a matrix containing vertically integrated logarithmic weighting functions corresponding to relative variations of the atmospheric parameters:

$\left\{\mathbf{W}_{j}^{\mathrm{par}}\right\}_{k, l}=\sum_{i=1}^{N_{i}}\left\{\hat{\mathbf{K}}_{j}\right\}_{l, N_{i}(k-1)+i}\left\{\boldsymbol{x}_{\mathrm{a}}\right\}_{N_{i}(k-1)+i}$.

Commonly, an error due to unknown atmospheric parameters which cannot be retrieved from the measurement (see the last term in Eq. 4), e.g., aerosols or surface albedo, is characterized by a broad-band spectral signature. Thus, a bulk of this error as well as all broad band instrumental features can be eliminated when considering only the differential spectral signals, i.e., the spectral structures highly varying with the wavelength. Approximating all broad-band spectral structures by a polynomial and taking into account Eq. (C3) the inverse problem given by Eq. (9) is rewritten as

$\hat{\boldsymbol{y}}_{j}=\hat{\boldsymbol{F}}_{\boldsymbol{j}}\left(\boldsymbol{x}_{\mathrm{a}}\right)+\mathbf{W}_{j}^{\mathrm{par}} \boldsymbol{p}+\mathbf{W}_{j}^{\mathrm{sc}} \boldsymbol{s}+P_{\lambda}$,

where vectors $\boldsymbol{p}$ and $\boldsymbol{s}$ contain fitting parameters obtained applying the least square fit technique.

The formulation of the inverse problem given by Eq. (C5) yields the main fitting equation used at the pre-processing stage of the global fit approach. This equation is obtained from the logarithmic representation of the general inverse problem, as given by Eq. (9), assuming (i) vertical profiles of all considered atmospheric species to be obtained by scaling corresponding a priori profiles and (ii) all broad-band spectral features to be approximated by a polynomial.

Acknowledgements. This work has been funded in parts by the German Ministry of Education and Research (BMBF) through the German Aerospace Center (DLR) within the SADOS project (20EE0027), EU project SHIVA (226224-FP7-ENV-2008-1), the University and the Land Bremen. We are thankful to ECMWF for providing pressure and temperature information (ECMWF Special Project SPDECDIO). The DOAS balloon experiments were supported by the Germany Ministry of Economics and Technology (BMWi) project ENVIVAL-LIFE (50EE0840), the German research foundation (DFG - Pf 384/5-1), the European Union through the Framework Programm 6 project SCOUT-O3 (505390-GOCE-CT-2004), the European Space Agency (ESA) (RFQ/3-12092/07/I-OL), and the French Strapolété project, which was funded by the French "Agence Nationale de la Recherche" (ANR-BLAN08-1_31627), the "Centre National d'Etudes Spatiales" (CNES), and the "Institut Polaire PaulEmile Victor" (IPEV). The ETHER database (Pôle thématique CNES-INSU-CNRS) and the "CNES sous-direction Ballon" are partners of the Strapolété project. Furthermore, we thank the CNES balloon launching team for successful operations and the Swedish Space Corporation at Esrange. The SAOZ flights were operated by the CNES, Esrange and IPMET/UNESP teams, who are gratefully acknowledged. The experiments were supported by the French Programme National de Chimie Atmospherique (CNRS-PNCA/LEFE), the EU EVK2-CT-2001-00111 (HIBISCUS) and the European Space Agency through the ESABC project. The ground-based $\mathrm{BrO}$ retrievals at the Belgian Institute for Space Aeronomy (BIRA-IASB) are funded by the PRODEX contract 
SECPEA and the EC projects GEOmon (FP6-2005-Global-4036677) and SHIVA (226224-FP7-ENV-2008-1); BIRA-IASB thanks M. P. Chipperfield for providing SLIMCAT output used in their retrieval.

Edited by: E. Kyrölä

\section{References}

Aliwell, S. R., Van Roozendael, M., Johnston, P. V., Richter, A., Wagner, T., Arlander, D. W., Burrows, J. P., Fish, D. J., Jones, R. L., Tørnkvist, K. K., Lambert, J.-C., Pfeilsticker, K., and Pundt, I.: Analysis for $\mathrm{BrO}$ in zenith-sky spectra: An intercomparison exercise for analysis improvement, J. Geophys. Res., 107, 4199, doi:10.1029/2001JD000329, 2002.

Backus, G. E. and Gilbert, F. E.: Uniqueness in the inversion of inaccurate gross Earth data, Philos. T. Roy. Soc. Lond. A, 266, 123-192, 1970.

Bogumil, K., Orphal, J., Homann, T., Voigt, S., Spietz, P., Fleischmann, O. C., Vogel, A., Hartmann, M., Bovensmann, H., Frerik, J., and Burrows, J. P.: Measurements of molecular absorption spectra with the SCIAMACHY pre-flight model: instrument characterization and reference data for atmospheric remote sensing in the 230-2380 $\mathrm{nm}$ region, J. Photoch. Photobio. A, 157, 167-184, doi:10.1016/S0010-4655(02)00555-6, 2003.

Bourassa, A. E., Degenstein, D. A., Gattinger, R. L., and Llewellyn, E. J.: Stratospheric aerosol retrieval with optical spectrograph and infrared imaging system limb scatter measurements, J. Geophys. Res., 112, D10217, doi:10.1029/2006JD008079, 2007.

Bovensmann, H., Burrows, J. P., Buchwitz, M., Frerick, J., Noël, S., Rozanov, V. V., Chance, K. V., and Goede, A. P. H.: SCIAMACHY: Mission objectives and measurement modes, J. Atmos. Sci., 56, 127-149, 1999.

Bracher, A., Sinnhuber, M., Rozanov, A., and Burrows, J. P.: Using a photochemical model for the validation of $\mathrm{NO}_{2}$ satellite measurements at different solar zenith angles, Atmos. Chem. Phys., 5, 393-408, doi:10.5194/acp-5-393-2005, 2005.

Brune, W. H., Anderson, J. G., and Chan, K. R.: In situ observations of BrO over Antarctica: ER-2 Aircraft results from $54^{\circ} \mathrm{S}$ to $72^{\circ} \mathrm{S}$ latitude, J. Geophys. Res., 94, 16639-16647, 1989.

Burrows, J. P., Hölzle, E., Goede, A. P. H., Visser, H., and Fricke, W.: SCIAMACHY - Scanning Imaging Absorption Spectrometer for Atmospheric Chartography, Acta Astronaut., 35, 445451, 1995.

Butz, A., Bösch, H., Camy-Peyret, C., Chipperfield, M., Dorf, M., Dufour, G., Grunow, K., Jeseck, P., Kühl, S., Payan, S., Pepin, I., Pukite, J., Rozanov, A., von Savigny, C., Sioris, C., Wagner, T., Weidner, F., and Pfeilsticker, K.: Inter-comparison of stratospheric $\mathrm{O}_{3}$ and $\mathrm{NO}_{2}$ abundances retrieved from balloon borne direct sun observations and Envisat/SCIAMACHY limb measurements, Atmos. Chem. Phys., 6, 1293-1314, doi:10.5194/acp-61293-2006, 2006.

Chance, K. and Spurr, R. J. D.: Ring effect studies: Rayleigh scattering, including molecular parameters for rotational Raman scattering and the Fraunhofer spectrum, Appl. Optics, 36, 52245230, 1997.

Clarke, D. and Basurah, H. M.: Polarisation measurements of the Ring effect in the daytime sky, Planet. Space Sci., 37, 627-630, 1989.
Deutschmann, T., Beirle, S., Frieß, U., Grzegorski, M., Kern, C., Kritten, L., Platt, U., Puksīte, J., Wagner, T., Werner, B., and Pfeilsticker, K.: The Monte Carlo Atmospheric Radiative Transfer Model McArtim: Introduction and Validation of Jacobians and 3D Features, J. Quant. Spectrosc. Ra., 112(6), 1119-1137, 2011.

Doicu, A. and Trautmann, T.: Discrete-ordinate method with matrix exponential for a pseudo-spherical atmosphere: Scalar case, J. Quant. Spectrosc. Ra., 110, 146-158, doi:10.1016/j.jqsrt.2008.09.014, 2009.

Doicu, A., Schreier, F., and Hess, M.: Iteratively regularized GaussNewton method for atmospheric remote sensing, Comput. Phys. Commun., 148, 214-226, doi:10.1016/S0010-4655(02)00555-6, 2002.

Doicu, A., Hilgers, S., von Bargen, A., Rozanov, A., Eichmann, K.-U., von Savigny, C., and Burrows, J.: Information operator approach and iterative regularization methods for atmospheric remote sensing, J. Quant. Spectrosc. Ra., 103, 340-350, doi:10.1016/j.jqsrt.2006.05.002, 2007.

Dorf, M., Bösch, H., Butz, A., Camy-Peyret, C., Chipperfield, M. P., Engel, A., Goutail, F., Grunow, K., Hendrick, F., Hrechanyy, S., Naujokat, B., Pommereau, J.-P., Van Roozendael, M., Sioris, C., Stroh, F., Weidner, F., and Pfeilsticker, K.: Balloonborne stratospheric $\mathrm{BrO}$ measurements: comparison with Envisat/SCIAMACHY BrO limb profiles, Atmos. Chem. Phys., 6, 2483-2501, doi:10.5194/acp-6-2483-2006, 2006.

Dorf, M., Butz, A., Camy-Peyret, C., Chipperfield, M. P., Kritten, L., and Pfeilsticker, K.: Bromine in the tropical troposphere and stratosphere as derived from balloon-borne $\mathrm{BrO}$ observations, Atmos. Chem. Phys., 8, 7265-7271, doi:10.5194/acp-8-72652008, 2008.

Engel, A., Schmidt, U., and Stachnik, R. A.: Partitioning between chlorine reservoir species deduced from observations in the Arctic winter stratosphere, J. Atmos. Chem., 27, 107-126, 1997.

Ernst, F., von Savigny, C., Rozanov, A., Rozanov, V., Bovensmann, H., and Burrows, J. P.: Retrieval of stratospheric aerosol distributions from SCIAMACHY limb measurements: first steps and methodology, Proceedings Atmospheric Science Conference, Barcelona, Spain, 7-11 September 2009, ESA Special Publication SP-676, 2009.

Ferlemann, F., Camy-Peyret, C., Fitzenberger, R., Harder, H., Hawat, T., Osterkamp, H., Perner, D., Platt, U., Schneider, M., Vradelis, P., and Pfeilsticker, K.: Stratospheric BrO Profiles Measured at Different Latitudes and Seasons: Instrument Description, Spectral and Profile Retrieval, Geophys. Res. Lett., 25, 3847-3850, 1998.

Ferlemann, F., Bauer, N., Fitzenberger, R., Harder, H., Osterkamp, H., Perner, D., Platt, U., Schneider, M., Vradelis, P., and Pfeilsticker, K.: Differential Optical Absorption Spectroscopy Instrument for stratospheric balloon-borne trace gas studies, Appl. Optics, 39, 2377-2386, 2000.

Fleischmann, O. C., Hartmann, M., Burrows, J. P., and Orphal, J.: New ultraviolet absorption cross-sections of $\mathrm{BrO}$ at atmospheric temperatures measured by time-windowing Fourier transform spectroscopy, J. Photoch. Photobio. A, 168, 117-132, 2004.

Flittner, D. E., Bhartia, P. K., and Herman, B. M.: $\mathrm{O}_{3}$ profiles retrieved from limb scatter measurements: Theory, Geophys. Res. Lett., 27, 2601-2604, doi:10.1029/1999GL011343, 2000. 
Fussen, D. and Bingen, C.: A volcanism dependent model for the extinction profile of stratospheric aerosols in the UV-visible range, Geophys. Res. Lett., 26, 703-706, 1999.

Grainger, J. F. and Ring, J.: Anomalous Fraunhofer Line Profiles, Nature, 193, 762, 1962.

Greenblatt, G. D., Orlando, J. J., Burkholder, J. B., and Ravishankara, A. R.: Absorption measurements of oxygen between 330 and 1140 nm, J. Geophys. Res., 95, 18577-18582, 1990.

Haley, C. S., Brohede, S. M., Sioris, C. E., Griffioen, E., Murtagh, D. P., McDade, I. C., Eriksson, P., Llewellyn, E. J., Bazureau, A., and Goutail, F.: Retrieval of stratospheric $\mathrm{O}_{3}$ and $\mathrm{NO}_{2}$ profiles from Odin Optical Spectrograph and Infrared Imager System (OSIRIS) limb-scattered sunlight measurements, J. Geophys. Res, 109, D16303, doi:10.1029/2004JD004588, 2004.

Harder, H., Camy-Peyret, C., Ferlemann, F., Fitzenberger, R., Hawat, T., Osterkamp, H., Perner, D., Platt, U., Schneider, M., Vradelis, P., and Pfeilsticker, K.: Stratospheric BrO Profiles Measured at Different Latitudes and Seasons: Atmospheric Observations, Geophys. Res. Lett., 25, 3843-3846, 1998.

Harder, H., Bösch, H., Camy-Peyret, C., Chipperfield, M., Fitzenberger, R., Payan, S., Perner, D., Platt, U., Sinnhuber, B., and Pfeilsticker, K.: Comparison of measured and modeled stratospheric BrO: Implications for the total amount of stratospheric bromine, Geophys. Res. Lett., 27, 3695-3698, 2000.

Hendrick, F., Rozanov, A., Johnston, P. V., Bovensmann, H., De Mazière, M., Fayt, C., Hermans, C., Kreher, K., Lotz, W., Sinnhuber, B.-M., Theys, N., Thomas, A., Burrows, J. P., and Van Roozendael, M.: Multi-year comparison of stratospheric $\mathrm{BrO}$ vertical profiles retrieved from SCIAMACHY limb and ground-based UV-visible measurements, Atmos. Meas. Tech., 2, 273-285, doi:10.5194/amt-2-273-2009, 2009.

Hoogen, R., Rozanov, V. V., and Burrows, J. P.: Ozone profiles from GOME satellite data: Algorithm description and first validation, J. Geophys. Res., 104, 8263-8280, doi:10.1029/1998JD100093, 1999.

Joiner, J., Barthia, P. K., Cebula, R. P., Hilsenrath, E., McPeters, R. D., and Park, H.: Rotational Raman scattering (Ring effect) in satellite backscatter ultraviolet measurements, Appl. Optics, 32, 4513-4525, 1995.

Kasai, Y., Takahashi, C., Tsujimaru, S., Ochiai, S., Buehler, S., Takahashi, K., Shirai, T., Ozeki, H., and Shiotani, M.: JEM/SMILES limb-sounding of stratospheric trace species II: simulation results for JEM/SMILES observations, Proc. SPIE, 4152, 263-273, doi:10.1117/12.410606, 2000.

Kattawar, G. W., Young, A. T., and Humphreys, T. J.: Inelastic Scattering in Planetary Atmospheres, I, The Ring effect, without aerosols, Astrophys. J., 243, 1049-1057, 1981.

Klenk, K. F., Bhartia, P. K., Kaveeshwar, V. G., McPeters, R. D., Smith, P. M., and Fleig, A. J.: Total Ozone Determination from the Backscattered Ultraviolet (BUV), J. Appl. Meteorol., 21, 1672-1684, 1982.

Kneizys, F., Abreu, L., Anderson, G., Chetwynd, J., Shettle, E., Berk, A., Bernstein, L., Robertson, D., Acharya, P., Rothman, L., Selby, J., Gallery, W., and Clough, S.: The MODTRAN 2/3 report and LOWTRAN 7 model, Tech. rep., Phillips Laboratory, Hanscom AFB, 1996.

Kovalenko, L. J., Livesey, N. L., Salawitch, R. J., Camy-Peyret, C., Chipperfield, M. P., Cofield, R. E., Dorf, M., Drouin, B. J., Froidevaux, L., Fuller, R. A., Goutail, F., Jarnot, R. F., Jucks,
K., Knosp, B. W., Lambert, A., MacKenzie, I. A., Pfeilsticker, K., Pommereau, J.-P., Read, W. G., Santee, M. L., Schwartz, M. J., Snyder, W. V., Stachnik, R., Stek, P. C., Wagner, P. A., and Waters, J. W.: Validation of Aura Microwave Limb Sounder BrO observations in the stratosphere, J. Geophys. Res., 112, D24S41, doi:10.1029/2007JD008817, 2007.

Krecl, P., Haley, C. S., Stegman, J., Brohede, S. M., and Berthet, G.: Retrieving the vertical distribution of stratospheric OClO from Odin/OSIRIS limb-scattered sunlight measurements, Atmos. Chem. Phys., 6, 1879-1894, doi:10.5194/acp-6-1879-2006, 2006.

Kühl, S., Puķīe, J., Deutschmann, T., Platt, U., and Wagner, T.: SCIAMACHY limb measurements of $\mathrm{NO}_{2}, \mathrm{BrO}$ and $\mathrm{OClO}, \mathrm{Re}-$ trieval of vertical profiles: Algorithm, first results, sensitivity and comparison studies, Adv. Space Res., 42, 1747-1764, 2008.

Langematz, U., Labitzke, K., and Reimer, E.: Synoptic analysis and trajectories during the MAP/GLOBUS campaign 1983, Planet. Space Sci., 35, 525-538, doi:10.1016/0032-0633(87)90120-6, 1987.

Lenoble, J.: Radiative Transfer in Scattering and Absorbing Atmospheres, A. DEEPAK Publishing, Hampton, Virginia, 1985.

Lichtenberg, G., Kleipool, Q., Krijger, J. M., van Soest, G., van Hees, R., Tilstra, L. G., Acarreta, J. R., Aben, I., Ahlers, B., Bovensmann, H., Chance, K., Gloudemans, A. M. S., Hoogeveen, R. W. M., Jongma, R. T. N., Noël, S., Piters, A., Schrijver, H., Schrijvers, C., Sioris, C. E., Skupin, J., Slijkhuis, S., Stammes, P., and Wuttke, M.: SCIAMACHY Level 1 data: calibration concept and in-flight calibration, Atmos. Chem. Phys., 6, 5347-5367, doi:10.5194/acp-6-5347-2006, 2006.

Lumpe, J. D., Fromm, M., Hopperl, K., Randall, R. M. B. C. E., Browell, E. V., Grant, W. B., McGee, T., Burris, J., Twigg, L., Richard, E. C., Toon, G. C., Margitan, J. J., Sen, B., Boesch, H., Fitzenberger, R., Pfeilsticker, K., Goutail, F., and Pommereau, J.P.: Comparison of POAM III ozone measurements with correlative aircraft and balloon data during SOLVE, J. Geophys. Res., 107, 8316, doi:10.1029/2001JD000472, 2002.

Marchuk, G. I., Mikhailov, G. A., Nazaraliev, M. A., Darbinyan, R. A., Kargin, B. A., and Elepov, B. S.: The Monte Carlo methods in atmospheric optics, Springer Verlag, New York, 1980.

McKinney, K. A., Pierson, J. M., and Toohey, D. W.: A wintertime in situ profile of $\mathrm{BrO}$ between 17 and $27 \mathrm{~km}$ in the Arctic vortex, Geophys. Res. Lett., 24, 853-856, 1997.

McLinden, C. A., McConnell, J. C., Griffioen, E., and McElroy, C. T.: A vector radiative transfer model for the Odin/OSIRIS project, Can. J. Phys., 80, 375-393, 2002a.

McLinden, C. A., McConnell, J. C., Strong, K., McDade, I. C., Gattinger, R. L., King, R., Solheim, B., Llewellyn, E. J., and Evans, W. J. F.: The impact of the OSIRIS grating efficiency on total radiance and trace-gas retrievals, Can. J. Phys., 80, 469481, 2002 b.

McLinden, C. A., Haley, C. S., Lloyd, N. D., Hendrick, F., Rozanov, A., Sinnhuber, B.-M., Goutail, F., Degenstein, D. A., Llewellyn, E. J., Sioris, C. E., Roozendael, M. V., Pommereau, J. P., Lotz, W., and Burrows, J. P.: Odin/OSIRIS observations of stratospheric BrO: Retrieval methodology, climatology, and inferred $\mathrm{Br}_{\mathrm{y}}$, J. Geophys. Res., 115, D15308, doi:10.1029/2009JD012488, 2010. 
Milz, M., von Clarmann, T., Fischer, H., Glatthor, N., Grabowski, U., Höpfner, M., Kellmann, S., Kiefer, M., Linden, A., Tsidu, G. M., Steck, T., Stiller, G. P., Funke, B., López-Puertas, M., and Koukouli, M. E.: Water vapor distributions measured with the Michelson Interferometer for Passive Atmospheric Sounding on board Envisat (MIPAS/Envisat), J. Geophys. Res., 110, D24307, doi:10.1029/2005JD005973, 2005.

Noël, S., Bovensmann, H., Burrows, J. P., Frerick, J., Chance, K. V., Goede, A. H. P., and Muller, C.: The SCIAMACHY Instrument on ENVISAT-1, in: Sensors, Systems, and NextGeneration Satellites II, Proc. SPIE, 3498, 94-104, 1998.

Noël, S., Bramstedt, K., Rozanov, A., Bovensmann, H., and Burrows, J. P.: Water vapour profiles from SCIAMACHY solar occultation measurements derived with an onion peeling approach, Atmos. Meas. Tech., 3, 523-535, doi:10.5194/amt-3-523-2010, 2010.

Pfeilsticker, K., Sturges, W. T., Bösch, H., Camy-Peyret, C., Chipperfield, M., Engel, A., Fitzenberger, R., Müller, M., Payan, S., and B.-M.Sinnhuber: Lower stratospheric organic and inorganic bromine budget for the arctic winter 1998/99, Geophys. Res. Lett., 27, 3305-3308, 2000.

Platt, U. and Stutz, J.: Differential Optical Absorption Spectroscopy, Springer Verlag, 2008.

Puķīte, J., Kühl, S., Deutschmann, T., Platt, U., and Wagner, T.: Accounting for the effect of horizontal gradients in limb measurements of scattered sunlight, Atmos. Chem. Phys., 8, 3045-3060, doi:10.5194/acp-8-3045-2008, 2008.

Puķīe, J., Kühl, S., Deutschmann, T., Wilms-Grabe, W., Friedeburg, C., Platt, U., and Wagner, T.: Retrieval of stratospheric trace gases from SCIAMACHY limb measurements, Proceedings of the First Atmospheric Science Conference, ESA SP-628, ESA/ESRIN, Frascati, Italy, 2006.

Puķīe, J., Kühl, S., Deutschmann, T., Platt, U., and Wagner, T.: Extending differential optical absorption spectroscopy for limb measurements in the UV, Atmos. Meas. Tech., 3, 631-653, doi:10.5194/amt-3-631-2010, 2010.

Pundt, I., Pommereau, J.-P., Chipperfield, M. P., Van Roozendael, M., and Goutail, F.: Climatology of the stratospheric BrO vertical distribution by balloon-borne UV-visible spectrometry, J. Geophys. Res., 107, 4806, doi:10.1029/2002JD002230, 2002.

Rodgers, C. D.: Inverse methods for atmospheric sounding: Theory and practice, World Scientific, Singapore, 2000.

Rozanov, A., Rozanov, V., and Burrows, J. P.: A numerical radiative transfer model for a spherical planetary atmosphere: combined differential-integral approach involving the Picard iterative approximation, J. Quant. Spectrosc. Ra., 69, 491-512, doi:10.1016/S0022-4073(00)00100-X, 2001.

Rozanov, A., Bovensmann, H., Bracher, A., Hrechanyy, S., Rozanov, V., Sinnhuber, M., Stroh, F., and Burrows, J.: $\mathrm{NO}_{2}$ and $\mathrm{BrO}$ vertical profile retrieval from SCIAMACHY limb measurements: Sensitivity studies, Adv. Space Res., 36, 846-854, doi:10.1016/j.asr.2005.03.013, 2005a.

Rozanov, A., Rozanov, V., Buchwitz, M., Kokhanovsky, A., and Burrows, J. P.: SCIATRAN 2.0 - A new radiative transfer model for geophysical applications in the $175-2400 \mathrm{~nm}$ spectral region, Adv. Space Res., 36, 1015-1019, doi:10.1016/j.asr.2005.03.012, 2005b.
Rozanov, A., Eichmann, K.-U., von Savigny, C., Bovensmann, H., Burrows, J. P., von Bargen, A., Doicu, A., Hilgers, S., GodinBeekmann, S., Leblanc, T., and McDermid, I. S.: Comparison of the inversion algorithms applied to the ozone vertical profile retrieval from SCIAMACHY limb measurements, Atmos. Chem. Phys., 7, 4763-4779, doi:10.5194/acp-7-4763-2007, 2007.

Rozanov, A., Weigel, K., Bovensmann, H., Dhomse, S., Eichmann, K.-U., Kivi, R., Rozanov, V., Vömel, H., Weber, M., and Burrows, J. P.: Retrieval of water vapor vertical distributions in the upper troposphere and the lower stratosphere from SCIAMACHY limb measurements, Atmos. Meas. Tech., 4, 933-954, doi:10.5194/amt-4-933-2011, 2011.

Rozanov, V. V. and Kokhanovsky, A. A.: Impact of single- and multi-layered cloudiness on ozone vertical column retrievals using nadir observations of backscattered solar radiation, in: Light Scattering Reviews 3, edited by: Kokhanovsky, A. A., Springer, Berlin, 133-189, 2008.

Russell III, J. M. and Drayson, S. R.: The Inference of Atmospheric Ozone Using Satellite Horizon Measurements in the $1042 \mathrm{~cm}^{1}$ Band, J. Atmos. Sci., 29, 376-390, 1972.

Salawitch, R. J., Sioris, C. E., Weisenstein, D. K., Wennberg, P. O., Kovalenko, L. J., Chance, K., Ko, M. K. W., and McLinden, C. A.: Sensitivity of ozone to bromine in the lower stratosphere, Geophys. Res. Lett., 32, L05811, doi:10.1029/2004GL021504, 2005.

Shefov, N. N.: Spectroscopic, Photoelectric, and Radar Investigations of Aurorae and the Nightglow, Izd. Akad. Nauk, 1(25), 1959.

Sinnhuber, B.-M., Rozanov, A., Sheode, N., Afe, O. T., Richter, A., Sinnhuber, M., Wittrock, F., Burrows, J. P., Stiller, G., von Clarmann, T., and Linden, A.: Global observations of stratospheric bromine monoxide from SCIAMACHY, Geophys. Res. Lett., 32, L20810, doi:10.1029/2005GL023839, 2005.

Sioris, C. E., Haley, C. S., McLinden, C. A., von Savigny, C., McDade, I. C., McConnell, J. C., Evans, W. F. J., Lloyd, N. D., Llewellyn, E. J., Chance, K. V., Kurosu, T. P., Murtagh, D., Frisk, U., Pfeilsticker, K., Bösch, H., Weidner, F., Strong, K., Stegman, J., and Mégie, G.: Stratospheric profiles of nitrogen dioxide observed by Optical Spectrograph and Infrared Imager System on the Odin satellite, J. Geophys. Res., 108, 4215-4233, doi:10.1029/2005JD006479, 2003.

Sioris, C. E., Kovalenko, L. J., McLinden, C. A., Salawitch, R. J., Roozendael, M. V., Goutail, F., Dorf, M., Pfeilsticker, K., Chance, K., von Savigny, C., Liu, X., Kurosu, T. P., Pommereau, J.-P., Bosch, H., and Frerick, J.: Latitudinal and vertical distribution of bromine monoxide in the lower stratosphere from Scanning Imaging Absorption Spectrometer for Atmospheric Chartography limb scattering measurements, J. Geophys. Res., 111, D14301, doi:10.1029/2002JD002672, 2006.

Sofieva, V. F., Tamminen, J., Haario, H., Kyrölä, E., and Lehtinen, M.: Ozone profile smoothness as a priori information in the inversion of limb measurements, Ann. Geophys., 22, 3411-3420, doi:10.5194/angeo-22-3411-2004, 2004.

Solomon, S., Schmeltekopf, A., and Sanders, R.: On the interpretation of zenith sky absorption measurements, J. Geophys. Res., 92, 8311-8319, 1987.

Thomas, G. E. and Stamnes, K.: Radiative transfer in the atmosphere and ocean, Cambridge University Press, Cambridge, 1 st edition, 1999. 
Tukiainen, S., Hassinen, S., Seppälä, A., Auvinen, H., Kyrölä, E., Tamminen, J., Haley, C. S., Lloyd, N., and Verronen, P. T.: Description and validation of a limb scatter retrieval method for Odin/OSIRIS, J. Geophys. Res., 113, D04308, doi:10.1029/2007JD008591, 2008.

Vountas, M., Rozanov, V. V., and Burrows, J. P.: Ring effect: Impact of rotational Raman scattering on radiative transfer in Earth's atmosphere, J. Quant. Spectrosc. Ra., 60, 943-961, 1998.
Wahner, A., Ravishankara, A. R., Sander, S. P., and Friedl, R. R.: Absorption cross section of $\mathrm{BrO}$ between 312 and $385 \mathrm{~nm}$ at 298 and 223 K, Chem. Phys. Lett., 152, 507-512, 1988.

Woyke, T., Müller, R., Stroh, F., McKenna, D. S., Engel, A., Margitan, J. J., Rex, M., and Carslaw, K. S.: A test of our understanding of the ozone chemistry in the Arctic polar vortex based on in situ measurements of $\mathrm{ClO}, \mathrm{BrO}$, and $\mathrm{O}_{3}$ in the 1994/1995 winter, J. Geophys. Res., 104, 18755-18768, 1999. 